$V_{T}$

NCER Working Paper Seriés

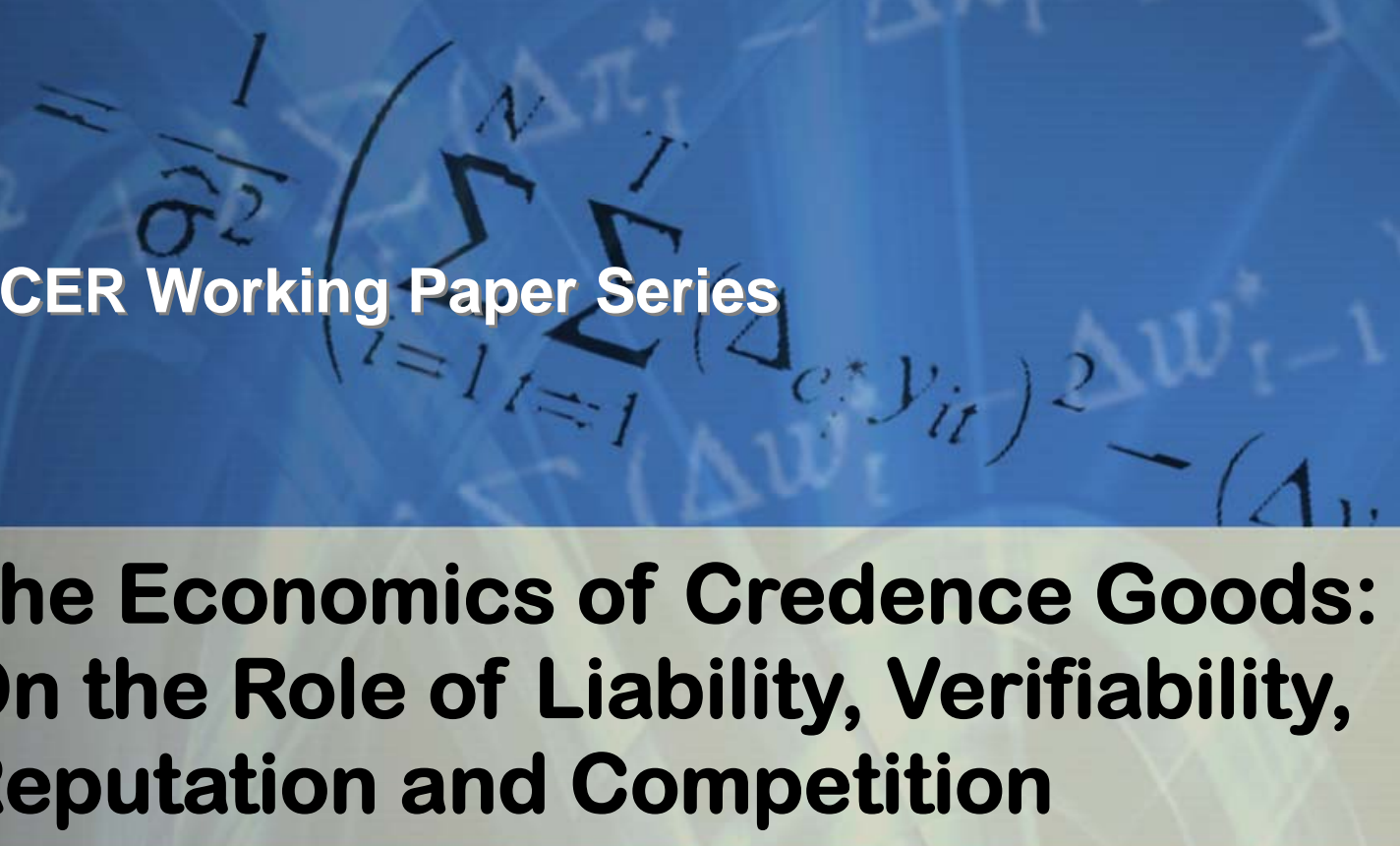

Uwe Dulleck

Rudolf Kerschbamer

Matthias Sutter

Working Paper \#42

March 2009 


\title{
The Economics of Credence Goods: \\ On the Role of Liability, Verifiability, Reputation and Competition*
}

\author{
Uwe Dulleck \\ Queensland University of Technology \\ Rudolf Kerschbamer \\ University of Innsbruck and CEPR
}

\begin{abstract}
Matthias Sutter ${ }^{*}$
University of Innsbruck and University of Gothenburg and IZA Bonn
\end{abstract}

\begin{abstract}
Credence goods markets are characterized by asymmetric information between sellers and consumers that may give rise to inefficiencies, such as under- and overtreatment or market break-down. We study in a large experiment with 936 participants the determinants for efficiency in credence goods markets. While theory predicts that either liability or verifiability yields efficiency, we find that liability has a crucial, but verifiability only a minor effect. Allowing sellers to build up reputation has little influence, as predicted. Seller competition drives down prices and yields maximal trade, but does not lead to higher efficiency as long as liability is violated.
\end{abstract}

\footnotetext{
* We received helpful comments from Dennis Dittrich, Winand Emons, Stephan Kroll, Wolfgang Luhan, and participants at the Econometric Society Meeting in Wellington, the ENABLE-Meeting in Mannheim, the $3^{\text {rd }}$ Australian Workshop on Experimental Economics in Melbourne, and seminar participants at University of Bonn, IZA Bonn, University of Hannover, University of Stavanger, University of Vienna, Max Planck Institute of Economics Jena, and Queensland University of Technology. Financial support from the Max Planck Society, the German Science Foundation (through the Gottfried Wilhelm Leibniz Price of the DFG, awarded to Axel Ockenfels) and the Austrian Science Foundation (FWF-grant P20796) is gratefully acknowledged.

\# Corresponding author's address: University of Innsbruck, Department of Public Finance, Universitaetsstrasse 15, A-6020 Innsbruck, Austria.e-mail: matthias.sutter@uibk.ac.at
} 
"I swear by Apollo the physician ... and all the gods and goddesses that, according to my ability and judgment, I will keep this Oath and this stipulation: ... Into whatever houses I enter, I will go into them for the benefit of the sick and will abstain from every voluntary act of mischief and corruption..." (Oath of Hippocrates, 460-377 B.C.)

\section{Introduction}

Medical treatment is a prime example of what is known as a credence good in the economics literature. Other examples include all types of repair services or the provision of complex goods like software programs, but also seemingly straightforward goods like taxi rides in an unknown city can exhibit the properties of credence goods. Generally speaking, credence goods have the characteristic that though consumers can observe the utility they derive from the good ex post, they cannot judge whether the type or quality of the good they have received is the ex ante needed one. Moreover, consumers may even ex post be unable to observe which type or quality they actually received. An expert seller, however, is able to identify the type or quality that fits a consumer's needs by performing a diagnosis. He can then provide the right quality and charge for it, or he can exploit the information asymmetry by defrauding the consumer.

An expert seller - a car mechanic, for instance - might have an incentive to cheat on a consumer in two dimensions: First, the repair might be inefficient. The mechanic might replace more parts than are actually necessary to bring the car back on the road (and charge for the additional time and material). This case is referred to as overtreatment because the additional benefits to the consumer are smaller than the additional costs. The mechanic's repair might also be insufficient, thus leaving the consumer with a bill, but with a car that is still not working properly. This latter case is referred to as undertreatment since any material and time spent on the repair is pure waste. Second, the repair might be appropriate, but the mechanic might charge the consumer for more than he has actually done (e.g., by claiming to have changed a filter without having done so). This kind of problem is known as overcharging and it can also lead to inefficiencies in the long run if the fear of getting 
overcharged deters consumers from trading on credence goods markets in the future, thereby creating an Akerlof (1970) type of market breakdown.

In this paper we present an experiment with 936 participants. Despite the importance of credence goods markets for many day-to-day decisions, this is the first large-scale experiment on credence goods. It provides controlled evidence of how institutional restrictions and market characteristics affect behavior on credence goods markets and how the inefficiencies arising from the asymmetric information on credence goods markets can be contained. Our experiment is based on a full $2 \times 2 \times 2 \times 2$ factorial design, varying the following factors:

- Liability, i.e. the necessity for the seller to provide a good of sufficient quality to meet a consumer's needs.

- Verifiability of a seller's action, i.e. the necessity for the seller to charge for the good provided.

- Reputation building, i.e. giving consumers the possibility to identify their trading partners (as opposed to an anonymous market).

- Competition, i.e. giving consumers an option to choose from several sellers (as opposed to bilateral matching between sellers and consumers).

We evaluate the experimental behavior against two sets of predictions, one assuming standard (own-money-maximizing) preferences, and the other one considering non-standard preferences. Our formalization of non-standard preferences is motivated by the opening quote from Hippocrates, because the latter implies a seller's concern for an appropriate treatment ("for the benefit of the sick") and a renunciation of exploiting consumers ("abstain from every voluntary act of mischief and corruption"). For some experimental treatment conditions, both models yield qualitatively very similar predictions. When the predictions differ, experimental behavior seems to be better captured by the model with non-standard preferences, though.

The experimental results show that liability and competition are the most important factors to increase trade on credence goods markets. If liability holds, the increase in trade causes an increase in efficiency. Without liability, the effect of increased trade on efficiency is ambiguous, because undertreatment occurs frequently. Verifiability of a seller's actions, although theoretically as powerful as liability, has only a minor impact. Similarly, the possibility of reputation building is of negligible influence as long as liability or verifiability holds. Hence, our results suggest that legal liability clauses are most suitable to cure many of the inefficiencies associated with the provision of credence goods.

The remainder of the paper is organized as follows. In section 2 we discuss briefly related literature and how our experiment can add insights and thus complement the empirical 
evidence. In Section 3 we describe the basic model and introduce the various conditions under which consumers and sellers might engage in trade. Section 4 contains the experimental design. Section 5 derives hypotheses both for the cases of standard and non-standard preferences. Section 6 presents the experimental results. Section 7 summarizes our main findings and discusses some policy implications.

\section{Related Literature and Rationale for an Experimental Study}

There are about two dozen theoretical contributions to the credence goods literature. The pioneering paper is by Darby and Karni (1973), who introduced the term credence goods and added this type of good to Nelson's (1970) classification of ordinary, search and experience goods. ${ }^{1}$ They study how market conditions (the presence or absence of idle capacities, regulation, etc.) and reputation concerns affect the equilibrium amount of fraud (i.e., underand overtreatment, and overcharging). Two other important early contributions, both assuming verifiability and both studying a competitive environment, are by Wolinsky. While Wolinsky (1993) emphasizes that the informational asymmetry in credence goods markets might lead to specialization, Wolinsky (1995) examines the role of customers' search for multiple opinions and experts' concerns for reputation in disciplining experts. Taylor (1995) provides a theoretical micro-foundation of several important features observed in markets for credence goods (as, for instance, the heavy reliance on ex post contracts and the prevalence of free diagnostic checks), while Emons (1997) studies the role of observability of capacities and treatments in inducing non-fraudulent behavior. Important recent theoretical contributions to the literature include Pesendorfer and Wolinsky (2003), who explore whether a competitive sampling of prices and opinions provides incentives for experts to provide costly but unobservable diagnostic effort, and Alger and Salanie (2006), who study a competitive credence goods market in which experts lie about the true diagnosis because an informed consumer would reject the price offer to get the treatment from a competing expert. A robust finding in this literature is that liability and verifiability are the most important institutional factors for experts' behavior, while reputation and competition are important market factors (see Dulleck and Kerschbamer, 2006, for details).

\footnotetext{
${ }^{1}$ Ordinary goods (such as petrol) have well-known characteristics, and subjects know where to get them. Search goods (like clothes) need to be inspected before buying in order to observe their characteristics. Experience goods (like wine) have unknown characteristics, but they are revealed after buying or consuming them.
} 
The empirical evidence on the problems with credence goods originates mainly from the market for car repairs and for health care services. Wolinsky $(1993,1995)$ refers to a survey conducted by the Department of Transportation estimating that more than half of car repairs are unnecessary, which is an indication of overtreatment. Hubbard (1998) shows that car mechanics conduct vehicle inspections differently depending on whether the vehicles are on warranty or not. Referring to the health care sector, the classic study by Fuchs (1978) reports a positive correlation between the supply of doctors in a geographical area and the cost and intensity of medical care. Emons (1997) cites a Swiss study reporting that the average person's probability of receiving one of seven major surgical interventions is one third above that of a physician or a member of a physician's family, indicating that a consumer's (presumed) education and information level affects the quality of treatment and the likelihood of overtreatment. He also mentions a study by the Federal Trade Commission that documents the tendency of optometrists to prescribe unnecessary, but profitable, treatment. Hughes and Yule (1992) find that the number of cervical cytology treatments is positively correlated with the fee for this treatment. Likewise, Gruber and Owings (1996) and Gruber, Kim and Mayzlin (1999) show that the relative frequency of Cesarean deliveries compared to normal child births reacts to the fee differentials of health insurance programs for both types of treatments and to the intertemporal development of birth rates. Iizuka (2007) investigates the Japanese drug prescription market where doctors often not only prescribe but also dispense drugs. Controlling for patients' health status, he finds that doctors' prescriptions respond to markup differences, i.e. to monetary incentives that are unrelated to warranted medication. ${ }^{2}$

Though empirical studies on credence goods markets have documented the existence of inefficiencies, they generally lack a controlled variation of factors that might influence the level of efficiency. For instance, some papers show that overtreatment is happening, without systematically exploring the conditions leading to it (see, e.g., the case studies mentioned in Wolinsky 1993 and 1995, or Emons 1997). Other studies vary only one particular aspect that influences the provision of credence goods - for example, the price differential between Cesarean section deliveries and normal child births (Gruber et al., 1999) - without controlling for and varying other important factors (like liability or verifiability or reputation building of sellers). By running a controlled laboratory experiment we are able to systematically vary

\footnotetext{
${ }^{2}$ Afendulis and Kessler (2007) show that the integration of diagnosis and treatment has raised the treatment costs of coronary artery disease. They also find that under some conditions the integration of diagnosis and treatment can lead to better health outcomes, though.
} 
several factors that may affect the provision of credence goods, and identify the effects of these factors on sellers' and consumers' behavior. Field data are naturally limited in the number of conditions that can be varied. Hence, our experiments complement the empirical literature by allowing for a much broader variation of important factors under ceteris-paribus conditions.

Turning to the experimental literature, closest to our paper are two articles by Huck, Lünser and Tyran $(2006,2007)$ who use a binary version of the well-known trust game (by Berg, Dickhaut and McCabe 1995) and interpret it as modeling a market for experience goods. ${ }^{3}$ Huck et al. (2007) show that experience goods are more efficiently provided when sellers can build up reputation than if this is not the case. Yet, it does not make a difference whether buyers can only observe how a particular seller has served them in the past or whether they know all past quality choices of all sellers in the market. Introducing competition (as compared to a bilateral matching of sellers and consumers), Huck et al. (2006) find even higher efficiency levels than with reputation, because competition lets sellers provide high quality in the present to attract consumers also in the future. Taking a trust game as an example for an experience goods market limits the analysis of inefficiencies to undertreatment (low quality for a given price) and no market interaction, though. The framework of credence goods is a much richer one as it adds opportunities for overtreatment and overcharging both of which constitute persistent problems on credence goods markets. It is noteworthy, however, that the setup of Huck et al. $(2006,2007)$ is a special case of our more general model. In the final section of this paper we will explain in more detail how the experience goods model of Huck et al. $(2006,2007)$ is embedded in our model and how our results compare to theirs.

\footnotetext{
${ }^{3}$ Experience goods differ from credence goods in several important dimensions. For example, (1) while the valuation of a consumer is strictly increasing in quality with experience goods, it is constant whenever the quality is sufficient with credence goods; (2) for given prices a consumer can tell exactly which quality he prefers in the case of experience goods, but he does not know it with credence goods; (3) whereas the quality of the good is unobservable ex ante but perfectly observable ex post with experience goods, it may be observable either ex ante, or ex post, or neither ex ante nor ex post with credence goods.
} 


\section{A Simple Model of a Credence Goods Market}

\subsection{The Basic Model}

Consumers are ex ante identical and know that they need a major treatment $\left(t^{h}\right)$ with probability $h$, and a minor treatment $\left(t^{l}\right)$ with probability $1-h$. Each consumer (he) is randomly matched with one seller (she) who sets prices $p^{h}$ and $p^{l}$ for the major, respectively minor, treatment (with $p^{h} \geq p^{l}$ ). The seller has costs $c^{h}$ for the major treatment, and $c^{l}$ for the minor one (with $c^{h}>c^{l}$ ).

The consumer only knows the prices for the different treatments, but not the type of treatment that he needs, when he makes his decision whether or not to interact with the seller. If the consumer decides against interaction then both the consumer and the seller receive an outside option of $o \geq 0$. In case of interaction, the seller gets to know which type of treatment the consumer needs. Then she provides one of the two treatments and charges one of the two prices. Consumers in need of the minor treatment $t^{l}$ are sufficiently treated in any case (receiving either $t^{l}$ or $t^{h}$ ). However, if the consumer needs the major treatment $t^{h}$, then only $t^{h}$ is sufficient. A sufficient treatment yields a value $v>0$ for the consumer, an insufficient treatment yields a value of zero. ${ }^{4}$ In case of an interaction, a consumer earns the value from being treated minus the price to be paid, whereas a seller receives the price charged minus the cost of the provided treatment ( $c^{l}$ if $t^{l}$ has been provided, otherwise $c^{h}$ ).

In the following, we extend this basic model in two steps. In extension 1 we limit the action space of the seller by considering liability and verifiability as institutional restrictions. In extension 2 we add reputation building and seller competition as two important features of market interaction.

\subsection{Extension 1: Liability and Verifiability}

Liability in credence goods markets implies the requirement that sellers provide a treatment that is sufficient to solve the consumer's problem. Thus, liability prevents undertreatment, but it does not preclude overtreatment and/or overcharging. Verifiability

\footnotetext{
${ }^{4}$ In order to keep the exposition as succinct as possible, we present the basic model as it will be implemented in the experiment. Of course, more general specifications would be possible, such as varying the value of the outside option with the type of player (seller vs. consumer) or the value from a sufficient treatment with the treatment needed by the consumer (minor vs. major treatment), or considering strictly positive diagnosis costs (which we set zero here). Dulleck and Kerschbamer (2006) discuss various generalizations, showing that many of them do not affect the theoretical results qualitatively. Hence, we use the simpler framework, which also prevents us from making the experiment too complicated for participants.
} 
means that consumers can observe and verify ex post the treatment that has been provided by the seller (without knowing, however, whether this treatment was needed). As a consequence, verifiability prevents overcharging, but it does not preclude under- and/or overtreatment.

The factorial combination of liability and verifiability creates four different institutional conditions that imply different sets of available actions for the seller (see Figure 1 for the sequence of actions).

1) In condition $\mathbf{N}$ (No Liability / No Verifiability) the seller is completely free in her choice of treatment provision and in which of the two posted prices she charges.

2) In condition L (Liability / No Verifiability) the seller must provide a sufficient treatment. However, she is allowed to charge any of her posted prices.

3) In condition $\mathbf{V}$ (No Liability / Verifiability) the seller is not restricted in her choice of treatment, but she must charge the price of the treatment actually provided.

4) In condition LV (Liability / Verifiability) the seller must provide sufficient treatment and charge the price of the treatment actually provided.

\section{Figure 1 about here}

\subsection{Extension 2: Reputation and Competition}

The basic model places two particular restrictions on consumers. First, consumers cannot identify their (past) trading partners. Second, consumers do not have a choice between different sellers, because they are bilaterally matched with one seller only. Our second extension lifts both restrictions, the first one by introducing an opportunity for reputationbuilding by making sellers identifiable, such that a consumer can keep track of his past experience with a particular seller (without knowing how this seller has treated other consumers, though). 5 The second restriction is removed by considering a competition condition where consumers can choose among several sellers, knowing the prices posted by them. In this condition the matching becomes endogenous. We assume that consumers face zero costs when comparing the different sellers' prices and sellers can treat more than one consumer (meaning that there are no capacity constraints). A factorial combination of allowing for reputation-building and seller competition yields the following four market conditions.

\footnotetext{
${ }^{5}$ Sellers can never identify consumers in our model, because we are primarily interested in the effect of seller reputation.
} 
1) In condition B (for "baseline"; No Competition / No Reputation) there is a bilateral matching of consumers and sellers, and consumers cannot identify their trading partners.

2) In condition $\mathbf{R}$ (No Competition / Reputation) there is a bilateral matching of consumers and sellers, and a consumer knows whether a particular seller has treated him sufficiently or not in the past and which price she has charged.

3) In condition C (Competition / No Reputation) consumers can choose among several sellers, but they cannot identify their trading partners.

4) In condition CR (Competition / Reputation) consumers can choose among different sellers and they can identify them.

\section{Table 1 about here}

Combining both extensions yields 16 different conditions for the interaction between consumers and sellers on credence goods markets. Table 1 summarizes the different conditions and how they are characterized with respect to the presence or absence of liability, verifiability, reputation-building, and seller-competition.

\section{Experimental Design}

\subsection{Treatments, Parameters, and Matching}

The 16 conditions of interaction between consumers and sellers in Table 1 constitute the 16 different experimental treatments of our study. Since we refer to sellers offering a "treatment" to consumers we will denote experimental treatments as conditions throughout the paper. The abbreviations in Table 1 for the 16 conditions are of the form $\mathbf{X} / \mathbf{Y}$, where $X \in$ $\{\mathrm{B}, \mathrm{R}, \mathrm{C}, \mathrm{CR}\}$, and $\mathrm{Y} \in\{\mathrm{N}, \mathrm{L}, \mathrm{V}, \mathrm{LV}\}$. For example, $\mathbf{C} / \mathbf{L V}$ denotes the condition with seller competition, where sellers can not build up reputation, but where both liability and verifiability apply. In the following we will often refer to a set of conditions by using a single element of the tuples $\mathbf{X} / \mathbf{Y}$ defined above. For instance, a reference to the set $\mathbf{R}$ includes all four conditions where reputation building is possible, but where seller-competition does not apply, i.e. set $\mathbf{R}$ includes $\mathbf{R} / \mathbf{N}, \mathbf{R} / \mathbf{L}, \mathbf{R} / \mathbf{V}$, and $\mathbf{R} / \mathbf{L} \mathbf{V}$.

In all experimental conditions we let the consumer's probability of needing the major treatment be $h=0.5$, and the value of a sufficient treatment be $v=10$. The costs of providing the minor (major) treatment is $c^{l}=2\left(c^{h}=6\right.$ ). The prices posted by the sellers, $p^{l}$ and $p^{h}$ (with 
$\left.p^{l} \leq p^{h}\right)$, have to be chosen in integer numbers from the interval $\{1,11\}$. The outside option if no trade takes place is set to $o=1.6$ both for the seller and the consumer.

We always use matching groups of eight subjects each, which is common knowledge in all conditions. Four subjects in each matching group are in the role of consumers, and four in the role of sellers. The assignment to roles is randomly determined at the beginning of the experiment, and roles are kept fixed throughout the entire experiment.

There are 16 periods of interaction between sellers and consumers in all conditions. Due to the repetition of the stage game, the matching of subjects is important. In the market conditions without reputation (i.e. in sets $\mathbf{B}$ and $\mathbf{C}$ ) it must not be possible for sellers to build up reputation in the course of the repeated interaction. This precludes the use of a partner matching (in which a seller would be matched with the same consumer in all 16 periods). Therefore, we use a stranger matching in which consumers and sellers are randomly rematched after each period.

In the conditions with competition (i.e. in sets $\mathbf{C}$ and $\mathbf{C R}$ ) the four sellers have to post prices first, and each of the four consumers is informed about the prices of all four sellers. Only then consumers have to choose with which seller, if any, to interact. Note that in condition $\mathbf{C}$ consumers cannot identify their (potential) trading partners. In order to make that more transparent, we stress in the experimental instructions (see supplementary material) that the order of presenting the four sellers' prices will be randomly determined in each period. Hence, seller $x$ in period $t$ need not be seller $x$ in period $t+1$.

In the conditions with reputation-building (i.e., sets $\mathbf{R}$ and $\mathbf{C R}$ ) consumers can keep track of their past experience with a particular seller through fixing the sellers' IDs. The feedback consists of information on which seller they visited in a particular period, which prices had been posted in that period, and what was the consumer's profit from the interaction. From the latter, consumers can infer whether they have been treated sufficiently or not and which price has been charged.

\subsection{Experimental Procedure}

All experimental sessions were run computerized (using zTree; Fischbacher, 2007) and recruiting was done with ORSEE (Greiner, 2004). A total of 936 undergraduate students participated in the experiment. All sessions started with an extensive description of the game. All parameters as well as the matching procedure were made common knowledge to all participants by reading them out aloud. Before the experiment started, participants had to answer a set of control questions correctly to ensure that they had fully understood the 
instructions. For every session we invited four subjects more than needed in order make sure that we got enough subjects answering all questions correctly. Once the number of subjects required to start a session had answered all questions correctly, the four remaining subjects were paid 4 Euro and dismissed. The average session length, including instructions and control questions, was 1.5 hours. Participants earned on average 14 Euro.

\section{Predictions}

\subsection{Assuming Standard Preferences}

In this subsection we assume that both sellers and consumers are rational and only interested in their own monetary payoff, and that this fact is common knowledge. We start by identifying equilibrium behavior for set $\mathbf{B}$, after which we continue with sets $\mathbf{R}, \mathbf{C}$, and $\mathbf{C R}$. Accompanying each prediction is a short rationale for it. The proofs are relegated to the supplementary material, Appendix A. Table 2 summarizes the predictions, where row [1] below each of the 16 conditions shows the predicted vector of prices posted by the seller and whether a consumer interacts with a seller or not. The first figure in curved parentheses refers to $p^{l}$, the second to $p^{h}$. For the conditions where interaction is predicted to take place, row [2] indicates whether the consumer is appropriately treated ("efficient provision"), undertreated, or overtreated, and row [3] refers to the seller's charging policy. ${ }^{6}$

\section{Table 2 about here}

\subsubsection{Standard Predictions for Set B (Baseline) - On the Role of Liability and Verifiability}

First note that under random matching and anonymity the predictions for the finitely repeated game are the same as the predictions for the underlying stage game. Since the stage game is solved through backward-induction we start (in prediction $\boldsymbol{B}^{\boldsymbol{S}} \mathbf{1}$ ) with the chronologically last decision in the stage game, which is the seller's provision and charging policy. Then we proceed backward through the game-tree (see Figure 1) by addressing the

\footnotetext{
${ }^{6}$ Here and throughout the article appropriate treatment refers to providing $t^{h}$ if the consumer needs the major treatment and providing $t^{l}$ if the consumer needs the minor treatment; undertreatment refers to providing $t^{l}$ when the consumer needs $t^{h}$; overtreatment refers to providing $t^{h}$ when the consumer needs $t^{l}$.
} 
consumer's acceptance behavior (in prediction $\boldsymbol{B}^{\boldsymbol{S}_{2}}$ ) and, finally, the seller's pricing policy and the implied prediction with respect to interaction (in prediction $\boldsymbol{B}^{\boldsymbol{S}_{3}}$ ). In our characterization of those policies we refer to the following types of price-vectors:

- an equal mark-up price-vector is defined as one that satisfies $p^{h}-p^{l}=c^{h}-c^{l}=4$.

- an undertreatment price-vector satisfies $p^{h}-p^{l}<c^{h}-c^{l}=4$.

- an overtreatment price-vector is characterized by $p^{h}-p^{l}>c^{h}-c^{l}=4$.

\section{Prediction $B^{S} 1$ (Provision and Charging Policy).}

(i) In $\mathbf{B} / \mathbf{N}$ sellers provide the minor, but charge for the major treatment under each pricevector.

(ii) In $\mathbf{B} / \mathbf{L}$ sellers provide the appropriate treatment and charge for the major treatment under each price-vector.

(iii) In $\mathbf{B} / \mathbf{V}$ sellers provide the appropriate treatment under equal mark-up vectors, but always the minor (major) treatment under undertreatment (overtreatment) price-vectors.

(iv) In $\mathbf{B} / \mathbf{L V}$ sellers provide the appropriate treatment under equal mark-up and undertreatment price-vectors, but only the major treatment under overtreatment vectors.

Prediction $\boldsymbol{B}^{S_{2}}$ (Acceptance Behavior). Anticipating sellers' behavior according to prediction $\boldsymbol{B}^{\boldsymbol{S}} \mathbf{1}$, consumers' acceptance behavior depends exclusively on $p^{h}$, but not on $p^{l}$, when $\mathbf{V}$ is violated. When $\mathbf{V}$ holds, acceptance behavior depends both on $p^{h}$ and $p^{l}$.

(i) In $\mathbf{B} / \mathbf{N}$ consumers accept to be treated if and only if (iff) $p^{h} \leq 3$.

(ii) In $\mathbf{B} / \mathbf{L}$ consumers accept to be treated iff $p^{h} \leq 8$.

(iii) In $\mathbf{B} / \mathbf{V}$ consumers accept an equal mark-up vector iff $p^{h} \leq 10$, they accept an undertreatment vector iff $p^{l} \leq 3$, and an overtreatment vector iff $p^{h} \leq 8$.

(iv) In $\mathbf{B} / \mathbf{L V}$ consumers accept an equal mark-up and an undertreatment vector iff ( $p^{l}+$ $\left.p^{h}\right) / 2 \leq 8$, and they accept an overtreatment vector iff $p^{h} \leq 8$.

Prediction $\boldsymbol{B}^{S} \mathbf{3}$ (Pricing Policy and Interaction). Interaction always takes place if either $\mathbf{L}$ or $\mathbf{V}$ (or both) holds; otherwise the market breaks down. With interaction, prices are such that sellers are induced to provide the appropriate treatment and that the gains from trade accrue to the sellers.

(i) In $\mathbf{B} / \mathbf{N}$ the market breaks down.

(ii) In $\mathbf{B} / \mathbf{L}$ sellers post a price-vector with $p^{h}=8, p^{l}$ is indeterminate.

(iii) In $\mathbf{B} / \mathbf{V}$ sellers post the equal mark-up vector $\{6,10\}$. 
(iv) In $\mathbf{B} / \mathbf{L V}$ sellers post an equal mark-up or an undertreatment vector with $p^{l}+p^{h}=16$.

Summarizing the standard predictions for set $\mathbf{B}$ we observe that if both liability and verifiability are violated, then the market breaks down. The reason is that in $\mathbf{B} / \mathbf{N}$ sellers cannot be induced to provide the major treatment and that always providing the minor treatment generates expected gains from trade of only $3\left(=(1-h) v-c^{l}\right)$ which is less than the sum of two outside options $(2 o=3.2)$. Thus, there exists no price where both parties of the interaction get at least their outside option. As soon as either $\mathbf{L}$ or $\mathbf{V}$ (or both) apply, however, sellers have an incentive to post prices which induce them to provide the appropriate treatment, making it profitable for consumers to enter the market in all periods in conditions $\mathbf{B} / \mathbf{L}, \mathbf{B} / \mathbf{V}$, and $\mathbf{B} / \mathbf{L V}$. This yields full efficiency then.

\subsubsection{Standard Predictions for Sets R, C and CR - On the Role of Reputation- Building and Competition}

In discussing the influence of an opportunity for reputation-building and competition on seller and consumer behavior we first present the predictions when either reputation-building or competition applies. Only after that we describe the effects if both apply jointly.

\subsubsection{The Effects of Reputation}

Reputation-building itself does not change any of the predictions for set $\mathbf{B}$ since the stage game has a unique equilibrium and the repeated game a fixed, commonly known end date.

Predictions $\boldsymbol{R}^{S} 1$ to $\boldsymbol{R}^{S}$ 3. Reputation itself does not affect the predicted behavior of sellers and consumers. Hence, predictions $\boldsymbol{B}^{\boldsymbol{S}} \mathbf{1}$ to $\boldsymbol{B}^{\boldsymbol{S}} \boldsymbol{3}$ also apply to set $\mathbf{R}$.

\subsubsection{The Effects of Competition}

The main effect of competition is on the pricing policy and the interaction frequency, while provision and charging policy are the same as in the baseline set $\mathbf{B}$.

Prediction $C^{S} 1$ (Provision and Charging Policy). Competition itself does not affect the sellers' provision and charging policy. Hence, prediction $\boldsymbol{B}^{\boldsymbol{S}} \mathbf{1}$ also applies to set $\mathbf{C}$.

In set $\mathbf{B}$ the matching between consumers and sellers is exogenous and the consumers' only decision is to accept or reject the seller's offer. Hence, in set $\mathbf{B}$ the prediction on consumer behavior is a prediction on acceptance behavior. With competition, however, 
consumers have to choose from a set of sellers, putting the determinants of this choice into the focus of analysis. To identify choice behavior, we will refer to price-vectors $\underline{\Delta}^{\mathrm{e}}, \underline{\Delta}^{\mathrm{u}}, \underline{\Delta}^{\mathrm{o}}$ and $\underline{\Delta}^{\mathrm{eu}}$. Among all equal mark-up vectors offered by the four sellers, $\underline{\Delta}^{\mathrm{e}}$ is the one with the lowest $\Delta^{\mathrm{e}}=p^{h}-c^{h}=p^{l}-c^{l}{ }^{7}$ Similarly, among all undertreatment (overtreatment) vectors, $\underline{\Delta}^{\mathrm{u}}\left(\underline{\Delta}^{\mathrm{o}}\right)$ is the one with the lowest $\Delta^{\mathrm{u}}=p^{l}-c^{l}\left(\Delta^{\mathrm{o}}=p^{h}-c^{h}\right)$. Finally, among all equal mark-up and all undertreatment vectors, $\underline{\Delta}^{\mathrm{eu}}$ is the one with the lowest $\Delta^{\mathrm{eu}}=\left(p^{h}-c^{h}+p^{l}-c^{l}\right) / 2 .^{8}$

Prediction $C^{S_{2}}$ (Visiting Behavior). When $\mathbf{V}$ is violated, a consumer's visiting behavior depends only on $p^{h}$, but not on $p^{l}$. When $\mathbf{V}$ holds, visiting behavior depends both on $p^{l}$ and $p^{h}$.

(i) In $\mathbf{C} / \mathbf{N}$ consumers visit the seller (or one of the sellers) with the lowest $p^{h}$, provided it satisfies $p^{h} \leq 3$. Otherwise consumers abstain from interaction with sellers.

(ii) In $\mathbf{C} / \mathbf{L}$ consumers visit a seller with the lowest $p^{h}$, provided it satisfies $p^{h} \leq 8$. Otherwise consumers abstain from interaction.

(iii) In $\mathbf{C} / \mathbf{V}$ the following applies:

- If $\underline{\Delta}^{\mathrm{e}} \leq \min \left\{\underline{\Delta}^{\mathrm{u}}+3, \underline{\Delta}^{\mathrm{o}}+2\right\}$ consumers visit the seller (or one of the sellers) who posts $\underline{\Delta}^{\mathrm{e}}$, provided $\underline{\Delta}^{\mathrm{e}} \leq 4$. Otherwise consumers abstain from interaction.

- If $\underline{\Delta}^{\mathrm{o}} \leq \min \left\{\underline{\Delta}^{\mathrm{u}}+1, \underline{\Delta}^{\mathrm{e}}-3\right\}$ consumers visit the seller (or one of the sellers) who posts $\underline{\Delta}^{\mathrm{o}}$, provided $\underline{\Delta}^{\mathrm{o}} \leq 2$. Otherwise consumers abstain from interaction.

- if $\underline{\Delta}^{\mathrm{u}} \leq \min \left\{\underline{\Delta}^{\mathrm{e}}-4, \underline{\Delta}^{\mathrm{o}}-2\right\}$ consumers visit the seller (or one of the sellers) who posts $\underline{\Delta}^{\mathrm{u}}$, provided $\underline{\Delta}^{\mathrm{u}} \leq 1$. Otherwise consumers abstain from interaction.

(iv) In $\mathbf{C} / \mathbf{L V}$ the following applies:

- If $\underline{\Delta}^{\mathrm{eu}} \leq \underline{\Delta}^{\mathrm{o}}+2$ consumers visit the seller (or one of the sellers) who posts $\underline{\Delta}^{\mathrm{eu}}$, provided $\underline{\Delta}^{\mathrm{eu}} \leq 4$. Otherwise consumers abstain from interaction.

- If $\underline{\Delta}^{\mathrm{eu}}>\underline{\Delta}^{\mathrm{o}}+2$ consumers visit the seller (or one of the sellers) who posts $\underline{\Delta}^{\mathrm{o}}$, provided $\underline{\Delta}^{\mathrm{o}} \leq 2$. Otherwise consumers abstain from interaction.

Prediction $C^{S} 3$ (Pricing Policy and Interaction). Interaction (almost) always takes place even in $\mathbf{C} / \mathbf{N}$, although sellers provide only the minor treatment there. In conditions $\mathbf{C} / \mathbf{L}, \mathbf{C} / \mathbf{V}$

\footnotetext{
${ }^{7}$ For convenience we denote not only a specific price-vector but also the implied mark-up by $\Delta$.

${ }^{8}$ To be precise if $\left\{p_{i}^{l}, p_{i}^{h}\right\}$ denote the prices posted by seller $i$ then $\underline{\Delta}^{\mathrm{e}}=\min _{i}\left\{p_{i}^{h}-c^{h} \mid p_{i}^{h}-c^{h}=p_{i}^{l}-c^{l}\right\}, \underline{\Delta}^{\mathrm{u}}=\min _{i}\left\{p_{i}^{l}\right.$ $\left.c^{l} \mid p_{i}^{h}-c^{h}<p_{i}^{l}-c^{l}\right\}, \underline{\Delta}^{\mathrm{o}}=\min _{i}\left\{p_{i}^{h}-c^{h} \mid p_{i}^{h}-c^{h}>p_{i}^{l}-c^{l}\right\}$, and $\underline{\Delta}^{\mathrm{eu}}=\min _{i}\left\{\left(p_{i}^{h}-c^{h}+p_{i}^{l}-c^{l}\right) / 2 \mid p_{i}^{h}-c^{h} \leq p_{i}^{l}-c^{l}\right\}$.
} 
and $\mathbf{C} / \mathbf{L V}$ prices are chosen such that sellers are induced to provide the appropriate treatment. In all conditions of set $\mathbf{C}$ the total gains from trade accrue to consumers. ${ }^{9}$

(i) In $\mathbf{C} / \mathbf{N}$ each seller posts $\{$ n.d, 3$\}$ with probability $x=0.844$ and a price-vector which is unattractive for consumers (due to $p^{h}>3$ ) with probability $1-x .^{10}$ If at least one seller posts $\{$ n.d, 3$\}$ then all consumers are (under-)treated, otherwise (with probability $(1-x)^{4}=0.06 \%$ ) there is no interaction. Each seller's profit in equilibrium is 1.6.

(ii) In $\mathbf{C} / \mathbf{L}$ each seller posts $\{$ n.d., 5 $\}$ with probability $x=0.839$ and \{n.d., 6 $\}$ with probability 1-x. Interaction always takes place and consumers get appropriate treatment. Each seller's profit in equilibrium is 1.604 .

(iii) In $\mathbf{C} / \mathbf{V}$ each seller posts $\{3,7\}$ with probability $x=0.839$ and $\{4,8\}$ with probability $1-x$. Interaction always takes place and consumers get appropriate treatment. Each seller's profit in equilibrium is 1.604 .

(iv) In $\mathbf{C} / \mathbf{L V}$ each seller posts either $\{4,5\}$ or $\{3,6\}$ with probability $x=0.132$, either $\{5,5\}$, or $\{4,6\}$, or $\{3,7\}$ with probability $y=0.280$, and either $\{5,6\}$ or $\{4,7\}$ with probability $1-x-y \cdot{ }^{11}$ Interaction always takes place and consumers get appropriate treatment. Each seller's profit in equilibrium is 1.683 .

The intuition for (almost) full interaction in $\mathbf{C} / \mathbf{N}$ runs as follows. Although sellers can still not be induced to provide the major treatment, each seller can now serve more than one consumer. The latter fact implies that there is now room for prices that are profitable for both parties of the interaction. Note, however, that the increase in the frequency of interaction

${ }^{9}$ Here we focus on symmetric equilibria. Note that in the price-posting stage of set $\mathbf{C}$ there are also asymmetric equilibria. Because there is no obvious way for sellers to coordinate on a specific asymmetric equilibrium we regard such equilibria as less plausible, and thus mention them only here in a footnote. Using similar techniques as in the proof of Prediction $C^{S} 3$ it can be shown that the following are asymmetric equilibria (and in fact the unique equilibria in pure strategies): In $\mathbf{C} / \mathbf{N}$ three sellers post $\{$ n.d, 3$\}$ and one seller posts a pricevector which is unattractive for consumers (with $p^{h}>3$ ); the three sellers who post $\{$ n.d, 3$\}$ earn 1.6493 in expectation, the forth seller gets 1.6 for sure. In $\mathbf{C} / \mathbf{L}(\mathbf{C} / \mathbf{V}$, respectively) three sellers post $\{$ n.d., 5$\}(\{3,7\}$, respectively) and one seller posts a price-vector that is less attractive for consumers; equilibrium profits are as in $\mathbf{C} / \mathbf{N}$. In $\mathbf{C} / \mathbf{L V}$ one seller posts $\{4,5\}$ or $\{3,6\}$ and three sellers post price-vectors that are less attractive for consumers; the seller posting the attractive price-vector earns 2 for sure, the other three sellers get the outside option.

${ }^{10}$ We round the probabilities of interaction to three decimals in this subsection.

${ }^{11}$ Note that within the three sets of price-vectors, both sellers and consumers are indifferent which price-vector is accepted. 
translates only in a minor increase in efficiency (less than a $1 / 7$ of the potential gains from trade are realized), as consumers are always undertreated in equilibrium.

\subsubsection{The Combined Effects of Reputation and Competition}

The main effect of combining competition with reputation arises in the $\mathbf{N}$-condition. In $\mathbf{C R} / \mathbf{N}$, competition increases the frequency of interaction (in comparison to $\mathbf{B} / \mathbf{N}$ and $\mathbf{R} / \mathbf{N}$ ) and reputation increases the efficiency of interaction (in comparison to $\mathbf{C} / \mathbf{N}$ ) by supporting equilibria with full interaction and appropriate treatment in early periods. The reason is that consumers can now costlessly reward a seller who has treated them appropriately in the past, simply by buying from this (and not from another) seller again even in the last periods of the experiment where sellers are known to act opportunistically in any case. Since $\mathbf{L}$ and/or $\mathbf{V}$ are already sufficient to yield full efficiency, we should find an effect of combining reputation and competition on efficiency only in set $\mathbf{N}$ :

Predictions $C R^{S} 1$ to $C R^{S}$ 3. Predictions $C^{S} 1$ to $C^{S} 3$ remain equilibrium predictions also in set CR. In $\mathbf{C R / N}$, there are additional equilibria where (some) sellers post \{n.d, 5$\}$ in the first 9 periods and in which consumers accept, because they anticipate (correctly) that they will get the appropriate treatment with sufficiently high probability.

Summarizing the standard predictions, we observe that either liability or verifiability or both lead to full efficiency while the absence of both leads to severe welfare losses. An opportunity for reputation building might substantially reduce the welfare losses, but only when combined with competition. Competition alone increases the frequency of interaction (without substantially increasing efficiency) if neither liability nor verifiability applies, but it has only redistribution effects (shifting the gains from trade from sellers to consumers) in all other cases.

\subsection{Assuming Non-Standard Preferences}

So far we have assumed that subjects are rational and only interested in their own monetary payoff. Motivated by the opening quote from Hippocrates, this section analyzes trade on credence goods markets when sellers have non-standard preferences. ${ }^{12}$ More

\footnotetext{
${ }^{12}$ To the best of our knowledge, Liu (2008) is the only paper in the credence goods literature that considers sellers (or experts) with non-standard preferences. She studies a credence goods market populated by both
} 
precisely, we assume that sellers care for appropriate treatment and correct charging. The former may be motivated by a desire for efficiency (see, e.g., Charness and Rabin, 2002, for evidence on the behavioral relevance of efficiency-concerns) and the latter by a desire for honesty and keeping one's word (see Gneezy, 2005, or Vanberg, 2008, for evidence on how a concern for honesty or an aversion against cheating influences behavior). ${ }^{13}$

We operationalize a sellers' desire for appropriate treatment and for honest charging as follows: Let $\theta \in\{l, h\}$ be the index of a consumer's type of problem, $\mu \in\{l, h\}$ the index of the treatment provided and $\kappa \in\{l, h\}$ the index of the treatment charged for. Then the utility of a seller of type $(\alpha, \beta, \gamma)$ who is interacting with a consumer is assumed to be given by

$$
U_{\alpha, \beta, \gamma}\left(p^{l}, p^{h}, \theta, \mu, \kappa\right)=p^{\kappa}-c^{\mu}-\alpha I_{\theta>\mu}-\beta I_{\theta<\mu}-\gamma I_{\mu<\kappa},
$$

where $\alpha \geq 0$ is the disutility from undertreatment, $\beta \geq 0$ is the disutility from overtreatment, and $\gamma \geq 0$ is the disutility from overcharging a consumer. $I$ is an indicator variable that takes the value of one if the condition in the subscript is met and the value of zero otherwise. ${ }^{14}$ The following predictions are based on the assumption that sellers are heterogeneous. More precisely, we assume that sellers' types are independently drawn from the same cumulative distribution $\mathrm{G}(\alpha, \beta, \gamma)$ with strictly positive density on $\left[0, \alpha^{\max }\right] \mathrm{x}\left[0, \beta^{\max }\right] \mathrm{x}\left[0, \gamma^{\max }\right]{ }^{15}$

In the following we will sometimes refer to consumers having optimistic expectations. Consumers are said to have optimistic expectations if they believe that at least $52 \%$ of sellers have an $\alpha \geq 4$. A parameter of $\alpha \geq 4$ means that a seller's disutility from undertreatment is

selfish and conscientious sellers. Selfish sellers simply maximize profits while the utility of conscientious sellers is derived from profits as well as from repairing the consumer's problems. The key feature of Liu's (2008) paper is that conscientious sellers are able to commit to treat consumers even if the prices they have posted do not cover treatment costs. That is, in Liu's (2008) model a conscientious seller has the same options and payoffs as a selfish seller except that he cannot turn down a consumer after the diagnosis. Our formulation of non-standard preferences differs considerably from this approach by keeping full freedom of action for the seller while allowing for a disutility from undertreatment, overtreatment or overcharging.

13 An aversion against undertreatment, overtreatment or overcharging is also implied by Charness and Dufwenberg's $(2005,2006)$ they of guilt aversion (see also Battigalli and Dufwenberg, 2007). In a nutshell, the theory of guilt aversion states that a player $i$ suffers from guilt to the extent that he believes that player $j \neq$ $i$ receives a lower payoff than $i$ believes $j$ believes she will receive. A seller with guilt aversion may not provide or charge for a wrong treatment if she does not want to disappoint the customer's beliefs about the payoffs from the interaction.

${ }^{14}$ Equation (1) uses the convention that $l \leq h$, but not vice versa.

${ }^{15}$ Note that the model introduced here collapses to the case of standard preferences discussed in Section 5.1 if $\alpha^{\max }=\beta^{\max }=\gamma^{\max }=0$. 
equal to or larger than the costs saved through undertreatment (i.e., $\alpha I_{\theta>\mu} \geq c^{h}-c^{l}=4$ ). In some of the predictions we also refer to a variable $x$ that is defined as

$$
x=\left(p^{h}-p^{l}\right)-\left(c^{h}-c^{l}\right)=p^{h}-p^{l}-4 .
$$

It is important to stress that we present only those predictions based on non-standard (NS) preferences that differ from those derived in Subsection 5.1 under the assumption of standard preferences. Note also that for more precise predictions it would have been necessary to assume a particular distribution of parameters $\alpha, \beta$ and $\gamma$ across sellers and that this distribution is common knowledge. We abstain from such far-reaching, yet empirically not validated, assumptions. ${ }^{16}$

\subsubsection{Non-Standard Predictions for Set B (Baseline) - On the Role of Liability and Verifiability}

Prediction $B^{N S} 1$ (Provision and Charging Policy). Contrary to the corresponding prediction with standard preferences, undertreatment, overtreatment and/or overcharging do not occur in all instances in which they are not prevented by institutional safeguards (i.e., by liability or verifiability). Also, behavior changes continuously in the price-difference $p^{h}-p^{l}$ instead of jumping discontinuously as in the standard prediction.

(i) Consider $\mathbf{B} / \mathbf{N}$ and suppose $\alpha^{\max }>4$ and $\gamma^{\max }>0$. Then the undertreatment rate is below $100 \%$. Furthermore, for prices satisfying $p^{h}-p^{l}<\gamma^{\max }$ the overcharging rate is below $100 \%$ and strictly increasing in the price difference $p^{h}-p^{l}$.

(ii) Consider $\mathbf{B} / \mathbf{L}$ and suppose $\gamma^{\max }>0$. Then for prices satisfying $p^{h}-p^{l}<\gamma^{\max }$ the overcharging rate is below $100 \%$ and strictly increasing in the price difference $p^{h}-p^{l}$.

(iii) Consider $\mathbf{B} / \mathbf{V}$ and suppose $\alpha^{\max }>0$ and $\beta^{\max }>0$. Then for prices satisfying $-x \in(0$, $\alpha^{\max }$ ) the undertreatment rate is below $100 \%$ and strictly decreasing in the price difference $p^{h}$ $-p^{l}$. Furthermore, for prices satisfying $x \in\left(0, \beta^{\max }\right)$ the overtreatment rate is below $100 \%$ and strictly increasing in the price difference $p^{h}-p^{l}$.

(iv) Consider $\mathbf{B} / \mathbf{L V}$ and suppose $\beta^{\max }>0$. Then for prices satisfying $x \in\left(0, \beta^{\max }\right)$ the overtreatment rate is below $100 \%$ and strictly increasing in the price difference $p^{h}-p^{l}$.

\footnotetext{
${ }^{16}$ Strictly speaking, the non-standard predictions on the provision and charging policy are predictions for exogenously given prices. To check whether exogenously imposed price vectors would yield different results we have run a control treatment where the price vectors were predetermined by the experimenter. The results of this robustness check are very briefly mentioned in footnote 21 . Further details are available upon request.
} 
Prediction $B^{N S} 2$ (Acceptance Behavior). Contrary to the corresponding prediction with standard preferences, the acceptance behavior of consumers depends on $p^{l}$ also in conditions $\mathbf{B} / \mathbf{N}$ and $\mathbf{B} / \mathbf{L}$. Furthermore, acceptance thresholds are higher.

(i) Consider $\mathbf{B} / \mathbf{N}$, suppose $\alpha^{\max }>4$ and that this is common knowledge. Then, for any $\left\{p^{l}, p^{h}\right\}$ with $p^{l}=p^{h} \leq 8$ there exist expectations such that a consumer with those expectations is willing to trade (in particular, a consumer might be willing to trade even if $p^{h}>3$ ). Furthermore, for any $\left\{p^{l}, p^{h}\right\}$ with $p^{l}<p^{h}, p^{h}-p^{l}<\gamma^{\max }$ and $\left(p^{l}+p^{h}\right) / 2 \leq 8$ there exist expectations such that a consumer with those expectations is willing to trade (in particular, a consumer might be willing to trade even if $p^{h}>8$ ).

(ii) Consider $\mathbf{B} / \mathbf{L}$, suppose that $\gamma^{\max }>0$ and that this is common knowledge. Then for any $\left\{p^{l}, p^{h}\right\}$ with $p^{l}<p^{h}, p^{h}-p^{l}<\gamma^{\max }$ and $\left(p^{l}+p^{h}\right) / 2 \leq 8$ there exist expectations such that a consumer with those expectations is willing to trade (in particular, a consumer might be willing to trade even if $p^{h}>8$ ).

(iii) Consider $\mathbf{B} / \mathbf{V}$, suppose $\alpha^{\max }>0$ and $\beta^{\max }>0$ and that this is common knowledge. Then for any $\left\{p^{l}, p^{h}\right\}$ with $|x| \leq \operatorname{Min}\left\{\alpha^{\max }, \beta^{\max }\right\}$ and $\left(p^{l}+p^{h}\right) / 2 \leq 8$ there exist expectations such that a consumer with those expectations is willing to trade (in particular, a consumer might be willing to accept an undertreatment vector with $p^{l}>3$, and an overtreatment vector with $p^{h}>8$ ).

(iv) Consider $\mathbf{B} / \mathbf{L V}$, suppose $\beta^{\max }>0$ and that this is common knowledge. Then for any $\left\{p^{l}, p^{h}\right\}$ with $x<\beta^{\text {max }}$ and $\left(p^{l}+p^{h}\right) / 2 \leq 8$ there exist expectations such that a consumer with those expectations is willing to trade (in particular, a consumer might be willing to accept an overtreatment vector with $p^{h}>8$ ).

Prediction $B^{N S} 3$ (Interaction). Suppose some consumers have optimistic expectations. Then there exists an equilibrium in which the frequency of interaction is strictly positive even if neither observability nor liability (nor both) holds, that is, even in $\mathbf{B} / \mathbf{N}$, where prediction $\boldsymbol{B}^{\boldsymbol{S}_{3}}$ predicts complete market break down.

\subsubsection{Non-Standard Predictions for Sets R, C and CR - On the Role of Reputation- Building and Competition}

\subsubsection{The Effects of Reputation}

Allowing for heterogeneous sellers with respect to their preferences and for consumers with incomplete information about a seller's type and her behavior creates reputation equilibria in the spirit of Kreps and Wilson (1982) and Milgrom and Roberts (1982). In these equilibria it is attractive even for completely selfish sellers (with $\alpha=\beta=\gamma=0$ ) to incur short- 
run costs to build up a reputation as a reliable seller in early periods in order to be able to exploit the reputation in the final periods of the finitely repeated game. In the following, we consider only $\mathbf{R} / \mathbf{N}$, since adding reputation when liability or verifiability already applies cannot improve efficiency.

Predictions $\boldsymbol{R}^{N S} 1$ to $\boldsymbol{R}^{N S} 3$. Suppose that $\alpha^{\max }>4$ and that this is common knowledge. Contrary to the prediction with standard preferences, equilibria exist in $\mathbf{R} / \mathbf{N}$ in which

- the interaction frequency is $100 \%$ in early rounds and remains strictly positive throughout the game and

- all sellers provide the appropriate treatment in early rounds and some sellers provide the appropriate treatment throughout the game.

\subsubsection{The Effects of Competition}

In the following prediction we refer to consumers with naïve expectations. Consumers are said to have naïve expectations if they assume that a seller's provision policy in $\mathbf{C} / \mathbf{N}$ is independent of the price-vector under which the consumer is treated. Note that naive expectations are fully justified in the benchmark of Subsection 5.1 (where $\alpha^{\max }=\beta^{\max }=\gamma^{\max }$ $=0)$.

Prediction $C^{N S} 1$ (Provision and Charging Policy). Suppose that $\alpha^{\max }>4$ and that (some) consumers have naive expectations. Then undertreatment is higher in $\mathbf{C} / \mathbf{N}$ than in $\mathbf{B} / \mathbf{N}$.

Prediction $C^{N S} 2$ (Visiting Behavior). Contrary to the corresponding prediction with standard preferences, consumers' visiting behavior depends on $p^{l}$ also in conditions $\mathbf{C} / \mathbf{N}$ and $\mathbf{C} / \mathbf{L}$.

Summarizing the non-standard predictions, we observe that appropriate treatment might occur in equilibrium even without verifiability and liability and that aggregate behavior changes continuously in price differences instead of being of the bang-bang variety as in the standard prediction. Also, in contrast to the standard prediction, an opportunity for reputation building might increase efficiency even in the absence of competition. 


\section{Experimental Results}

In line with the presentation of the basic model and its extensions in Section 3, subsection 6.1 deals with the impact of liability and verifiability in set $\mathbf{B}$, and subsection 6.2 examines the effects of reputation and competition. Subsection 6.3 illustrates the main effects of liability, verifiability, reputation and competition on the basis of an econometric estimation.

\subsection{Behavior in Set B (Baseline) - Descriptive analysis}

Main Result 1 (On the Role of Liability and Verifiability): Liability has a highly significantly positive impact on the frequency of interaction and on the degree of efficiency, as standard theory predicts. However, verifiability has no significant impact on those variables, contrary to the standard prediction. In fact, aggregate behavior is very similar between $\mathbf{B} / \mathbf{N}$ and $\mathbf{B} / \boldsymbol{V}$, and the overall performance in both conditions is better than the standard prediction for $\mathbf{B} / \mathbf{N}$, but worse than the standard prediction for $\mathbf{B} / \boldsymbol{V}$. Our model with non-standard preferences explains only the 'better' part of the latter result, but fails to account for the 'worse' part.

Table 3 presents the main results for set $\mathbf{B}$. The first row reveals that the average frequency of interaction between consumers and sellers is only around $50 \%$ in conditions without liability $(\mathbf{B} / \mathbf{N}, \mathbf{B} / \mathbf{V})$, but significantly higher and above $80 \%$ in conditions with liability $(\mathbf{B} / \mathbf{L}, \mathbf{B} / \mathbf{L V}) .{ }^{17}$ Looking at efficiency in the second row yields a similar picture. ${ }^{18}$ Efficiency is below $20 \%$ without liability, but above $80 \%$ with liability. The third row reveals that, apart from the low frequencies of interaction, the high undertreatment rates $(53 \%$ in $\mathbf{B} / \mathbf{N}$ and $60 \%$ in $\mathbf{B} / \mathbf{V}$ ) are responsible for the low efficiency in $\mathbf{B} / \mathbf{N}$ and $\mathbf{B} / \mathbf{V}$. Overtreatment, by contrast, is no substantial problem in any of the conditions (see fourth row). Hence, liability is crucial for behavior, while verifiability has no positive effect in the aggregate, contrary to the standard theory's prediction.

Table 3 and Figure 2 about here

\footnotetext{
17 In Table 3 we check for significant differences between two conditions each by using two-sided nonparametric Mann-Whitney U-tests (with a matching group of 8 subjects constituting one independent observation).

${ }^{18}$ Efficiency is defined as the ratio of the average actual profit per subject to the average maximally possible profit per subject, where the outside option is disregarded for both measures.
} 
While Table 3 presents overall averages, Figure 2 illustrates the development of key variables across the 16 periods of the experiment. Panel [A] shows that the frequency of interaction is rather stable, and high, if liability holds (in $\mathbf{B} / \mathbf{L}$ and $\mathbf{B} / \mathbf{L V}$ ), while it has a steady downward trend whenever liability is violated (in $\mathbf{B} / \mathbf{N}$ and $\mathbf{B} / \mathbf{V}$ ). Panels [B] to [D] display the time path of undertreatment, overtreatment, and overcharging, showing in particular that overcharging is increasing over time, while there is no clear time trend for under- and overtreatment. Panels [E] and [F] show the development of (accepted) prices $p^{l}$ and $p^{h}$, indicating that consumers are willing (and have) to pay the highest prices in conditions where liability applies. In the following, we present for each of our predictions an accompanying result that adds further details.

\section{Result B1 (Provision and Charging Policy).}

(i) In $\mathbf{B} / \mathbf{N}$ the undertreatment rate is $53 \%$, which is far below the standard prediction of $100 \%$. In fact, 13 out of 48 sellers always provide the appropriate treatment across all 16 periods. Whereas the standard prediction $\boldsymbol{B}^{\boldsymbol{S}} \boldsymbol{1}$ obviously fails to explain this pattern, prediction $\boldsymbol{B}^{N S} \boldsymbol{1}$ with non-standard preferences can account for it. The non-standard prediction also implies the pattern observed with overcharging, as overcharging is below $100 \%$ and increasing in the price difference $p^{h}-p^{l} .^{19}$

(ii) In $\mathbf{B} / \mathbf{L}$ the average overcharging rate is $65 \%$, contrary to $100 \%$ according to prediction $\boldsymbol{B}^{S}$ 1. In fact, twelve out of 48 sellers always charge for the actually provided treatment even when $p^{h}>p^{l}$. Also, overcharging rate is increasing in the price difference..$^{20}$ All those findings are consistent with prediction $B^{N S} \mathbf{1}$, but not accounted for in the standard prediction $\boldsymbol{B}^{\boldsymbol{S}} \boldsymbol{1}$.

(iii) In $\mathbf{B} / \mathbf{V}$ we observe equal mark-up vectors in only $4 \%$ of cases (29 out of 704 ), while in $94 \%$ of cases sellers post an undertreatment price-vector. For the former type of pricevectors the standard model predicts appropriate treatment while we observe overtreatment in about $40 \%$ of the cases. For the latter type of price-vectors the standard model predicts

\footnotetext{
${ }^{19}$ Overcharging occurs whenever the minor treatment is provided, but the major treatment is charged, and $p^{h}>$ $p^{l}$. For example, holding the high price constant at $p^{h}=8$ (in $\mathbf{B} / \mathbf{N}$ the high price is at 8 in roughly $50 \%$ of price-vectors), the relative frequency of overcharging is $75 \%$ when the low price is $p^{l}=7$, but increases monotonically to $100 \%$ with a decrease in the low price down to $p^{l}=3$.

${ }^{20}$ For example, holding the high price constant at $p^{h}=8$ (in $\mathbf{B} / \mathbf{L}$ the high price is at 8 in more than $80 \%$ of pricevectors), the relative frequency of overcharging is $65 \%$ when the low price is $p^{l}=7$, but increases monotonically to $100 \%$ with a decrease in the low price down to $p^{l}=3$.
} 
undertreatment in all cases, while it is observed in only $60 \%$ of cases. While behavior under the former type of price vector is inconsistent with the non-standard model, behavior under the latter type can be explained by it. The non-standard prediction also captures the feature that the undertreatment rate is decreasing in the price difference $p^{h}-p^{l}$ and that the overtreatment rate is increasing in it. ${ }^{21}$

(iv) In B/LV equal mark-up vectors are extremely rare (12 out of 640 observations), the vast majority of price-vectors (about 95\%) are of the undertreatment type. While the provision behavior under undertreatment vectors is roughly consistent with both, the standard and the non-standard prediction, the provision behavior under equal mark-up vectors (about 50\% overtreatment) is not.

\section{Result B2 (Acceptance Behavior).}

(i) In $\mathbf{B} / \mathbf{N}$ consumers accept price-vectors with average prices $p^{h}=7.28$ and $p^{l}=4.67$. The standard-model would imply rejecting such high prices, yet for optimistic expectations acceptance can be rationalized, as indicated in prediction $\boldsymbol{B}^{N S}$. The average profits of consumers are only 1.00 , however, which is less than their outside option and shows that consumers' expectations are too optimistic, on average.

(ii) In $\mathbf{B} / \mathbf{L}$ the average accepted $p^{h}$ is 8.00 , which is the point prediction in $\boldsymbol{B}^{\boldsymbol{S}} \mathbf{2}$, and which is also compatible with the non-standard prediction $\boldsymbol{B}^{N S}$.

(iii) In $\mathbf{B} / \mathbf{V}$ the overall average accepted $p^{l}$ is 5.84 , which seems fairly close to the standard model's predicted low price of 6 in an equal mark-up price-vector $\{6,10\}$. Yet, as noted above, equal mark-up price-vectors are extremely rare - the vast majority (94\%) of price-vectors are undertreatment vectors. The standard prediction $\boldsymbol{B}^{\boldsymbol{S}} \boldsymbol{2}$ implies a lower price of $p^{l}=3$ under these circumstances, while the average $p^{l}$ in accepted undertreatment vectors is 5.66. For very optimistic expectations such acceptance behavior is consistent with the nonstandard prediction $\boldsymbol{B}^{N S}$. However, consumers are again found to be too optimistic, since their average profit is less than 1 , and thus smaller than the outside option.

(iv) In $\mathbf{B} / \mathbf{L V}$ the average accepted $\left(p^{h}+p^{l}\right) / 2$ under equal mark-up and undertreatment vectors is 7.46 , which is roughly consistent with both sets of predictions.

\footnotetext{
${ }^{21}$ For instance, the undertreatment rate is $100 \%$ for price-vector $\{8,8\}$, and it falls monotonically when the low price is decreased step by step, reaching $0 \%$ for price-vector $\{4,8\}$. The overtreatment rate is $0 \%$ for vectors $\{7,8\}$ and $\{8,8\}$, and it increases with a decrease in the low price, reaching $38 \%$ for vector $\{4,8\}$. In a control treatment (not reported here) with exogenously given prices we found very similar results.
} 


\section{Result B3 (Pricing Policy and Interaction).}

(i) In $\mathbf{B} / \mathbf{N}$ the most frequently posted price-vectors are $\{6,8\}$ in $23 \%$ and $\{4,8\}$ in $10 \%$ of cases. The former would split the gains from trade equally between sellers and consumers if sellers always provided the appropriate treatment and always charged for the provided treatment. The latter is an equal mark-up price-vector. Compared to the standard prediction $\boldsymbol{B}^{S} 3$ posted prices are way too high (only 3 out of 768 cases had a high price satisfying $p^{h} \leq$ 3). The non-standard prediction $\boldsymbol{B}^{N S} \mathbf{3}$ can account for interaction also taking place with higher prices.

(ii) In $\mathbf{B} / \mathbf{L}$ sellers post price-vectors with $p^{h}=8$ in more than $80 \%$ of the observations, which is largely consistent with the standard prediction. The most frequent price-vectors are $\{6,8\}$ with $24 \%$, and $\{7,8\}$ with $23 \%$ of cases.

(iii) As noted above, in $\mathbf{B} / \mathbf{V}$ sellers post equal mark-up vectors in only $4 \%$ of cases, but undertreatment vectors in $94 \%$ of observations, which is in sharp contrast to the standard prediction. The most popular price-vectors are $\{6,8\}$ and $\{7,8\}$, accounting for about $40 \%$, respectively $10 \%$, of observations. Such vectors are acceptable if consumers expect sellers to have non-standard preferences (prediction $\boldsymbol{B}^{N S_{2}}$ ).

(iv) In B/LV sellers almost always (in $96 \%$ of the observations) post an undertreatment price-vector, which is largely consistent with standard and non-standard preferences of sellers. The most prominent price-vectors are $\{6,8\},\{7,8\}$ and $\{8,8\}$, accounting for about $80 \%$ of the observations.

As regards the relative frequency of interaction across the conditions in set $\mathbf{B}$ we note that the relatively high level in $\mathbf{B} / \mathbf{N}$ (45\% when the standard model predicts complete market breakdown) can be explained by some sellers having non-standard preferences and consumers having optimistic expectations (prediction $B^{N S} 3$ ). However, the poor performance of $\mathbf{B} / \mathbf{V}$ can not be accounted for by any of our models, since they would not have predicted the almost universal use of undertreatment price-vectors that yield strong incentives for undertreatment. Having liability of sellers increases the relative frequency of interaction significantly (to above $80 \%$ ), though the level of interaction falls a bit short of the predicted $100 \%$.

\subsection{Behavior in Sets R, C and CR - Descriptive Analysis} Main Result 2 (On the Role of Reputation-Building and Competition):

Set $\boldsymbol{R}$. An opportunity for reputation building (without competition) increases the frequency of interaction and decreases the frequency of overcharging when neither liability nor verifiability applies - which is in line with the non-standard predictions $\boldsymbol{R}^{N S} \mathbf{1}$ to $\boldsymbol{R}^{N S} \mathbf{3}$ while 
inconsistent with the standard predictions $\boldsymbol{R}^{\boldsymbol{S}} \mathbf{1}$ to $\boldsymbol{R}^{\mathbf{S}_{3}}$ - but reputation building has no significant effect on behavior in all other cases - which is consistent with both types of predictions.

Set C. Competition (without an opportunity for reputation-building) has a tremendous impact on the frequency of interaction, independently of whether liability and/or verifiability applies or is violated. For condition $\mathrm{C} / \mathrm{N}$, this effect of competition is consistent with both the standard and non-standard predictions. In all other conditions both types of predictions did not suggest an effect on the frequency of interaction of adding competition to the baseline set B, however.

Set CR. Adding an opportunity for reputation-building to competition has virtually no effect in comparison to behavior when only competition applies, except for condition $\mathbf{N}$ where adding $\boldsymbol{R}$ to $\boldsymbol{C}$ increases the frequency of interaction (without significantly affecting efficiency, however).

Table 4 presents the main results for all 16 experimental conditions. Comparing across the four columns within each of the four panels $[\mathbf{N}],[\mathbf{L}],[\mathbf{V}]$, or $[\mathbf{L V}]$ allows checking how behavior is affected by competition and reputation building, holding liability and verifiability constant. We use two-sided Mann-Whitney U-tests to indicate significant differences between two conditions each within a given panel. The overall pattern emerging from Table 4 is the following.

(i) The frequency of interaction increases with competition (with or without reputation). The impact of competition on efficiency is ambiguous, however. In particular, efficiency is not increased by introducing $\mathbf{C}$ when liability and verifiability are both violated, but the impact is positive in all other cases although the effect is only significant in V. Panel A of Figure 3 shows the development of the interaction frequency, confirming that it is always highest with competition.

(ii) There are no clear-cut effects of competition on undertreatment, as can be seen from panel B of Figure 3.

(iii) When verifiability applies both competition and reputation increase overtreatment while there is no such effect when verifiability is violated, as can be seen in Table 4 and in panel C of Figure 3.

(iv) An opportunity for reputation building decreases overcharging in set $\mathbf{N}$ while there is no significant effect in all other conditions, as can be seen in Table 4 and in panel D of Figure 3. 
(v) Prices $p^{l}$ and $p^{h}$ are on average about 2 units lower with seller-competition than without (see panels E and F of Figure 3). The gains from trade shift (almost completely) from sellers to consumers when shifting from a condition without seller-competition to one where sellers compete.

\section{Table 4 and Figure 3 about here}

We add further details to the main result stated above by considering each of the predictions derived for behavior with reputation-building and/or competition.

\subsubsection{The Effects of Reputation in the Absence of Competition}

Results $\boldsymbol{R} 1$ to $\boldsymbol{R} 3$. As expected from the non-standard (but not from the standard) prediction, we find that an opportunity for reputation building induces significant behavioral changes when neither liability nor verifiability applies whereas reputation has only a minor impact in all other cases: Table 4 shows a significant increase in the frequency of interaction in $\mathbf{R} / \mathbf{N}$, compared to $\mathbf{B} / \mathbf{N}$. Likewise, overcharging decreases. Undertreatment was expected to decrease (see prediction $\boldsymbol{R}^{N S} 1$ ), but this is not the case. An opportunity for reputation building seems to induce trust of consumers in sellers, hence the higher frequency of interaction, but trust does not pay in this condition, since the profits of consumers are not higher in $\mathbf{R} / \mathbf{N}$ than in $\mathbf{B} / \mathbf{N}$ while those of sellers are significantly increased. In sum, adding an opportunity for reputation building has only important effects when there are no institutional safeguards against sellers' misbehavior (in $\mathbf{R} / \mathbf{N}$ ), but reputation benefits the sellers only. This finding is roughly in line with the non-standard predictions $R^{N S} 1$ to $R^{N S} 3$. Note, however, that the negative part of the predictions (no impact of reputation if either $\mathbf{L}$ or $\mathbf{V}$ or both apply) is based on the presumption that the presence of $\mathbf{L}$ and/or $\mathbf{V}$ per se is already enough to yield full efficiency (so that adding $\mathbf{R}$ was expected to be of no help). Since the actual frequency of interaction and degree of efficiency are rather low in set $\mathbf{V}$, there would have been room for efficiency improvements, which has not been exploited, though.

\subsubsection{The Effects of Competition in the Absence of Reputation}

Result C1 (Provision and Charging Policy). In conditions L, V and LV competition alone does not have a significant influence on the provision and charging policy, as expected from the models with standard and non-standard preferences. In condition $\mathbf{N}$, however, competition 
increases undertreatment from $53 \%$ to $73 \%$, which is qualitatively in line with prediction $C^{N S} 1$, even though it fails significance.

\section{Table 5 about here}

Result C2 (Visiting Behavior). Table 5 presents evidence on consumers' visiting behavior. It shows the properties of accepted price-vectors. Standard theory predicts that consumers visit the seller with the lowest $p^{h}$ if verifiability is violated, but that consumers' visiting behavior depends on both prices if $\mathbf{V}$ holds. Looking at the upper panel of Table 5 we see that, when $\mathbf{V}$ applies, the share of accepted price-vectors that include the lowest price $p^{h}$ goes down, whereas price-vectors with the minimum price $p^{l}$ (that do not also have the minimum price $p^{h}$ ) become more often accepted. ${ }^{22}$ Thus, consumers' visiting behavior is largely in line with the standard theory's prediction $\boldsymbol{C}^{\boldsymbol{S}} \boldsymbol{2}$. The strongest deviation can be found in $\mathbf{C} / \mathbf{N}$ where in $32 \%$ of the observations a consumer does not visit the seller with the lowest $p^{h}$. Such behavior can be rationalized, though, when consumers expect sellers to have non-standard preferences (as assumed in prediction $C^{N S}$ ).

\section{Result C3 (Pricing Policy and Interaction).}

(i) Whereas standard theory would have predicted a price-vector with $p^{h}=3$ (with any $p^{l}$ up to $p^{h}$ ) in $\mathbf{C} / \mathbf{N}$, price-vectors with $p^{h} \leq 3$ are chosen in less than $1 \%$ of cases. Thus, average prices are too high to be consistent with standard predictions. The most prominent pricevectors are the equal mark-up vectors $\{3,7\}$ with $12 \%$ and $\{4,8\}$ with $8 \%$ of observations. The lower prices, compared to $\mathbf{B} / \mathbf{N}$, lead to a significantly higher interaction frequency $(73 \%$ vs. $45 \%)$.

(ii) According to the standard prediction price-vectors of the type \{n.d., 5\} should be posted in around $84 \%$ of observations in $\mathbf{C} / \mathbf{L}$, but they are proposed in only $13 \%$. Vectors \{n.d., 6\} have been predicted in about $16 \%$ of cases, but observed in $33 \%$. The most prominent vectors are again $\{3,7\}$ with $12 \%$ of observations, as well as $\{4,8\}$ and $\{5,5\}$ with $8 \%$ each. The frequency of interaction of $99 \%$ is at the edge of the predicted $100 \%$.

\footnotetext{
${ }^{22}$ Applying a $\chi^{2}$-test, we find that the distribution of accepted price-vectors between rows a) and b) in Table 5 is significantly different between $\mathbf{C} / \mathbf{N}$ and $\mathbf{C} / \mathbf{V}$, and between $\mathbf{C} / \mathbf{L}$ and $\mathbf{C} / \mathbf{L V}(p<0.05)$. Another way of stating this result is that the share of accepted price-vectors that include the minimum price $p^{h}$ is significantly higher in $\mathbf{C} / \mathbf{N}$ than in $\mathbf{C} / \mathbf{V}$, and also higher in $\mathbf{C} / \mathbf{L}$ than in $\mathbf{C} / \mathbf{L V}(p<0.05)$.
} 
(iii) In $\mathbf{C} / \mathbf{V}$ sellers post equal mark-up vectors in $23 \%$ of cases only, which is less than predicted by the standard model, but more than was observed in $\mathbf{B} / \mathbf{N}$. The predicted vector $\{3$, $7\}$ is the most prominent vector with $11 \%$, and the alternative prediction of $\{4,8\}$ is observed in $8 \%$ of observations. The majority of vectors $(64 \%)$ are undertreatment vectors. The most prominent ones of the latter type are $\{5,5\}$ and $\{4,6\}$ with $10 \%$, respectively $9 \%$, of observations. The frequency of interaction is $88 \%$, and thus is slightly below the predicted $100 \%$.

(iv) The set of price-vectors expected from prediction $C^{S_{3}}$ account for $50 \%$ of observations in $\mathbf{C} / \mathbf{L V}$. The most prominent vectors are $\{4,6\},\{4,7\}$, and $\{3,7\}$ which account for $10 \%$ each. Undertreatment vectors are observed in $67 \%$ of cases, equal mark-up vectors in $23 \%$. The relative frequency of interaction is $99 \%$, and thus practically identical to the predicted $100 \%$.

\subsubsection{The Combined Effects of Reputation and Competition}

Results $C R 1$ to $C R 3$. Prediction $C R^{S} 1$ had indicated that adding reputation to competition does not change any of the predictions, except that it would admit equilibria in $\mathbf{C R} / \mathbf{N}$ in which there is appropriate treatment in earlier periods and, consequently, higher prices. We do not find evidence for this type of equilibrium, though, since adding reputation-building keeps both the undertreatment rate and the posted, respectively accepted, prices basically at the same levels as in $\mathbf{C} / \mathbf{N}$. Despite this, the relative frequency of interaction increases significantly (compare the entries for $\mathbf{C} / \mathbf{N}$ and $\mathbf{C R} / \mathbf{N}$ in Table 4), again indicating that an opportunity of reputation building induces trust of consumers. When liability or verifiability (or both) applies, adding an opportunity for reputation building to competition does not change any of the important variables substantially. This is a remarkable analogy to the previous results that adding reputation to the baseline condition has no effects as soon as either verifiability or liability applies. 


\subsection{Estimating the Effects of Liability, Verifiability, Reputation-Building and Competition}

In Table 6 we report the coefficients from random effects probit regressions where we examine the impact of liability, verifiability, reputation-building and competition on the relative frequency of interaction, undertreatment, overtreatment, and overcharging. ${ }^{23}$

\section{Table 6 about here}

Column [1] of Table 6 considers the frequency of interaction on the seller side. ${ }^{24}$ Looking at the main treatment effects one can see that liability and competition have a significant effect, whereas verifiability and reputation per se are insignificant. All other things being equal, liability has a strong positive effect on the likelihood of interaction, because consumers can be sure to receive a sufficient treatment. Competition has a significant negative main effect on the probability of a particular seller having an interaction, since it leads to a concentration of several consumers visiting the same seller, leaving more sellers without any consumer. The row "average \# of consumers" in Table 4 shows that sellers have on average between 1.54 and 2.29 consumers per period in conditions with seller competition. This concentration leaves other sellers without an interaction, hence the negative coefficient for competition. Contrary to the standard (and non-standard) prediction, verifiability has no significant main effect. Reputation also lacks a significant main effect, consistent with the standard prediction. Both prices, $p^{l}$ and $p^{h}$, have a significant negative effect on the likelihood of interaction. Recall that the standard prediction for conditions $\mathbf{N}$ and $\mathbf{L}$ (prediction $\boldsymbol{B}^{\boldsymbol{S}_{2}}$ ) had

${ }^{23}$ The models presented in Table 6 were selected on the basis of the Bayesian Information Criterion for goodness of fit. Note that none of the third-order or fourth-order interaction effects of the main treatment variables liability, verifiability, reputation and competition (as well as the interaction of these higher-order effects with period and prices) had been found significant when including them as independent variables. The model fit was also improved by dropping any interaction terms where either the period or any of the two prices $\left(p^{l}\right.$ or $\left.p^{h}\right)$ had been interacted with a second-order interaction of the main treatment variables (for example, "Period $\times$ Liability $\times$ Verifiability), since these terms were never significant. In columns [2] to [4] of Table 6 we also drop the second-order interaction effects of the main treatment variables since BIC gets better (i.e., lower) by doing so.

${ }^{24}$ We use the frequency of interaction on the seller (and not on the consumer) side as dependent variable here because among the independent variables there are the prices $p^{h}$ and $p^{l}$ and because in the competition conditions (where consumers can choose from four price-vectors) it would not be clear on which prices the frequency of interaction on the consumer side should be conditioned upon. 
implied that the low price $p^{l}$ has no impact on a consumer's acceptance decision. This is obviously not what we observe. Rather, the low price lures consumers into the market. Prediction $\boldsymbol{B}^{N S} 2$ accounts for this finding. Another noteworthy effect is the interaction of the high price with verifiability. If verifiability holds, the negative main effect of the high price $p^{h}$ on the likelihood of interaction is reduced - consistent with our non-standard prediction because an increase in the high price renders undertreatment less attractive for sellers. Similarly, reputation has a positive interaction effect with the high price $p^{h}$, indicating that reputation building allows for a (relatively small) increase in the high price without endangering the consumer's willingness to interact with the seller in set $\mathbf{N}$. Finally note that the frequency of interaction is declining significantly across periods, and that this downward trend is only partially offset when liability or verifiability applies.

\section{Figure 4 about here}

In panel [1] of Figure 4 we show the estimated likelihood of interaction on the seller side for specific sets of independent variables, based on the estimation reported in column [1] of Table 6. We consider only the final period of the experiment (i.e., period 16), because we want to see how behavior looks like when subjects have experience with the intricacies of credence goods markets. Furthermore, we fix the low price at $p^{l}=4$ on the left-hand side, respectively $p^{l}=5$ on the right-hand side within each of the four sets $\mathbf{N}, \mathbf{L}, \mathbf{V}$, and $\mathbf{L V}$. For a given $p^{l}$ we consider a high price $p^{h} \in\{5,6,7,8\}$. The pattern emerging from the estimated likelihood of interaction illustrates the main results from Table 6 very clearly. An increase in $p^{l}$ or $p^{h}$ decreases ceteris paribus the likelihood of interaction. Also, consistent with the nonstandard prediction, the negative impact of $p^{h}$ on the likelihood of interaction is significantly lower in set $\mathbf{V}$ than in set $\mathbf{N}$ (since increasing $p^{h}$ in conditions where verifiability holds decreases the undertreatment rate). Liability has a strong and positive effect, whereas competition has a negative one. Verifiability has a small effect. Reputation increases the likelihood of interaction if $\mathbf{L}$ is violated whereas it has no effect at all if $\mathbf{L}$ holds. This confirms our earlier finding that an opportunity for reputation building has only an impact if there is no institutional safeguard against sellers' misbehavior. Remember that introducing an opportunity of reputation building increases the frequency of interaction in set $\mathbf{N}$, but not in set $\mathbf{V}$. The reason seems to be that the presence of $\mathbf{R}$ induces sellers to substantially increase $p^{h}$ in set $\mathbf{V}$, but that consumers are not willing to accept that increase (see " $p^{h}$ without interaction" in panel [V] of Table 4). 
Column [2] of Table 6 considers the likelihood of undertreatment. The most interesting finding from the viewpoint of our predictions is the significant negative effect of the high price $p^{h}$, whereas the low price $p^{l}$ is not significant. Note also that the interaction terms between both prices and $\mathbf{V}$ show the predicted sign and are highly significant. This implies that the likelihood of undertreatment is decreasing in the price difference $p^{h}-p^{l}$, as expected from the non-standard predictions $B^{N S} 1, R^{N S} 1$, and $C^{N S} 1$. Undertreatment also becomes more likely with more experience across periods. Despite its significantly positive main effect, reputation does not increase the likelihood of undertreatment in total, because it has a negative interaction effect with prices. This can be much easier discerned from panel [2] of Figure 4, where it becomes clear that experimental conditions with reputation have ceteris paribus the lowest likelihood of undertreatment. This is consistent with the non-standard prediction $\boldsymbol{R}^{N S}$ 1. Comparing sets $\mathbf{N}$ and $\mathbf{V}$ reveals that an increase in the high price $p^{h}$ has a much stronger negative impact on the likelihood of undertreatment in set $\mathbf{V}$ than in set $\mathbf{N}$, as the non-standard model predicts.

As predicted, column [3] of Table 6 reveals that the likelihood of overtreatment depends on the low and the high price only in case verifiability applies. The negative interaction effect "Price $p^{l} \times$ Verifiability" and the positive interaction effect "Price $p^{h} \times$ Verifiability" simply mean that overtreatment increases on average in the price difference $p^{h}-p^{l}$, as implied by the non-standard prediction $\boldsymbol{B}^{\text {NS }}$ 1. Panel [3] of Figure 4 shows that overtreatment is practically non-existent as long as verifiability is violated (in sets $\mathbf{N}$ and $\mathbf{L}$ ), while it increases with the high price and decreases with the low price in sets $\mathbf{V}$ and $\mathbf{L V}$.

Overcharging (see column [4] of Table 6) depends only on a seller's prices. The likelihood of overcharging decreases with the low price $p^{l}$ and increases with the high price $p^{h}$, as implied by the non-standard predictions. This pattern can also clearly be seen from panel [4] of Figure 4. From there we can also see that reputation decreases overcharging as indicated earlier. 


\section{Conclusion}

In this paper, we have analyzed behavior on credence goods markets. These markets are prone both in reality and in our experiment to problems of undertreatment, overtreatment, and overcharging. We start the conclusion by noting that even under the most disadvantageous market conditions for consumers the sellers of credence goods have provided an appropriate treatment in about half of the cases in our experiment. Hence, even in the absence of liability laws, a large fraction of sellers is honest. This finding is much in the spirit of Hippocrates' oath that we quoted in the beginning of this paper and which motivated our approach for formulating predictions where sellers have non-standard preferences. This finding also means that social or moral norms (like not to exploit others or cheat on them) contribute to a considerable extent to the functioning of credence goods markets.

In this paper we have been mainly interested in studying which other means - besides an intrinsic motivation or moral commitment of sellers - may yield efficient interaction on credence goods markets. More precisely, we have examined in a $2 \times 2 \times 2 \times 2$ experimental design the role of liability, verifiability, reputation, or competition. Contrary to our predictions, verifiability has been found to have almost no effect (compared to a situation where only moral norms may apply). It seems safe to conclude, therefore, that forcing sellers of credence goods to charge only for the treatment they have provided does not approach the roots of the problems. Hence, it cannot be an effective remedy of the problems on credence goods markets to ask a car mechanic, for example, to put the replaced parts in the boot of the car in order to verify the presumed action.

Liability to provide a sufficient treatment has been found to have a very strong effect not only on the likelihood of trade on our experimental credence goods markets, but also on its efficiency. It seems straightforward that liability makes it very attractive for consumers to trade with sellers, as undertreatment is precluded. However, liability does not solve the problems of overtreatment (which may also create inefficiencies) or overcharging (which is another form of cheating on the consumer). It seems that consumers care most of all for the safety not to be treated insufficiently. Overtreatment or overcharging are of much less concern for consumers, and the likelihood of overtreatment or overcharging has not been affected by liability in our experiment.

Reputation-building has been found to be effective in increasing trade on credence goods markets, but only when none of the other effective means (liability and competition, as it turns out) is present. In this case $(\mathbf{R} / \mathbf{N})$, reputation-building benefits only the sellers, however, as they get more interaction (since consumers are more likely to trust them), but do not 
change their behaviour (i.e., the undertreatment rate is not decreasing with reputation in the aggregate).

Competition among sellers has been found to be very influential in, first of all, bringing down the prices for credence goods (compared with a situation of a bilateral matching of sellers and consumers), and then increasing the frequency of trade on the market. This is not to say that competition solves all the problems on credence goods markets, because we have also found that the likelihood of undertreatment, overtreatment, or overcharging, is not reduced (but interestingly not increased either) through seller competition. This means that the effects of competition on trade are first and foremost driven by price cuts through competition, while the overall level of efficiency is not increased through competition (except when verifiability applies).

As noted in the introduction, our paper is most closely related to two recent papers by Huck et al. $(2006,2007)$ where they study how reputation and competition affect the efficiency on markets for experience goods. Our model of a credence goods market can be seen as a generalization of their experience goods market model. In particular, if we set the probability of needing the major treatment in our credence goods market equal to one ( $h=1$ in our notation), then our $\mathbf{N}$-conditions $(\mathbf{B} / \mathbf{N}, \mathbf{R} / \mathbf{N}$, and $\mathbf{C} / \mathbf{N})$ corresponded exactly to their design of a market for experience goods. Huck et al. (2007) compare the equivalents of our $\mathbf{B} / \mathbf{N}$ - and $\mathbf{R} / \mathbf{N}$-condition, and Huck et al. (2006) relate analogously $\mathbf{B} / \mathbf{N}$ to $\mathbf{C} / \mathbf{N}$. Huck et al. $(2006,2007)$ report pretty large effects of reputation and competition. Whereas competition has also very strong effects in our design, we find much weaker effects of reputation. One possible explanation is that cheating is always detected in the set-up of Huck et al. (2007) which makes a good reputation all the more valuable - whereas in our design cheating may remain undetected. The latter possibility weakens the importance, and ultimately the effects, of reputation. It should also be noted that our design allows for a comparative assessment of reputation and competition, and it also shows the comparative effects of liability and verifiability, both of which have been determined theoretically to be equally powerful to create efficiency in credence goods markets (Dulleck and Kerschbamer, 2006).

We conclude by noting that our analysis of the experimental behavior has been guided not only by standard predictions (along the lines developed in Dulleck and Kerschbamer, 2006), but also by predictions that are based on non-standard preferences of sellers. In particular, we have studied a model where agents are motivated not only by own profits but also by other motives such as those mentioned in the oath of Hippocrates. Except for Liu (2008) we are not aware of any model of credence goods markets that allows for non-standard 
preferences. Our simple model with non-standard preferences has been found to explain the behavior in credence goods markets in most cases better than a model with standard preferences. Scope for further research is suggested by several unexplained observations, such as for instance the prominence of the price-vector $\{6,8\}$ at the price posting stage of the game and the frequent cases of overtreatment under equal mark-up price-vectors. Both of these findings suggest that relative payoffs matter for provision behavior (the price-vector $\{6,8\}$ splits the gains form trade equally between sellers and consumers - if sellers always provided the appropriate treatment and always charged for the provided treatment; and most of the chosen equal mark-up vectors are such that appropriate treatment yields a higher monetary payoff for the consumer than for the expert when the consumer has the minor problem). One natural extension would therefore be to include relative payoff concerns of agents in our model. The outcome-based models of Fehr and Schmidt (1999) or Bolton and Ockenfels (2000) may serve as a good starting point in that respect. Another extension would be to consider concerns for reciprocity in sequential and repeated interactions (in the spirit of Dufwenberg and Kirchsteiger, 2004, for example). While our simple model has abstracted from seller's expectations about the consumer's expectations, applying the theory of guilt aversion (Charness and Dufwenberg, 2006; Battigalli and Dufwenberg, 2007) to our model would add the important role of first-order and second-order expectations and their role for behavior on credence goods markets. Though all of these extensions promise to increase our knowledge of which conditions lead to more efficient trade on credence goods markets, they are beyond the scope of this paper and are left for future research. 


\section{References}

Afendulis, C. C., Kessler, D. P. (2007), Tradeoffs from integrating diagnosis and treatment in markets for health care. American Economic Review 97: 1013-1020.

Akerlof, G. (1970), The market for lemons: Quality uncertainty and the market mechanism. Quarterly Journal of Economics 890: 488-500.

Alger, I., Salanie, F. (2006), a theory of fraud and over-consumption in experts markets. Journal of Economics and Management Strategy 15: 853-81.

Battigalli, P., Dufwenberg, M. (2007), Guilt in games. American Economic Review, Papers and Proceedings, 97: 170-176.

Berg, J., Dickhaut, J., McCabe, K. (1995), Trust, reciprocity, and social history. Games and Economic Behavior 10: 122-142.

Bolton, G. E., Ockenfels, A. (2000), ERC - A theory of equity, reciprocity and competition. American Economic Review 90: 166-193.

Charness, G., Dufwenberg, M. (2005), Deception: The role of guilt. Working Paper. University of Arizona, Tucson.

Charness, G., Dufwenberg, M. (2006), Promises and partnerships. Econometrica 74: 15791602.

Charness, G., Rabin, M. (2002), Understanding social preferences with simple tests. Quarterly Journal of Economics 117: 817-869.

Darby, M. R., Karni, E. (1973), Free competition and the optimal amount of fraud. Journal of Law and Economics 16: 67-88.

Dufwenberg, M., Kirchsteiger, G. (2004), A theory of sequential reciprocity. Games and Economic Behavior 47: 268-298.

Dulleck, U., Kerschbamer, R. (2006), On doctors, mechanics, and computer specialists: The economics of credence goods. Journal of Economic Literature 44: 5-42.

Emons, W. (1997), Credence goods and fraudulent experts. RAND Journal of Economics 28: 107-119.

Fehr, E., Schmidt, K. (1999), A Theory of fairness, competition, and cooperation. Quarterly Journal of Economics 114: 817-868.

Fischbacher, U. (2007), Z-tree: Zürich toolbox for readymade economic experiments. Experimental Economics 10: 171-178.

Fuchs, V. (1978), The supply of surgeons and the demand for operations. Journal of Human Resources 13: 35-56. 
Gneezy, U. (2005), Deception: The role of consequences. American Economic Review 95: 384394.

Greiner, B. (2004), An Online Recruitment System for Economic Experiments. In: Kremer, K. and Macho, V. (eds.): Forschung und wissenschaftliches Rechnen 2003. GWDG Bericht 63. Gesellschaft für Wissenschaftliche Datenverarbeitung, Göttingen, 79-93.

Gruber, J., Kim, J., Mayzlin, D. (1999), Physician fees and procedure intensity: The case of cesarean delivery. Journal of Health Economics 18: 473-490.

Gruber, J., Owings, M. (1996), Physician financial incentives and Cesarean section delivery. RAND Journal of Economics 27: 99-123.

Hubbard, T. N. (1998), An empirical examination of moral hazard in the vehicle inspection market. RAND Journal of Economics 29: 406-426.

Huck, S., Lünser, G., Tyran, J.-R. (2006), Competition fosters trust. UCL Working Paper.

Huck, S., Lünser, G., Tyran, J.-R. (2007), Pricing and trust. UCL Working Paper.

Hughes, D., Yule, B. (1992), The effect of per-item fees on the behavior of general practitioners. Journal of Health Economics 11: 413-437.

Iizuka, T. (2007), Experts' agency problems: Evidence from the prescription drug market in Japan. RAND Journal of Economics 38: 844-862.

Kreps, D., Wilson, R. (1982), Reputation and imperfect information. Journal of Economic Theory 27: 253-279

Liu, T. (2008), Credence goods markets with conscientious and selfish experts. Working Paper.

Milgrom, P., Roberts, J. (1982), Predation, reputation and entry deterrence. Journal of Economic Theory 27: 280-312.

Nelson, P. (1970), Information and consumer behavior. Journal of Political Economy 78: 311 329.

Pesendorfer, W., Wolinsky, A. (2003), Second opinions and price competition: Inefficiency in the market for expert advice. Review of Economic Studies 70: 417-437

Taylor, C. (1995), The economics of breakdowns, checkups, and cures. Journal of Political Economy 103, 53-74

Vanberg, C. (2008), Why do people keep their promises? An experimental test of two explanations. Econometrica 76: 1467-1480.

Wolinsky, A. (1993), Competition in a market for informed experts' services. RAND Journal of Economics 24: 380-398.

Wolinsky, A. (1995), Competition in markets for credence goods. Journal of Institutional and Theoretical Economics 151: 117-131. 


\section{Tables and Figures}

Table 1. The 16 Conditions of Interaction between Consumers and Sellers

\begin{tabular}{|c|c|c|c|c|}
\hline market condition & $\overline{\mathbf{B}}$ & $\overline{\mathbf{R}}$ & $\overline{C C}$ & $\overline{C \text { CR }}$ \\
\hline institutional condition & $\begin{array}{c}\text { No Competition / } \\
\text { No Reputation }\end{array}$ & $\begin{array}{c}\text { No Competition / } \\
\text { Reputation }\end{array}$ & $\begin{array}{l}\text { Competition / } \\
\text { No Reputation }\end{array}$ & $\begin{array}{c}\text { Competition / } \\
\text { Reputation }\end{array}$ \\
\hline $\begin{array}{c}\mathbf{N} \\
\text { No Liability / } \\
\text { No Verifiability }\end{array}$ & $\mathrm{B} / \mathrm{N}$ & $\mathrm{R} / \mathrm{N}$ & $\mathrm{C} / \mathrm{N}$ & $\mathrm{CR} / \mathrm{N}$ \\
\hline $\begin{array}{c}\mathbf{L} \\
\text { Liability / } \\
\text { No Verifiability }\end{array}$ & $\mathrm{B} / \mathrm{L}$ & $\mathrm{R} / \mathrm{L}$ & $\mathrm{C} / \mathrm{L}$ & $\mathrm{CR} / \mathrm{L}$ \\
\hline $\begin{array}{c}\mathbf{V} \\
\text { No Liability / } \\
\text { Verifiability }\end{array}$ & $\mathrm{B} / \mathrm{V}$ & $\mathrm{R} / \mathrm{V}$ & $\mathrm{C} / \mathrm{V}$ & $\mathrm{CR} / \mathrm{V}$ \\
\hline $\begin{array}{l}\text { LV } \\
\text { Liability / } \\
\text { Verifiability }\end{array}$ & $\mathrm{B} / \mathrm{LV}$ & $\mathrm{R} / \mathrm{LV}$ & $\mathrm{C} / \mathrm{LV}$ & $\mathrm{CR} / \mathrm{LV}$ \\
\hline
\end{tabular}


Table 2. Standard Predictions on Interaction and Pricing-, Provision- and Charging-Policy

\begin{tabular}{|c|c|c|c|c|c|}
\hline $\begin{array}{r}\begin{array}{r}\text { market } \\
\text { condition }\end{array} \\
\text { institutional }\end{array}$ & & $\begin{array}{l}\text { No Competition / } \\
\text { No Reputation }\end{array}$ & $\begin{array}{l}\text { No Competition / } \\
\text { Reputation }\end{array}$ & $\begin{array}{c}\mathbf{C} \\
\text { Competition / } \\
\text { No Reputation }\end{array}$ & $\begin{array}{c}\text { CR } \\
\text { Competition / } \\
\text { Reputation }\end{array}$ \\
\hline $\begin{array}{c}\mathbf{N} \\
\text { No Liability / } \\
\text { No Verifiability }\end{array}$ & $\begin{array}{l}{[2]} \\
{[3]}\end{array}$ & $\begin{array}{c}\mathbf{B} / \mathbf{N} \\
\text { no interaction }\end{array}$ & $\begin{array}{c}\mathbf{R} / \mathbf{N} \\
\text { no interaction }\end{array}$ & $\begin{array}{c}\mathbf{C} / \mathbf{N} \\
\text { mixed eq.: high prob. } \\
\text { on }\{\text { n.d, } 3\} \\
\text { undertreatment } \\
\text { overcharging }\end{array}$ & $\begin{array}{c}\mathbf{C R} / \mathbf{N} \\
\text { mixed as in } \mathrm{C} / \mathrm{N} ; \\
\text { or }\{\mathrm{n} . \mathrm{d} ., 5\} \text { in } \\
\text { earlier rounds. } \\
\text { undertr. or effic. } p \text {. } \\
\text { overcharging or } \\
\text { honest charging }\end{array}$ \\
\hline $\begin{array}{c}\text { L } \\
\text { Liability / } \\
\text { No Verifiability }\end{array}$ & $\begin{array}{l}{[2]} \\
{[3]}\end{array}$ & $\begin{array}{c}\text { efficient provision } \\
\text { overcharging }\end{array}$ & $\begin{array}{c}\text { efficient provision } \\
\text { overcharging }\end{array}$ & $\begin{array}{c}\mathbf{C} / \mathbf{L} \\
\text { mixed eq.: high prob. } \\
\text { on }\{\text { n.d, } 5\}, \text { low prob. } \\
\text { on }\{\text { n.d., } 6\} \\
\text { efficient provision } \\
\text { overcharging }\end{array}$ & $\begin{array}{c}\mathbf{C R} / \mathbf{L} \\
\text { mixed as in C/L; or } \\
\{\text { n.d., } 5\} \\
\text { efficient provision } \\
\text { overcharging or } \\
\text { honest charging }\end{array}$ \\
\hline $\begin{array}{c}\text { V } \\
\text { No Liability / } \\
\text { Verifiability }\end{array}$ & $\begin{array}{l}{[2]} \\
{[3]}\end{array}$ & $\begin{array}{c}\mathbf{B} / \mathbf{V} \\
\{6,10\} \\
\text { efficient provision } \\
\text { honest charging }\end{array}$ & $\begin{array}{c}\mathbf{R} / \mathbf{V} \\
\{6,10\} \\
\text { efficient provision } \\
\text { honest charging }\end{array}$ & $\begin{array}{c}\mathbf{C} / \mathbf{V} \\
\text { mixed eq.: high prob. } \\
\text { on }\{3,7\}, \text { low on }\{4,8\} \\
\text { efficient provision } \\
\text { honest charging }\end{array}$ & $\begin{array}{c}\mathbf{C R} / \mathbf{V} \\
\text { mixed as in } \mathrm{C} / \mathrm{V} ; \\
\text { or }\{3,7\} \\
\text { efficient provision } \\
\text { honest charging }\end{array}$ \\
\hline $\begin{array}{c}\text { LV } \\
\text { Liability / } \\
\text { Verifiability }\end{array}$ & $\begin{array}{l}{[2]} \\
{[3]}\end{array}$ & $\begin{array}{c}\mathbf{B} / \mathbf{L V} \\
\{6,10\},\{7,9\} \text {, or } \\
\{8,8\} \\
\text { efficient provision } \\
\text { honest charging }\end{array}$ & $\begin{array}{c}\mathbf{R} / \mathbf{L V} \\
\{6,10\},\{7,9\} \text {, or } \\
\{8,8\} \\
\text { efficient provision } \\
\text { honest charging }\end{array}$ & $\begin{array}{c}\mathbf{C} / \mathbf{L V} \\
\text { mixed eq.: high prob. } \\
\text { on }\{5,6\} \text { or }\{4,7\} \\
\text { efficient provision } \\
\text { honest charging }\end{array}$ & $\begin{array}{c}\mathbf{C R} / \mathbf{L V} \\
\text { mixed as in } \mathrm{C} / \mathrm{LV} ; \\
\text { or }\{4,5\} \text { or }\{3,6\} \\
\text { efficient provision } \\
\text { honest charging }\end{array}$ \\
\hline $\begin{array}{lr}\text { Legend } & \\
{[1]} & \text { predicti } \\
\{x, y\} & \text { sel } \\
\text { n.d. } & \text { no } \\
\text { mixed eq. } & \text { eq } \\
\text { prob. } & \text { pro } \\
{[2]} & \text { predicti } \\
\text { undertr. } & \text { un } \\
\text { effic. p. } & \text { eff } \\
{[3]} & \text { predicti }\end{array}$ & libr & $\begin{array}{l}\text { action and (if applicable } \\
\text { ice } x \text { for } t^{l} \text { and price } y \text { fo } \\
d \text { in theoretical solution } \\
\text { mixed strategies } \\
\text { ision policy } \\
\text { nt } \\
\text { ision, i.e. providing the } t \\
\text { ging policy }\end{array}$ & thent that is needed & & \\
\hline
\end{tabular}


Table 4. Overview of Results Across All Conditions

\begin{tabular}{|c|c|c|c|c|c|c|c|c|}
\hline \multirow{3}{*}{$\begin{array}{l}\text { Averages per Period } \\
\text { Interaction on Cons. Side }^{1}\end{array}$} & \multicolumn{4}{|c|}{$[\mathrm{N}]$} & \multicolumn{4}{|c|}{$\begin{array}{c}{[\mathbf{L}]} \\
\text { Liability / No Verifiability }\end{array}$} \\
\hline & $\mathbf{B} / \mathbf{N}$ & $\mathbf{R} / \mathbf{N}$ & $\mathbf{C} / \mathbf{N}$ & $\mathrm{CR} / \mathrm{N}$ & B/L & $\mathbf{R} / \mathbf{L}$ & $\mathrm{C} / \mathrm{L}$ & $\mathbf{C R} / \mathbf{L}$ \\
\hline & $0.45^{a, b, c}$ & $0.63^{\mathrm{a}, \mathrm{d}, \mathrm{e}}$ & $0.73^{b, d, f}$ & $0.85^{\mathrm{c}, \mathrm{e}, \mathrm{f}}$ & $0.82^{b, c}$ & $0.76^{\mathrm{d}, \mathrm{e}}$ & $0.99^{b, d}$ & $0.98^{\mathrm{c}, \mathrm{e}}$ \\
\hline Avg. \# of Consumers ${ }^{2}$ & 1 & 1 & 1.54 & 1.54 & 1 & 1 & 2.29 & 2.28 \\
\hline Interaction on Seller S. ${ }^{3}$ & $0.45^{\mathrm{a}, \mathrm{c}}$ & $0.63^{\mathrm{a}, \mathrm{d}}$ & $0.47^{\mathrm{d}, \mathrm{f}}$ & $0.55^{\mathrm{c}, \mathrm{f}}$ & $0.82^{b, c}$ & $0.76^{\mathrm{d}, \mathrm{e}}$ & $0.43^{\mathrm{b}, \mathrm{d}}$ & $0.43^{\mathrm{c}, \mathrm{e}}$ \\
\hline Efficiency $^{4}$ & 0.18 & 0.27 & 0.13 & 0.14 & 0.84 & $0.72^{\mathrm{d}, \mathrm{e}}$ & $0.92^{\mathrm{d}}$ & $0.96^{\mathrm{e}}$ \\
\hline Undertreatment $^{5}$ & 0.53 & 0.56 & 0.73 & 0.64 & - & - & - & - \\
\hline Overtreatment $^{6}$ & 0.06 & 0.06 & 0.08 & 0.10 & $0.03^{\mathrm{c}}$ & 0.08 & 0.06 & $0.13^{\mathrm{c}}$ \\
\hline Overcharging $^{7}$ & $0.86^{\mathrm{a}, \mathrm{b}, \mathrm{c}}$ & $0.53^{\mathrm{a}}$ & $0.65^{\mathrm{b}}$ & $0.50^{\mathrm{c}}$ & 0.65 & 0.68 & 0.56 & 0.63 \\
\hline$p^{l}$ with Interaction & $4.67^{\mathrm{b}, \mathrm{c}}$ & $5.09^{\mathrm{d}, \mathrm{e}}$ & $3.19^{\mathrm{b}, \mathrm{d}}$ & $3.31^{\mathrm{c}, \mathrm{e}}$ & $5.94^{\mathrm{b}, \mathrm{c}}$ & $5.47^{\mathrm{d}, \mathrm{e}}$ & $3.36^{\mathrm{b}, \mathrm{d}}$ & $3.06^{\mathrm{c}, \mathrm{e}}$ \\
\hline$p^{l}$ without Interaction & $5.17^{\mathrm{b}}$ & $5.72^{d}$ & $4.16^{\mathrm{b}, \mathrm{d}}$ & 4.65 & $6.12^{\mathrm{b}}$ & $6.07^{\mathrm{d}}$ & $4.13^{\mathrm{b}, \mathrm{d}}$ & 4.23 \\
\hline$p^{h}$ with Interaction & $7.28^{\mathrm{b}, \mathrm{c}}$ & $7.60^{\mathrm{d}, \mathrm{e}}$ & $5.73^{\mathrm{b}, \mathrm{d}}$ & $6.33^{\mathrm{c}, \mathrm{e}}$ & $8.00^{\mathrm{b}, \mathrm{d}}$ & $8.02^{\mathrm{d}, \mathrm{e}}$ & $5.72^{\mathrm{b}, \mathrm{d}}$ & $5.76^{\mathrm{c}, \mathrm{e}}$ \\
\hline$p^{h}$ without Interaction & 7.91 & 8.09 & 7.55 & 7.60 & $8.77^{\mathrm{b}}$ & $9.11^{\mathrm{d}}$ & $7.64^{\mathrm{b}, \mathrm{d}}$ & 7.55 \\
\hline Actually paid price & $7.08^{b, c}$ & $7.14^{\mathrm{d}, \mathrm{e}}$ & $5.35^{\mathrm{b}, \mathrm{d}}$ & $5.80^{\mathrm{c}, \mathrm{e}}$ & $7.77^{\mathrm{b}, \mathrm{c}}$ & $7.56^{\mathrm{d}, \mathrm{e}}$ & $5.42^{\mathrm{b}, \mathrm{d}}$ & $5.24^{\mathrm{c}, \mathrm{e}}$ \\
\hline Profits Sellers ${ }^{8}$ & $2.69^{\mathrm{a}}$ & $3.21^{\mathrm{a}, \mathrm{d}}$ & $2.36^{\mathrm{d}}$ & 2.65 & $3.44^{\mathrm{b}, \mathrm{c}}$ & $2.98^{\mathrm{d}, \mathrm{e}}$ & $1.23^{\mathrm{b}, \mathrm{d}}$ & $1.19^{\mathrm{c}, \mathrm{e}}$ \\
\hline Profits Consumers ${ }^{8}$ & 1.00 & 0.75 & 1.21 & 0.94 & $2.12^{\mathrm{b}, \mathrm{d}}$ & $2.24^{\mathrm{d}, \mathrm{e}}$ & $4.56^{\mathrm{b}, \mathrm{d}}$ & $4.71^{\mathrm{c}, \mathrm{e}}$ \\
\hline \multirow[t]{2}{*}{ Number of Subjects } & 96 & 48 & 48 & 48 & 96 & 48 & 48 & 48 \\
\hline & \multicolumn{4}{|c|}{ [V] } & \multicolumn{4}{|c|}{$\begin{array}{c}{[\mathbf{L V}]} \\
\text { Liability / Verifiabi }\end{array}$} \\
\hline Averages per period & $\mathrm{B} / \mathrm{V}$ & $\mathbf{R} / \mathbf{V}$ & $\mathrm{C} / \mathrm{V}$ & $\mathrm{CR} / \mathrm{V}$ & B/LV & $\mathbf{R} / \mathbf{L V}$ & C/LV & CR/LV \\
\hline Interaction on Cons. Side & $0.50^{b, c}$ & $0.60^{\mathrm{d}, \mathrm{e}}$ & $0.88^{b, d}$ & $0.93^{\mathrm{c}, \mathrm{e}}$ & $0.82^{b, c}$ & $0.76^{\mathrm{d}, \mathrm{e}}$ & $0.98^{b, d}$ & $0.99^{\mathrm{c}, \mathrm{e}}$ \\
\hline Avg. \# of Consumers ${ }^{2}$ & 1 & 1 & 1.63 & 1.60 & 1 & 1 & 2.27 & 1.92 \\
\hline Interaction on Seller $\mathrm{S} .^{3}$ & 0.50 & 0.60 & 0.54 & 0.58 & $0.82^{b, c}$ & $0.76^{\mathrm{d}, \mathrm{e}}$ & $0.43^{\mathrm{b}, \mathrm{d}}$ & $0.52^{\mathrm{c}, \mathrm{e}}$ \\
\hline Efficiency $^{4}$ & $0.16^{\mathrm{b}, \mathrm{c}}$ & 0.30 & $0.34^{\mathrm{b}}$ & $0.46^{\mathrm{c}}$ & 0.81 & $0.71^{\mathrm{d}, \mathrm{e}}$ & $0.88^{\mathrm{d}}$ & $0.93^{\mathrm{e}}$ \\
\hline Undertreatment $^{5}$ & $0.60^{\mathrm{c}}$ & 0.38 & 0.53 & $0.36^{\mathrm{c}}$ & - & - & - & - \\
\hline Overtreatment $^{6}$ & $0.05^{\mathrm{a}, \mathrm{b}, \mathrm{c}}$ & $0.12^{\mathrm{a}}$ & $0.13^{b}$ & $0.19^{c}$ & $0.03^{b, c}$ & 0.07 & $0.12^{\mathrm{b}}$ & $0.09^{\mathrm{c}}$ \\
\hline Overcharging $^{7}$ & - & - & . & - & - & - & - & - \\
\hline$p^{l}$ with Interaction & $5.84^{\mathrm{b}, \mathrm{c}}$ & $5.74^{\mathrm{d}, \mathrm{e}}$ & $4.06^{\mathrm{b}, \mathrm{d}}$ & $3.99^{\mathrm{c}, \mathrm{e}}$ & $6.88^{\mathrm{b}, \mathrm{c}}$ & $6.48^{\mathrm{d}, \mathrm{e}}$ & $4.19^{\mathrm{b}, \mathrm{d}}$ & $4.20^{\mathrm{c}, \mathrm{e}}$ \\
\hline$p^{l}$ without Interaction & $6.21^{\mathrm{b}}$ & $6.31^{\mathrm{d}}$ & $4.84^{\mathrm{b}, \mathrm{d}}$ & 4.84 & $7.46^{\mathrm{b}, \mathrm{c}}$ & $6.75^{\mathrm{d}, \mathrm{e}}$ & $4.59^{\mathrm{b}, \mathrm{d}}$ & $4.43^{\mathrm{c}, \mathrm{e}}$ \\
\hline$p^{h}$ with Interaction & $7.70^{\mathrm{b}, \mathrm{c}}$ & $7.69^{d}$ & $6.41^{\mathrm{b}, \mathrm{d}}$ & $6.97^{\mathrm{c}}$ & $7.96^{\mathrm{b}, \mathrm{c}}$ & $8.04^{\mathrm{d}, \mathrm{e}}$ & $6.19^{\mathrm{b}, \mathrm{d}}$ & $6.38^{\mathrm{c}, \mathrm{e}}$ \\
\hline$p^{h}$ without Interaction & $7.82^{\mathrm{a}}$ & $8.38^{\mathrm{a}}$ & 7.72 & 7.79 & $8.83^{b, c}$ & $9.10^{\mathrm{d}, \mathrm{e}}$ & $7.94^{\mathrm{b}, \mathrm{d}}$ & $7.65^{\mathrm{c}, \mathrm{e}}$ \\
\hline Actually paid price & $6.44^{\mathrm{b}, \mathrm{c}}$ & $6.60^{\mathrm{d}, \mathrm{e}}$ & $5.19^{\mathrm{b}, \mathrm{d}}$ & $5.58^{\mathrm{c}, \mathrm{e}}$ & $7.46^{\mathrm{b}, \mathrm{c}}$ & $7.39^{\mathrm{d}, \mathrm{e}}$ & $5.44^{\mathrm{b}, \mathrm{d}}$ & $5.49^{\mathrm{c}, \mathrm{e}}$ \\
\hline Profits Sellers ${ }^{8}$ & $2.58^{\mathrm{b}, \mathrm{c}}$ & $2.51^{\mathrm{e}}$ & $1.96^{\mathrm{b}}$ & $1.90^{\mathrm{c}, \mathrm{e}}$ & $3.10^{\mathrm{b}, \mathrm{c}}$ & $2.83^{\mathrm{d}, \mathrm{e}}$ & $1.15^{\mathrm{b}, \mathrm{d}}$ & $1.31^{\mathrm{c}, \mathrm{e}}$ \\
\hline Profits Consumers ${ }^{8}$ & $1.06^{\mathrm{b}, \mathrm{c}}$ & $1.53^{\mathrm{e}}$ & $2.18^{\mathrm{b}}$ & $2.59^{\mathrm{c}, \mathrm{e}}$ & $2.37^{\mathrm{b}, \mathrm{c}}$ & $2.37^{\mathrm{d}, \mathrm{e}}$ & $4.51^{b, d}$ & $4.49^{\mathrm{c}, \mathrm{e}}$ \\
\hline Number of Subjects & 88 & 48 & 48 & 48 & 80 & 48 & 48 & 48 \\
\hline 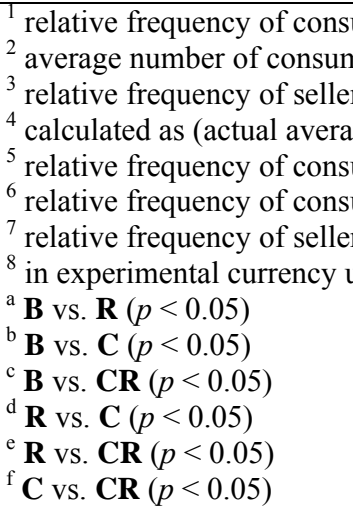 & $\begin{array}{l}\text { e profit -o } \\
\text { ner needs } t \\
\text { ner needs } t \\
\text { provides } t^{l} \text {, } \\
\text { its }\end{array}$ & $\begin{array}{l}\text { tside option } \\
\text {, but seller } \\
\text { but seller } \mathrm{p} \\
\text { but charges }\end{array}$ & $\begin{array}{l}\text { / (maximl } \\
\text { rovides } t^{l} \text {. } \\
\text { rovides } t^{h} \text {. } \\
\text { (with } p^{h} \text {. }\end{array}$ & $\begin{array}{l}\begin{array}{l}\text { one con } \\
\text { r } \\
\text { possibl } \\
\text { and co }\end{array}\end{array}$ & $\begin{array}{l}\text { e profit } \\
\left.\text { needs } t^{l}\right)\end{array}$ & Dutsic & & \\
\hline
\end{tabular}


Table 5. Visiting Behavior when Competition Applies (sets $\boldsymbol{C}$ and $\mathbf{C R}$ )

C (Competition / No Reputation)

C/N $\quad$ C/L $\quad$ C/V $\quad$ C/LV

Relative frequency with which an accepted price-vector included

a) the minimum price $p^{h}$ (irrespective of order of $p^{l}$ )

$\begin{array}{llll}0.68 & 0.90 & 0.52 & 0.77\end{array}$

b) the minimum price $p^{l}$ (but not the minimum price $p^{h}$ )

$\begin{array}{lll}0.13 & 0.02 & 0.23\end{array}$

0.15

c) neither of the above

$0.19 \quad 0.08$

0.25

281

381

337

0.08

\# observations

CR/N CR/L CR/V CR/LV

\section{CR (Competition / Reputation)}

Relative frequency with which an accepted price-vector included
a) the minimum price $p^{h}$ (irrespective of order of $p^{l}$ )

$\begin{array}{llll}0.64 & 0.87 & 0.44 & 0.76\end{array}$
b) the minimum price $p^{l}$ (but not the minimum price $p^{h}$ )
$0.17 \quad 0.08$
0.33
0.76
c) neither of the above
$0.19 \quad 0.05$
0.23
\# observations

$\begin{array}{llll}326 & 378 & 359 & 382\end{array}$


Table 6. Panel Probit Regressions Using Data from All Conditions

\begin{tabular}{|c|c|c|c|c|}
\hline independent variables & $\begin{array}{r}{[1]} \\
\text { Interaction } \\
\text { on seller side }\end{array}$ & $\begin{array}{r}{[2]} \\
\text { Undertreatment }\end{array}$ & $\begin{array}{r}{[3]} \\
\text { Overtreatment }\end{array}$ & $\begin{array}{r}\text { [4] } \\
\text { Overcharging }\end{array}$ \\
\hline Liability $(\mathrm{L}=1)$ & $5.45 * *$ & n.a. & 0.16 & -0.31 \\
\hline Verifiability $(\mathrm{V}=1)$ & -0.55 & -0.26 & -0.15 & n.a. \\
\hline Reputation $(\mathrm{R}=1)$ & 0.02 & $2.20 * *$ & 0.45 & -0.54 \\
\hline Competition $(\mathrm{C}=1)$ & $-0.85 *$ & -1.04 & 0.73 & -0.35 \\
\hline Price $p^{l}$ & $-0.13 * *$ & 0.04 & -0.12 & $-0.74^{* *}$ \\
\hline Price $p^{h}$ & $-0.46^{* *}$ & $-0.22 * *$ & 0.12 & $0.55^{* *}$ \\
\hline Price $p^{l} \times$ Liability & 0.03 & n.a. & -0.04 & 0.02 \\
\hline Price $p^{h} \times$ Liability & $-0.56 * *$ & n.a. & 0.03 & 0.03 \\
\hline Price $p^{l} \times$ Verifiability & -0.05 & $0.34 * *$ & $-0.52 * *$ & n.a. \\
\hline Price $p^{h} \times$ Verifiability & $0.11 * *$ & $-0.18 * *$ & $0.33 * *$ & n.a. \\
\hline Price $p^{l} \times$ Reputation & $-0.06 *$ & $-0.18 *$ & -0.16 & -0.06 \\
\hline Price $p^{h} \times$ Reputation & $0.08 *$ & $-0.18 *$ & 0.08 & 0.04 \\
\hline Price $p^{l} \times$ Competition & 0.00 & 0.14 & 0.07 & 0.06 \\
\hline Price $p^{h} \times$ Competition & 0.04 & 0.01 & $-0.18 *$ & -0.12 \\
\hline Period & $-0.08 * *$ & $0.07 * *$ & $-0.07 * *$ & 0.02 \\
\hline Period $\times$ Liability & $0.04 * *$ & n.a. & -0.03 & 0.01 \\
\hline Period $\times$ Verifiability & $0.03 * *$ & $-0.05 * *$ & $0.05 * *$ & n.a. \\
\hline Period $\times$ Reputation & 0.02 & -0.03 & 0.01 & 0.01 \\
\hline Period $\times$ Competition & -0.01 & 0.01 & -0.02 & 0.00 \\
\hline Intercept & $4.75 * *$ & $1.14 *$ & $-1.52 * *$ & 0.49 \\
\hline Liability $\times$ Verifiability & -0.00 & & & \\
\hline Liability $\times$ Reputation & $-0.41 * *$ & & & \\
\hline Liability $\times$ Competition & $-2.16 * *$ & & & \\
\hline Verifiability $\times$ Reputation & -0.11 & & & \\
\hline Verifiability $\times$ Competition & $0.26 *$ & & & \\
\hline Reputation $\times$ Competition & -0.04 & & & \\
\hline \# Observations & 7,488 & 1,225 & 2,902 & 1,366 \\
\hline Bayesian Information & & & & \\
\hline Criterion (BIC) & $8,044.73$ & $1,581.60$ & $1,450.96$ & $1,495.03$ \\
\hline
\end{tabular}

** (*) significant at the $1 \%(5 \%)$ level.

n.a. not applicable, i.e. a given action (dependent variable) is not possible in a particular condition (independent variable)

The two-way interaction terms of main treatment variables $(\mathrm{L}, \mathrm{V}, \mathrm{R}, \mathrm{C})$ have not been included in the regressions for undertreatment, overtreatment and overcharging due to model selection based on BIC. 
Figure 1. The Four Institutional Conditions

\section{N (No liability / No Verifiability)}

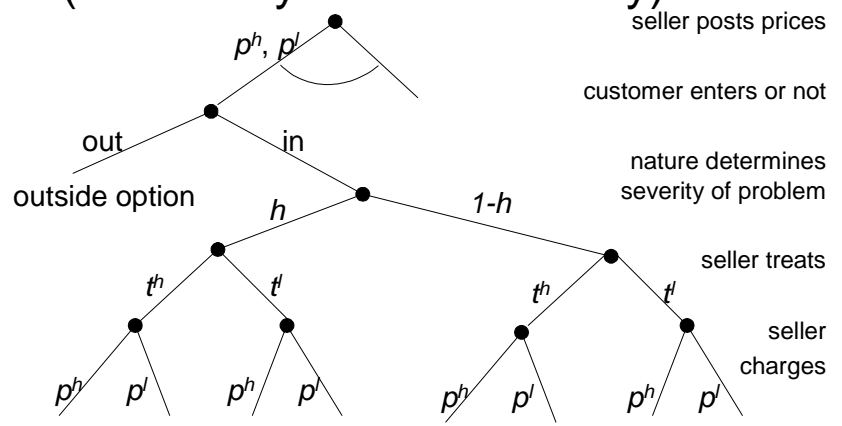

V (No Liability / Verifiability)

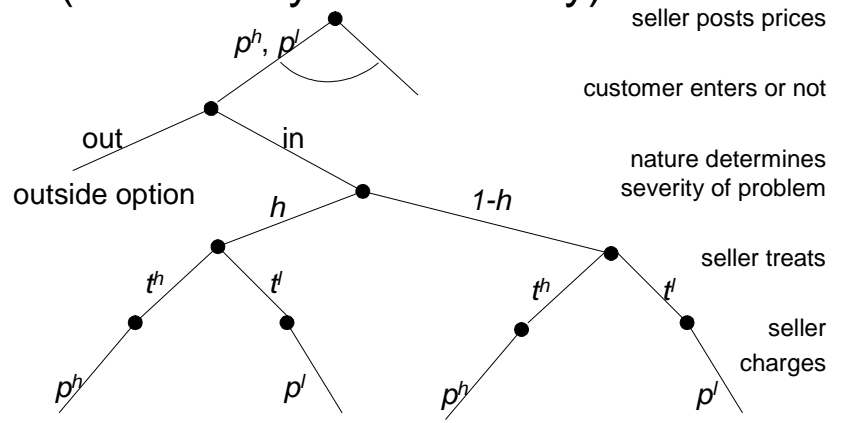

\section{L (Liability / No Verifiability)}
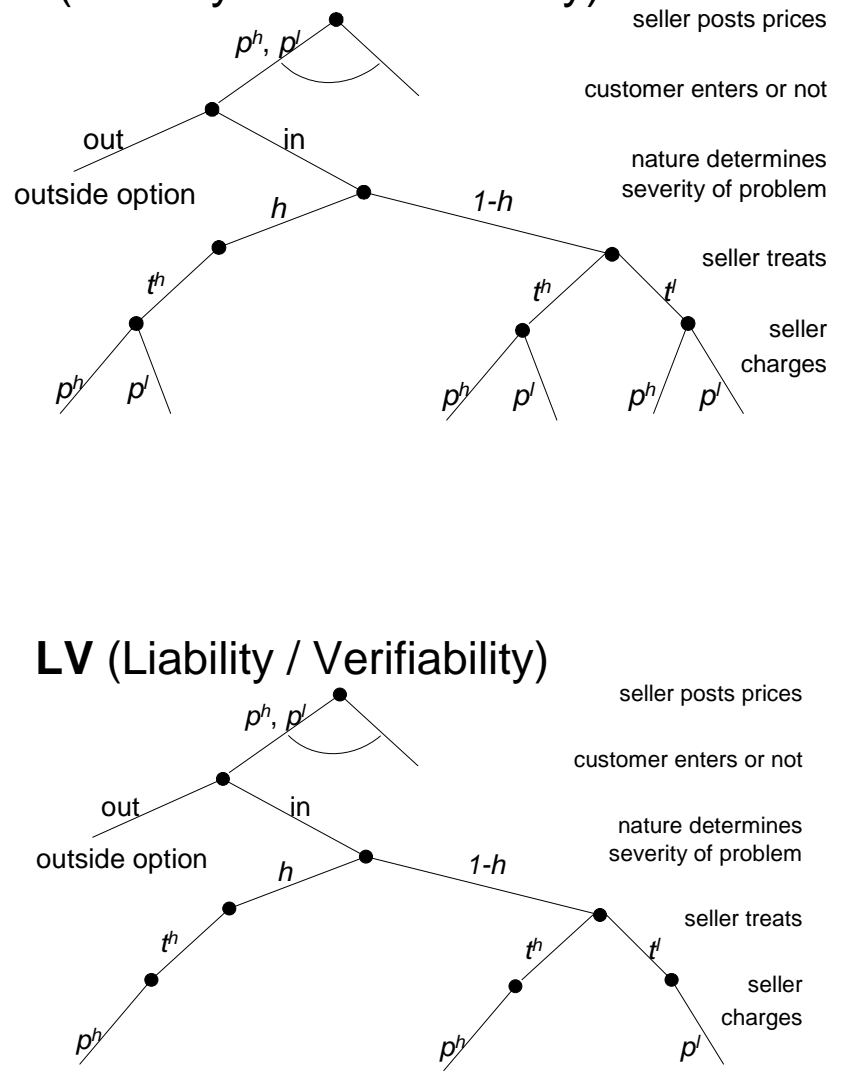
Figure 2. Interaction, Provision-, Charging- and Pricing-Policy in Set $\mathbf{B}$

[A] Relative frequency of interaction

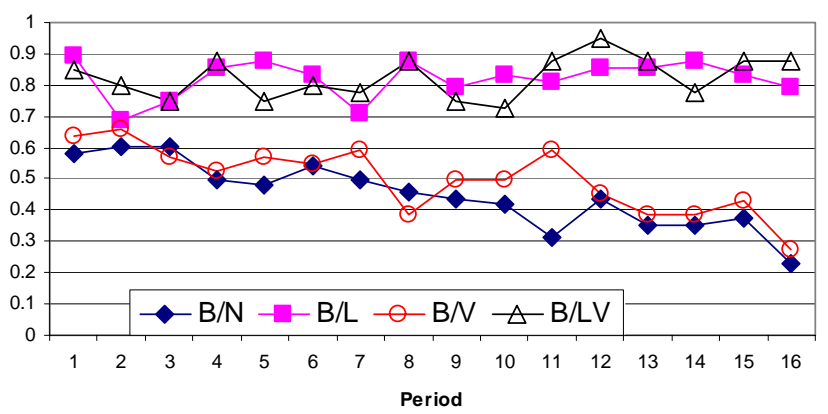

[C] Average rate of overtreatment

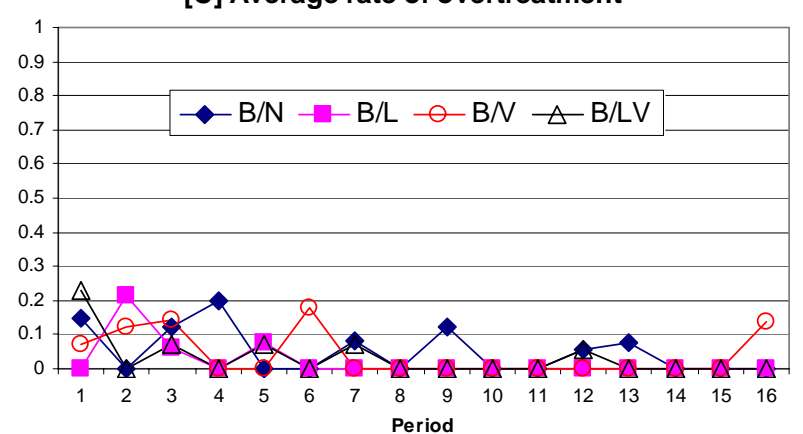

[E] Average accepted price $p^{\prime}$

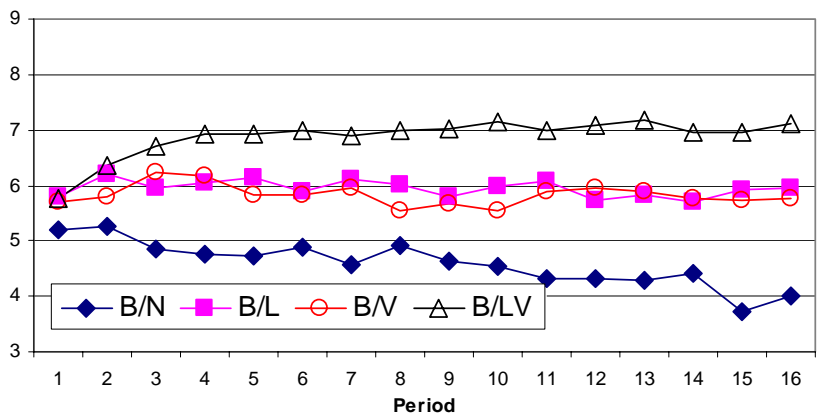

[B] Average rate of undertreatment

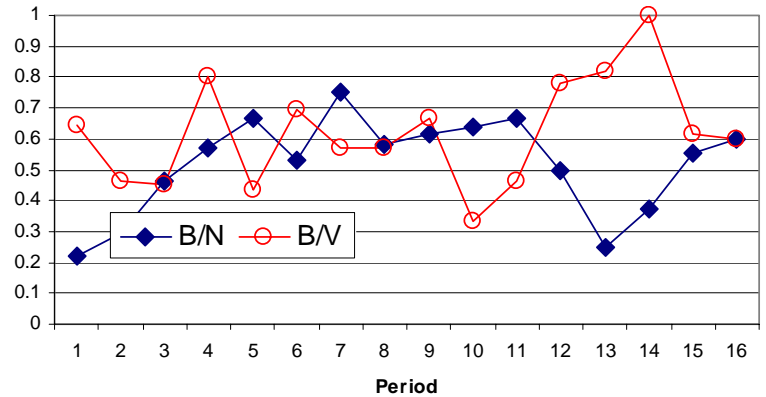

[D] Average rate of overcharging

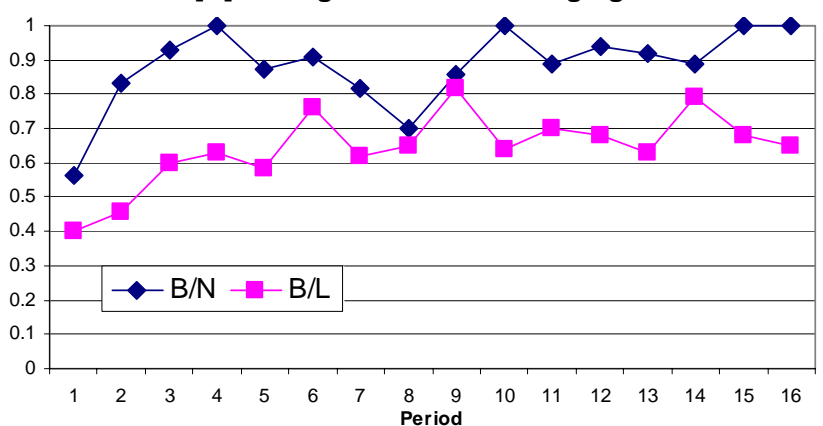

[F] Average accepted price $p^{h}$

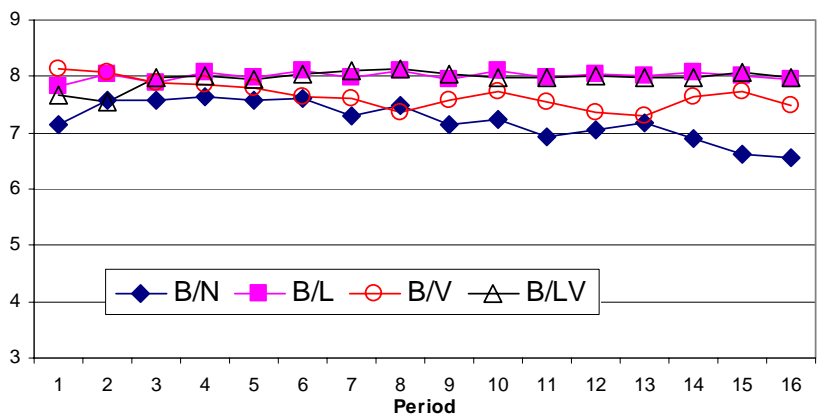


Figure 3. Development of Behavior Across All Conditions

\section{A. Relative frequency of interaction on consumer side}

Set N (No Liability / No Verifiability)

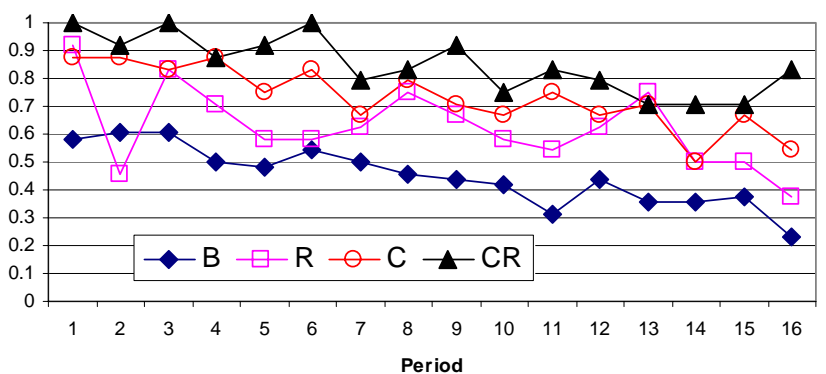

Set V (No Liability / Verifiability)

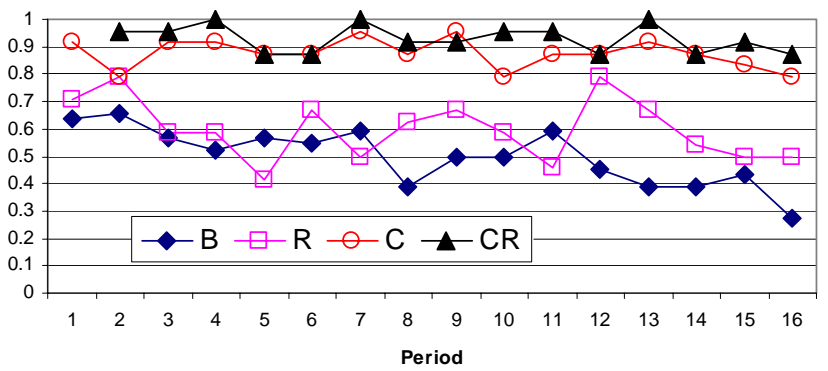

\section{B. Relative frequency of undertreatment}

Set N (No Liability / No Verifiability)

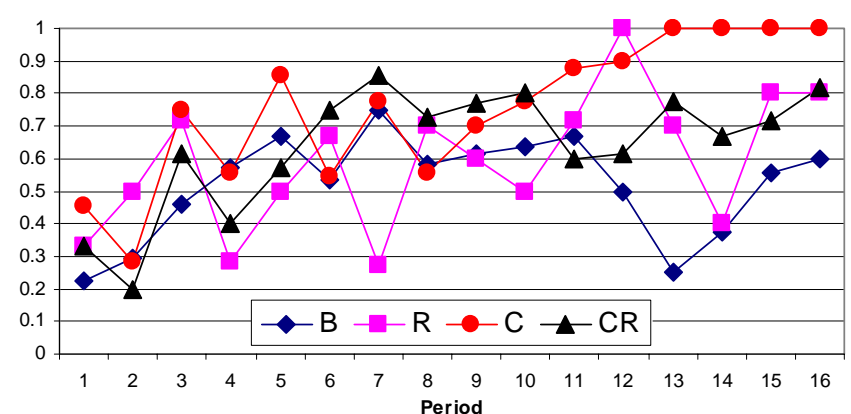

Set L (Liability / No Verifiability)

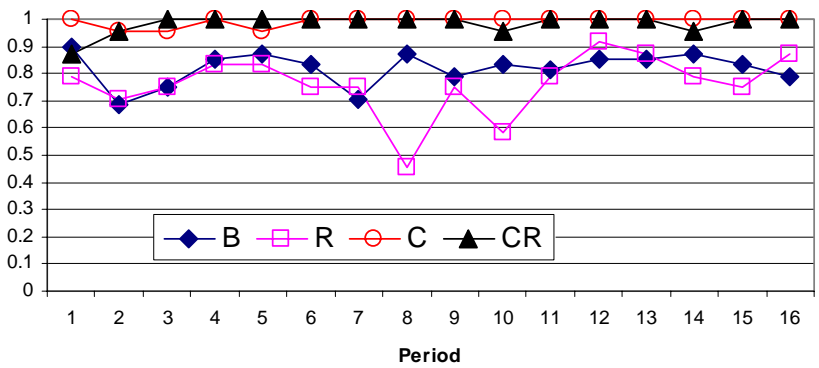

Set LV (Liability / Verifiability)

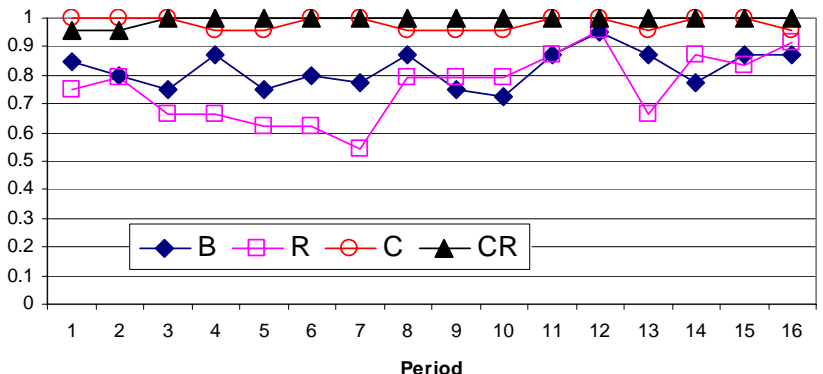

Set V (No Liability / Verifiability)

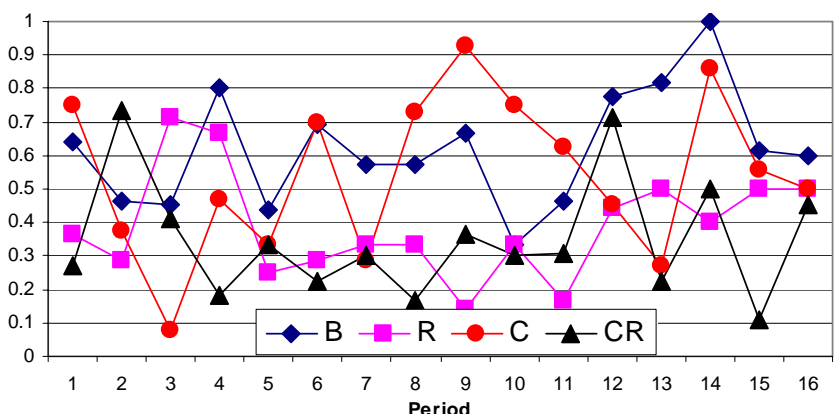


Figure 3 - continued

\section{Relative frequency of overtreatment}
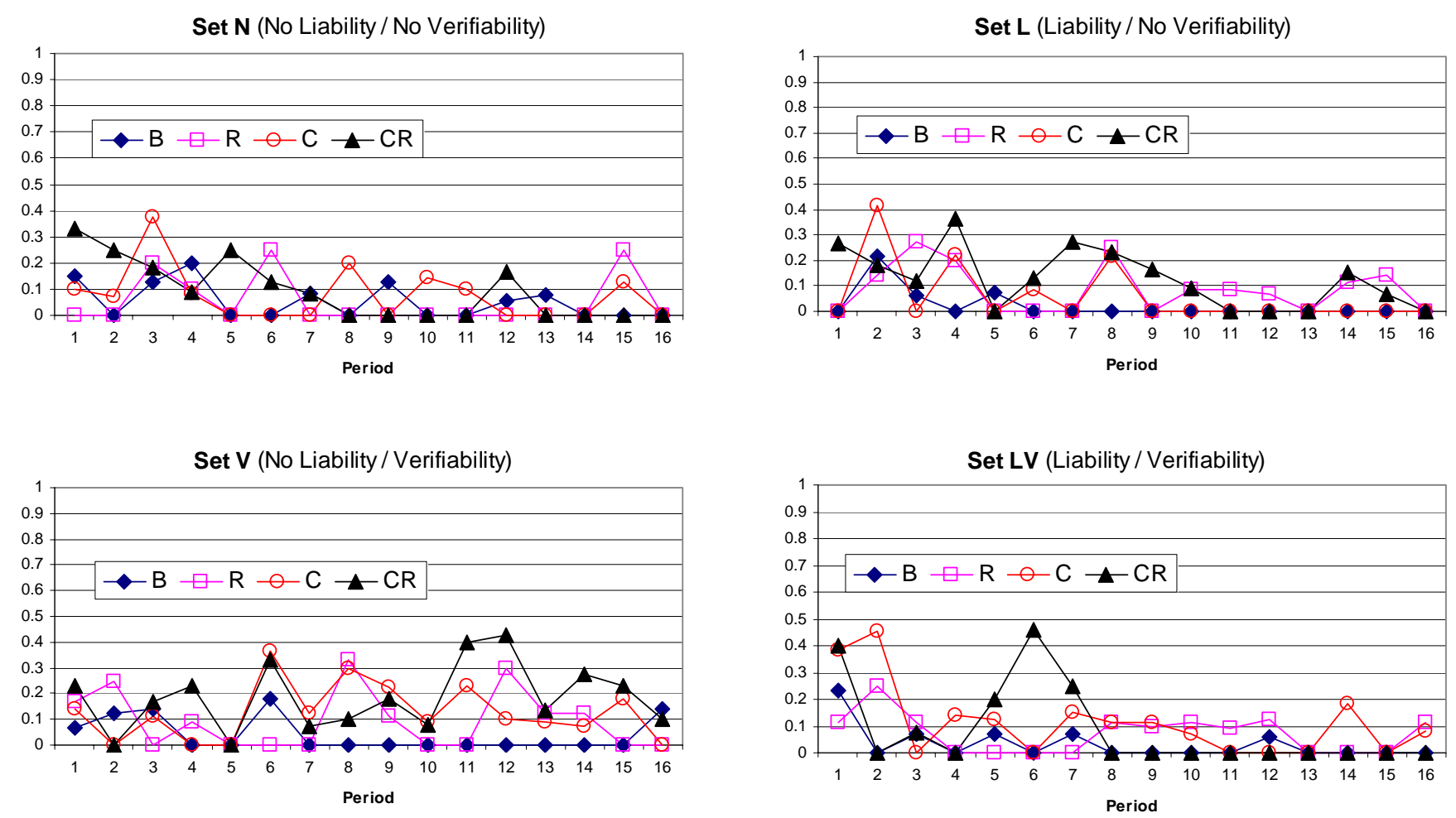

\section{Relative frequency of overcharging}

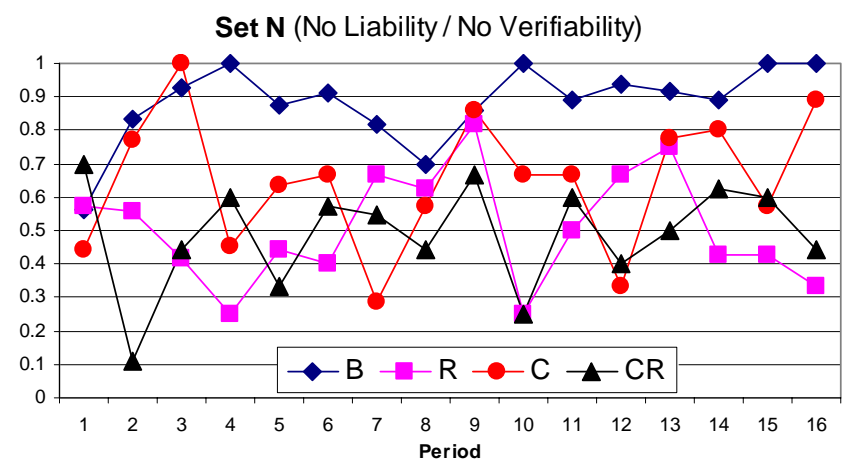

Set L (Liability / No Verifiability)

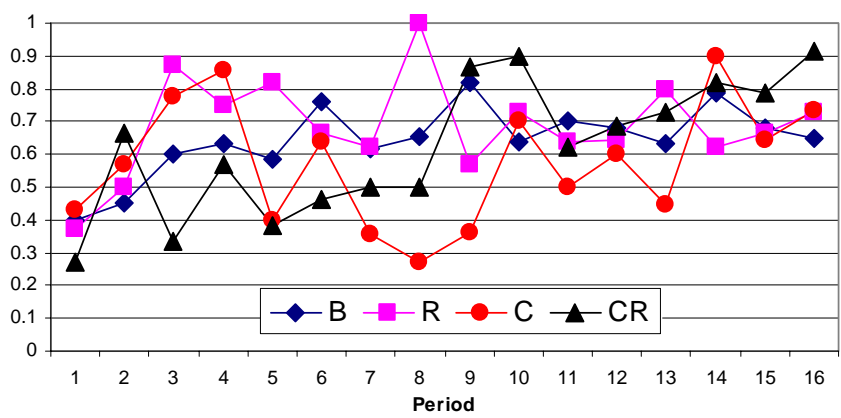




\section{E. Accepted price $p^{l}$}

Set N (No Liability / No Verifiability)

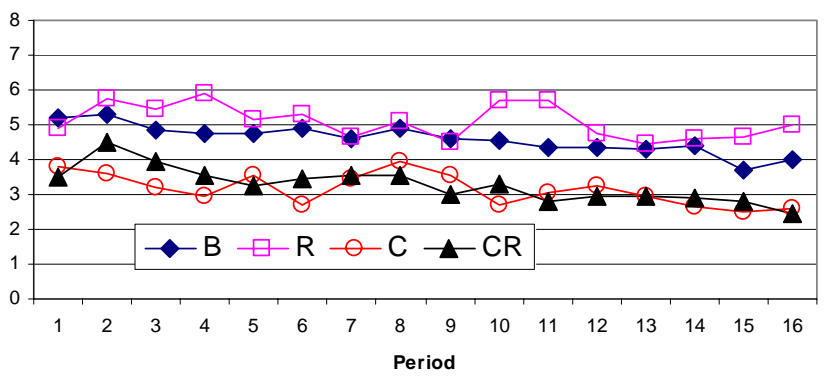

Set V (No Liability / Verifiability)

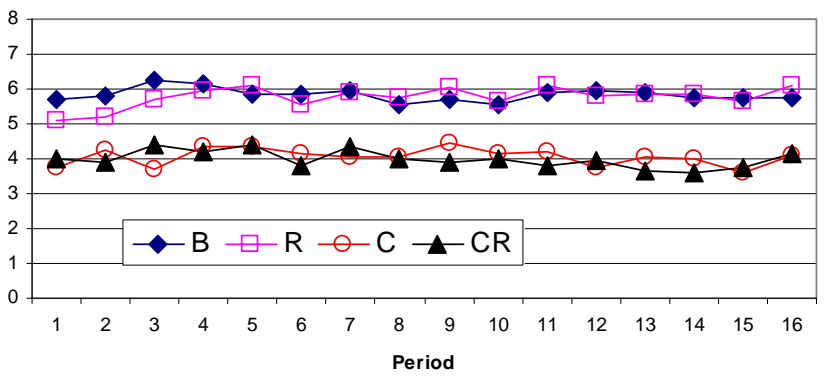

\section{F. Accepted price $p^{h}$}

Set N (No Liability / No Verifiability)

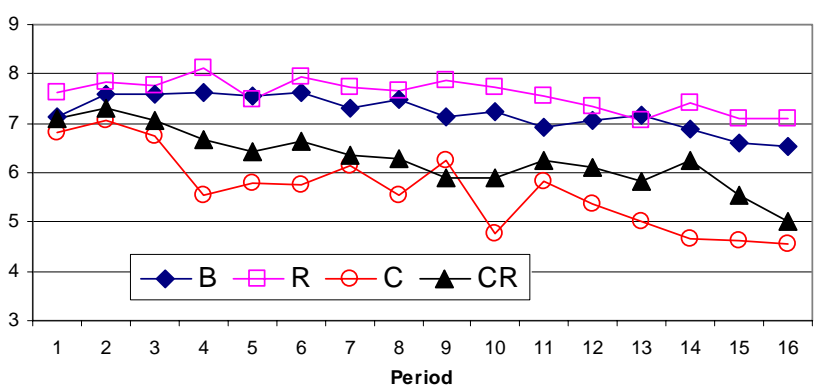

Set V (No Liability / Verifiability)

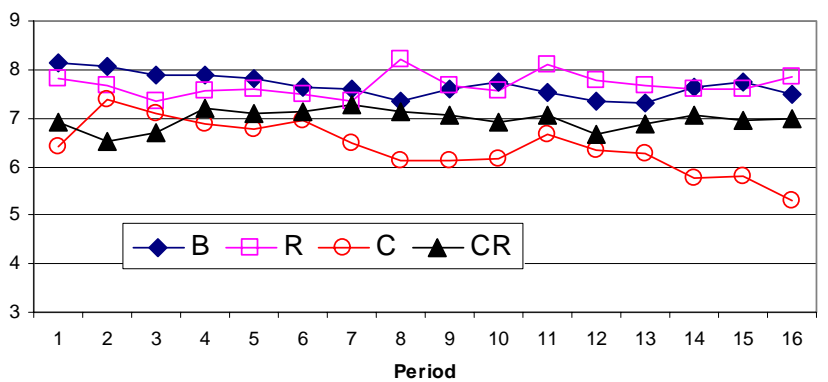

Set L (Liability / No Verifiability)

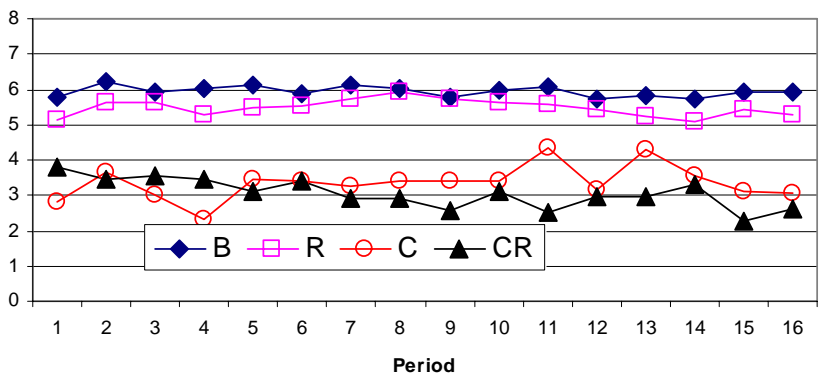

Set LV (Liability / Verifiability)

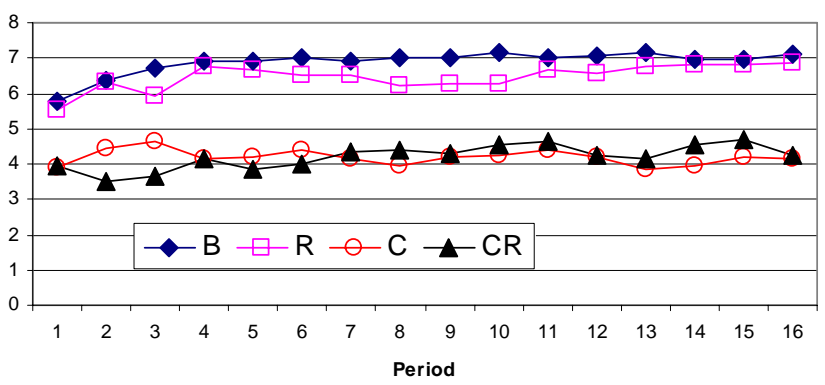

Set L (Liability / No Verifiability)

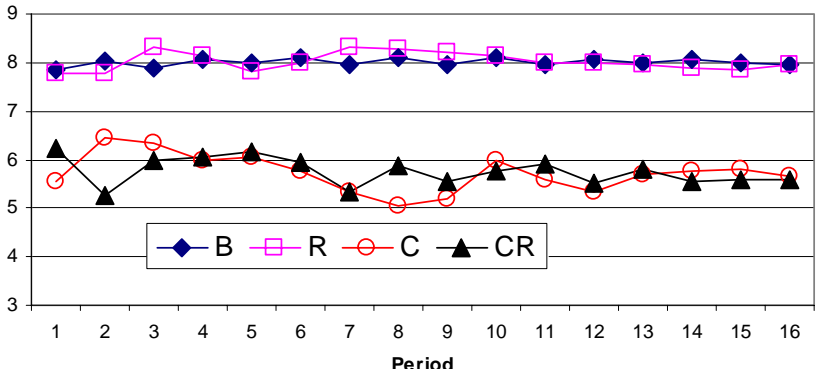

Set LV (Liability / Verifiability)

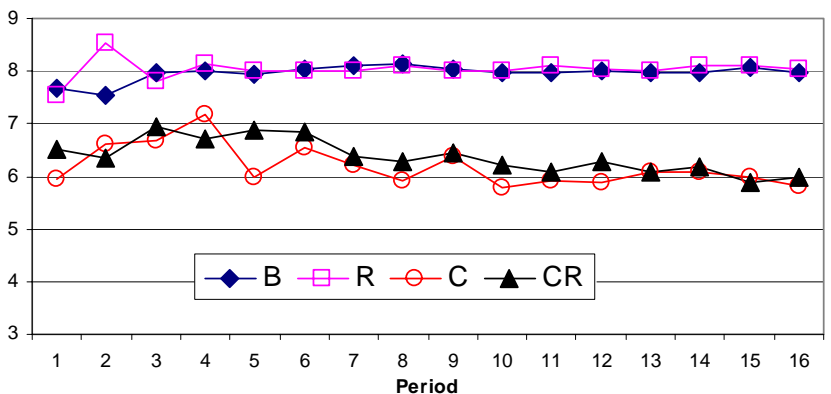




\section{[1] Likelihood of interaction on seller side ${ }^{25}$}

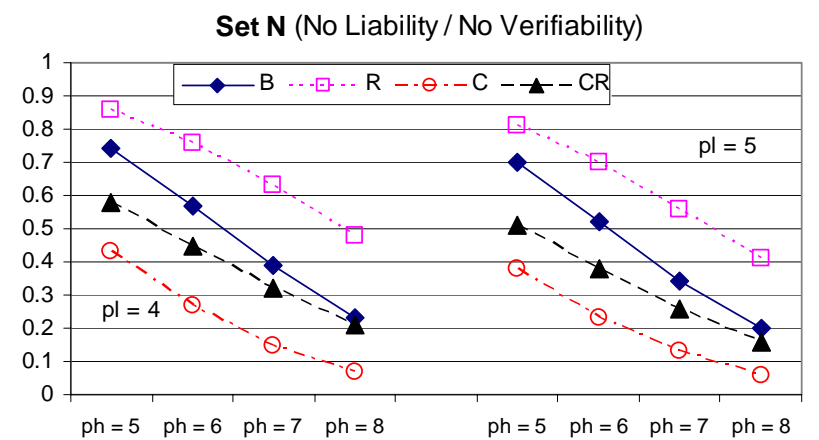

Set V (No Liability / Verifiability)

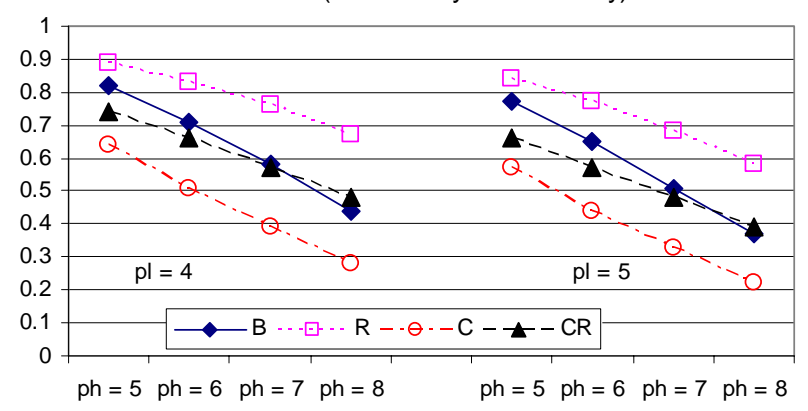

Set L (Liability / No Verifiability)
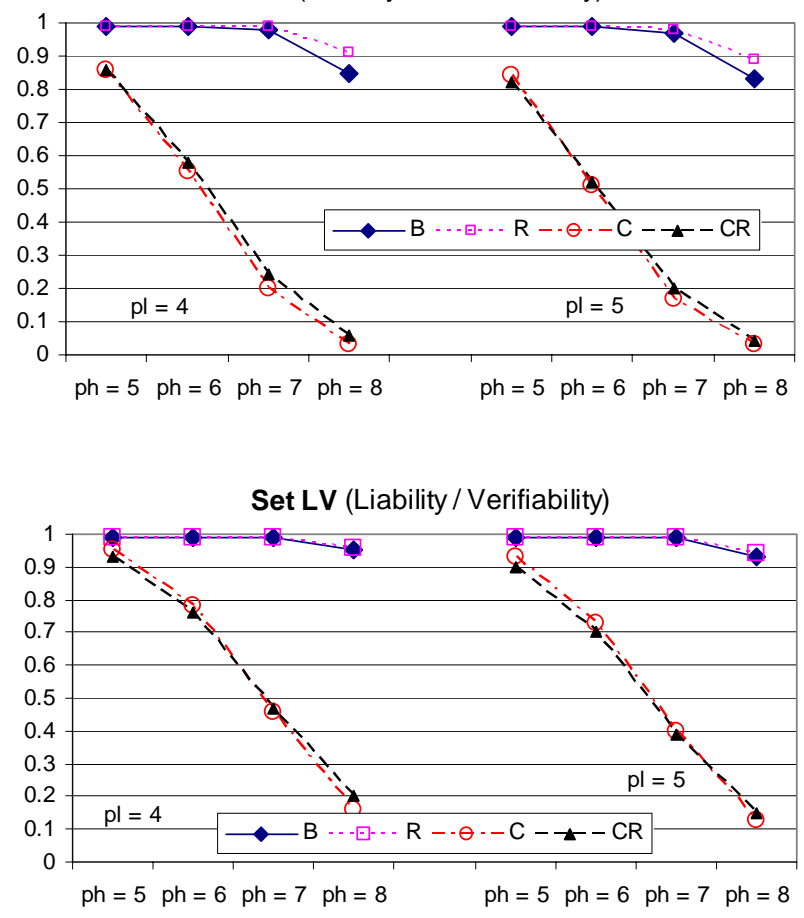

\section{[2] Likelihood of undertreatment}
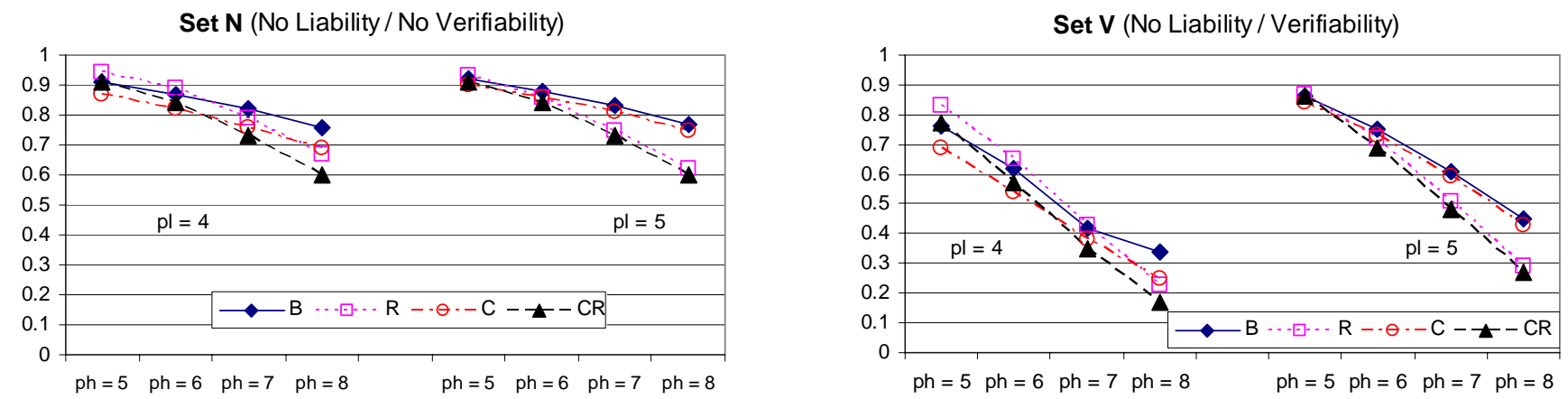

${ }^{25}$ Likelihood of seller having one (or more) consumers for interaction 
Figure 4-continued

\section{[3] Likelihood of overtreatment}
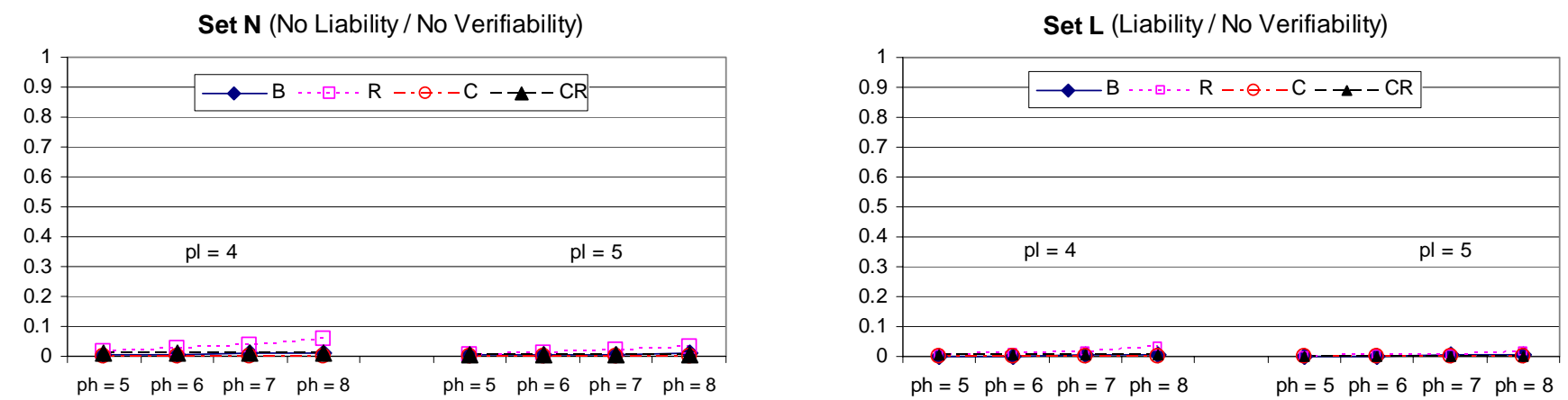

Set V (No Liability / Verifiability)
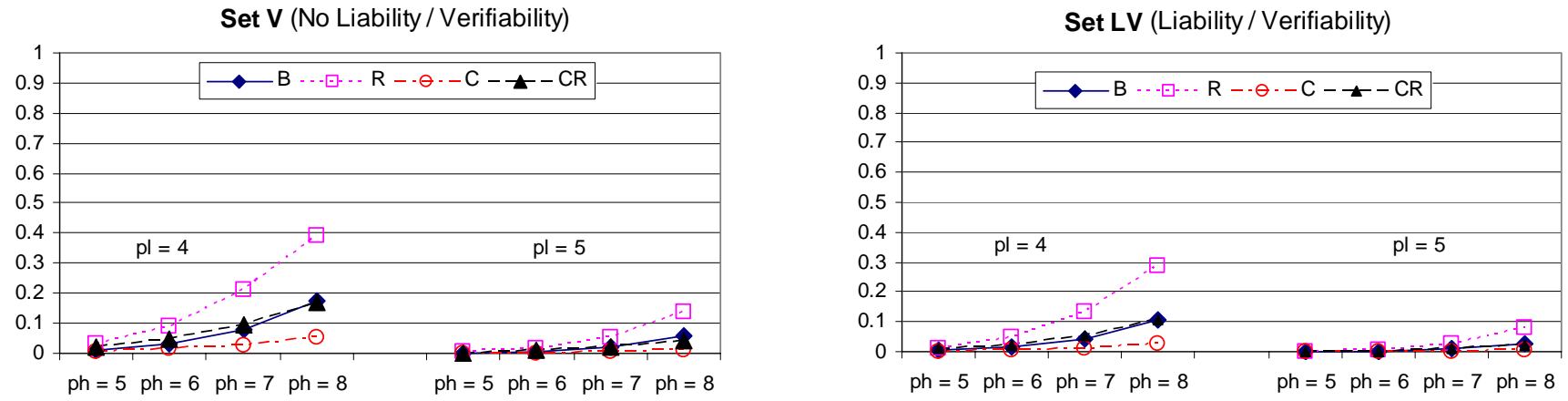

\section{[4] Likelihood of overcharging}
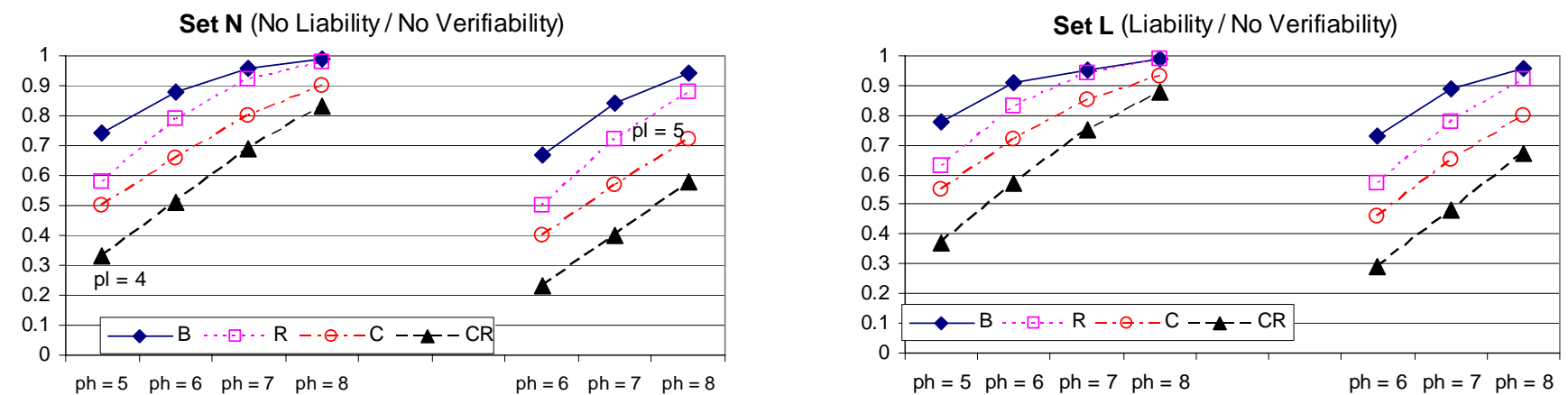


\section{Supplementary material accompanying \\ "The economics of credence goods - On the role of liability, verifiability, reputation and competition"}

\section{Not intended for print publication}

\section{Appendix A. Derivation of Predictions}

Throughout we assume that a consumer who is indifferent between visiting an expert and not visiting an expert decides for a visit, and that a customer who is indifferent between two or more experts randomizes (with equal probability) among them. The equilibrium concept we apply is Perfect Bayesian Equilibrium (PBE). Our main focus is on symmetric equilibria. In many cases there are also asymmetric equilibria. However, given that there is no obvious way for sellers to coordinate on a specific asymmetric equilibrium we regard such equilibria as less plausible and mention them only in footnotes. As in the main text, sellers are female, consumers are male.

\section{Standard Predictions}

Predictions $\boldsymbol{B}^{\boldsymbol{S}_{1}}$ to $\boldsymbol{B}^{S_{3}}$ as well as predictions $\boldsymbol{C}^{\boldsymbol{S}_{1}}$ and $\boldsymbol{C}^{S_{2}}$ follow from Dulleck and Kerschbamer (2006), and predictions $\boldsymbol{R}^{\boldsymbol{S}} \mathbf{1}$ to $\boldsymbol{R}^{\boldsymbol{S}_{3}}$ follow from the arguments in the text. Here we prove the rest of the predictions.

Prediction $C^{S}$ (Pricing Policy and Interaction). The following are symmetric mixed strategy equilibria of the price posting stage of the game:

(i) In $\mathbf{C} / \mathbf{N}$ each seller posts $\{$ n.d, 3$\}$ with probability $x=0.84398$ and a price-vector which is unattractive for consumers (due to $p^{h}>3$ ) with probability $1-x .{ }^{1}$ If at least one seller posts $\{$ n.d, 3$\}$ then all consumers are (under-)treated, otherwise (with probability $(1-x)^{4}=$ $0.06 \%$ ) there is no interaction. Each seller's profit in equilibrium is 1.6.

(ii) In $\mathbf{C} / \mathbf{L}$ each seller posts $\{$ n.d., 5 $\}$ with probability $x=0.83927$ and \{n.d., 6$\}$ with probability 1-x. Interaction always takes place and consumers get appropriate treatment. Each seller's profit in equilibrium is 1.6038 .

\footnotetext{
${ }^{1}$ We round the probabilities to five decimals in this subsection.
} 
(iii) In $\mathbf{C} / \mathbf{V}$ each seller posts $\{3,7\}$ with probability $x=0.83927$ and $\{4,8\}$ with probability 1-x. Interaction always takes place and consumers get appropriate treatment. Each seller's profit in equilibrium is 1.6038 .

(iv) In $\mathbf{C} / \mathbf{L V}$ each seller posts either $\{4,5\}$ or $\{3,6\}$ with probability $x=0.13227$, either $\{5,5\}$, or $\{4,6\}$, or $\{3,7\}$ with probability $y=0.28003$, and either $\{5,6\}$ or $\{4,7\}$ with probability $1-x-y$. Interaction always takes place and consumers get appropriate treatment. Each seller's profit in equilibrium is 1.6825 .

Proof: Suppose $a(=1,2,3,4)$ sellers post price-vectors among which consumers are indifferent while the other $4-a$ sellers post price-vectors that are less attractive for consumers. Then the probability that one of the $a$ sellers gets exactly $b(=0,1,2,3,4)$ customers is given by

$$
P(b \mid a)=\left(\begin{array}{l}
4 \\
b
\end{array}\right)\left(\frac{a-1}{a}\right)^{4-b}\left(\frac{1}{a}\right)^{b}
$$

Consider condition $\mathbf{C} / \mathbf{N}$ and therein seller $i$. Suppose the other three sellers behave as specified in the prediction. Then, from $i$ 's perspective, the probability that exactly $c(=0,1,2$, 3 ) of the other three sellers post $\{$ n.d, 3$\}$ is given by

$$
W(c)=\left(\begin{array}{l}
3 \\
c
\end{array}\right)(x)^{3-c}(1-x)^{c} .
$$

In equilibrium, seller $i$ is indifferent between offering a price-vector that is unattractive for consumers (which gives him a payoff of 1.6 for sure) and posting \{n.d, 3$\}$ which generates an expected payoff of

$$
\sum_{c=0}^{3} W(c)\left[\sum_{b=1}^{4} P(b \mid c+1) * b+P(0 \mid c+1) * 1.6\right]
$$

Thus, setting (A1) equal to 1.6 and solving for $x$ gives the $x$-part of the result, the rest is obvious. The argument for conditions $\mathbf{C} / \mathbf{L}$ and $\mathbf{C} / \mathbf{V}$ is similar, the only difference being that in those conditions the less attractive price-vector (with a mark-up of 2) also potentially attracts customers ${ }^{2}$ thereby increasing the expected payoff of a seller who posts the unattractive price-vector from 1.6 (the value of the outside option) to

$$
(1-W(0))^{*} 1.6+W(0) *\left(\Sigma_{\mathrm{b}=1}^{4} P(b \mid 4) * 2 b\right)+P(0 \mid 4) * 1.6>1.6 .
$$

\footnotetext{
${ }^{2}$ The high price offer $\{$ n.d., 6$\}(\{4,8\}$, respectively) attracts customers if no seller posts $\{$ n.d., 5$\}(\{3,7\}$, respectively).
} 
Thus, in conditions $\mathbf{C} / \mathbf{L}$ and $\mathbf{C} / \mathbf{V}$ setting (A1) equal to (A2) and solving for $x$ gives the $x$-part of the result and inserting $x$ into (A1) (or into (A2)) gives equilibrium profits. Condition $\mathbf{C} / \mathbf{L V}$ is slightly more complicated. In that condition three different classes of price-vectors are potential candidates for equilibrium price-vectors, vectors in class 1 (consisting of $\{4,5\}$ and $\{3,6\}$ ) yield an expected profit of 0.5 per customer, vectors in class 2 (comprising $\{5,5\}$, $\{4,6\}$ and $\{3,7\}$ ) yield 1 per customer and vectors in class 3 (i.e., $\{5,6\}$ and $\{4,7\}$ ) yield 1.5 per customer. ${ }^{3}$ Using similar techniques as before it is (burdensome but) straightforward to show that there is no symmetric equilibrium in which sellers place strictly positive probability only on vectors in a single class or on vectors in two different classes and that there is a unique symmetric mixed strategy equilibrium in which sellers randomize among vectors in all three classes. All vectors in the support of the mixed strategy must attract the same expected profit; this determines $x, y$ and equilibrium profits.

Predictions $C R^{S} 1$ to $C R^{S}$ 3. Predictions $C^{S} 1$ to $C^{S} 3$ remain equilibrium predictions also in set CR. In $\mathbf{C R / N}$, there are additional equilibria where (some) sellers post $\{$ n.d, 5$\}$ in the first 9 periods and in which consumers accept, because they anticipate (correctly) that they will get the appropriate treatment with sufficiently high probability.

Proof: Consider the following strategies and beliefs:

Consumers' Beliefs: Each consumer believes that each seller always charges $p^{h}$ independently of the price-vector under which he is treated. He believes to be served efficiently iff (a) he is treated under a $\{$ n.d, 5$\}$ price-vector and the seller has at least two customers; (b) the seller has either never undertreated him before or has only undertreated him in a situation where all sellers had exactly one customer; and (c) the game is in any of the rounds 1-9. ${ }^{4}$ If at least one of (a)-(c) is not fulfilled, the consumer believes to always get the minor treatment.

Consumers' Strategy: In round 1 consumers randomize with equal probability among sellers who have posted $\{$ n.d, 5\}. If no seller has posted $\{$ n.d, 5\}, they randomize with equal probability among sellers who have posted \{n.d, 3$\}$. If there is neither a seller who has posted $\{$ n.d, 5$\}$ nor a seller who has posted $\{$ n.d, 3$\}$ then they refrain from interacting. In rounds 2 to 9, among the sellers who are expected to serve efficiently, the consumer chooses the one with

\footnotetext{
${ }^{3}$ Notice that vectors in a given class are exchangeable from both the consumers' and the sellers' perspective because the ex ante expected price and the ex ante expected profit is the same for all vectors in a class.

${ }^{4}$ When a consumer decides which seller (if any) to visit, he does not know whether a seller will serve two or more customers, of course.
} 
strictly the most customers in the previous round; if no seller had strictly the most customers in the previous round (i.e. in the case where each seller had exactly one customer or where two sellers had two customers each) consumers randomize with equal probability among sellers who are expected to serve efficiently. If no seller is expected to serve efficiently, the consumer randomizes with equal probability among sellers who have posted \{n.d, 3$\}$. If there is neither a seller who is expected to serve efficiently nor a seller who has posted $\{$ n.d, 3$\}$ then the consumer refrains from interacting. In rounds 10-16 consumers buy from sellers offering $\{$ n.d, 3$\}$. If there is more than one such seller they choose the one that served most customers in round 9 unless they were undertreated in any of rounds 1-9 by this seller in a situation where the seller had more than one customer. In the latter case they randomize among the remaining sellers offering $\{$ n.d, 3$\}$. If there is no seller who offers $\{$ n.d, 3$\}$ they refrain from interacting.

Sellers' Strategy: In rounds 1-9: All sellers post \{n.d., 5\}; they serve customers efficiently if they have two or more customers and provide low quality otherwise. In rounds 10-16: If one seller had strictly the most customers in round 9, all sellers post \{n.d., 3 \} and always deliver low quality; otherwise, i.e. if each seller had exactly one customer or two sellers had two customers each, then all sellers play the mixed equilibrium as outlined in Prediction $C^{S} \mathbf{3}$ (i).

We now verify that these strategies and beliefs form a PBE. First notice that consumers' beliefs reflect sellers' strategy. Next consider consumers' strategy. In rounds 1-9 consumers' strategy is rational, because the minimum expected payoff from interacting in these rounds at prices $\{$ n.d., 5$\}$ is larger than the outside option: The only case where a consumer may be undertreated is if he ends up as a single customer with a seller. This is only possible if the game is in round 1 or no seller had strictly the most customers in the previous round. In this case each consumer has an incentive to participate because the payoff from using a random seller in the current round is $\left[0.5+0.5^{*}\left(1-0.75^{3}\right)\right]^{* 5}-0.5^{*} 0.75^{3} * 5=2.8906>1.6-$ where the term in square brackets is the probability that a consumer is efficiently treated - i.e. he needs $t^{l}$, or he needs $t^{h}$ and at least one other consumer visits the same seller. ${ }^{5}$ In rounds 10-16 a consumer's behavior is rational either because he is undertreated under $\{n . d, 3\}$ (yielding an expected payoff of 2) or because he is not served at all (yielding the outside option). Finally consider sellers' strategies: We start with the behavior in rounds 10-16. Two events are to be

\footnotetext{
${ }^{5}$ If in a previous round one seller had strictly the most customers, all customers are treated efficiently for sure, ie. the payoff is 5 .
} 
considered: a) One Seller had strictly the most customers in round 9. In that case that seller has all the customers from round 10 onwards provided she did not deliver $t^{l}$ to a customer who needed $t^{h}$ in round 9. Given that future customer behavior is not affected, always delivering low quality is a dominant strategy for this seller. The other three sellers have no possibility of getting more than the outside option, thus their behavior is optimal too. b) No seller had a strict majority of customers in round 9. In this case the reasoning of the proof of prediction $C^{S} 3$ (i) applies. Next consider round 9. Three cases are to be considered. a) One seller has 3 or 4 customers in this round, i.e. a certain strict majority of consumers. In that case serving all customers efficiently guarantees a maximum additional future payoff of 16.8 $(=7 * 2.4)$ in rounds $10-16$ which is strictly more than the maximum additional current payoff from deviating (which is equal to 16 - in the case that the seller serves four consumers who all need $\left.t^{h}\right) .{ }^{6}$ b) A seller has exactly two customers in this round. Given the behavior of consumers, the conditional probability that she is the seller with a strict majority of customers given that she has exactly two customers is equal to $(3 * 1 / 3 * 2 / 3) /\left[3 *(1 / 3)^{2}+(3 * 1 / 3 * 2 / 3)\right]=$ $2 / 3$. Thus, the expected additional future payoff from treating efficiently is $16.8 * 2 / 3=11.2$ which is strictly more than 8 , the maximum additional current payoff from deviating (if both consumers need $\left.t^{h}\right) .^{7} \mathrm{c}$ ) If a seller has only one customer in round 9 there is no additional future payoff from treating efficiently and she will therefore cheat. The arguments for rounds 1-8 are similar to those for round 9 , the main difference being that the additional expected future payoff from treating efficiently is higher, the incentives to deviate therefore lower.

\section{Non-Standard Predictions}

\section{Prediction $B^{N S} 1$ (Provision and Charging Policy).}

(i) Consider $\mathbf{B} / \mathbf{N}$ and suppose $\alpha^{\max }>4$ and $\gamma^{\max }>0$. Then the undertreatment rate is below $100 \%$. Furthermore, for prices satisfying $p^{h}-p^{l}<\gamma^{\max }$ the overcharging rate is below $100 \%$ and strictly increasing in the price difference $p^{h}-p^{l}$.

(ii) Consider $\mathbf{B} / \mathbf{L}$ and suppose $\gamma^{\max }>0$. Then for prices satisfying $p^{h}-p^{l}<\gamma^{\max }$ the overcharging rate is below $100 \%$ and strictly increasing in the price difference $p^{h}-p^{l}$.

\footnotetext{
${ }^{6}$ Mistreating only one of the customers yields an additional current profit of 4 and a loss in future profit of 7 , mistreating tow of the customers yields an additional current profit of 8 and a loss in future profit of 14, etc.

${ }^{7}$ Here notice that there is no additional expected future payoff from treating efficiently if exactly two sellers have two customers each in round 9.
} 
(iii) Consider $\mathbf{B} / \mathbf{V}$ and suppose $\alpha^{\max }>0$ and $\beta^{\max }>0$. Then for prices satisfying $-x \in(0$, $\alpha^{\max }$ ) the undertreatment rate is below $100 \%$ and strictly decreasing in the price difference $p^{h}$ $-p^{l}$. Furthermore, for prices satisfying $x \in\left(0, \beta^{\max }\right)$ the overtreatment rate is below $100 \%$ and strictly increasing in the price difference $p^{h}-p^{l}$.

(iv) Consider $\mathbf{B} / \mathbf{L V}$ and suppose $\beta^{\max }>0$. Then for prices satisfying $x \in\left(0, \beta^{\max }\right)$ the overtreatment rate is below $100 \%$ and strictly increasing in the price difference $p^{h}-p^{l}$.

Proof: Part (i): Since $c^{h}-c^{l}=4$, sellers with an $\alpha>4$ will abstain from undertreatment. Thus, if $\alpha^{\max }>4$ the undertreatment rate must be below $100 \%$ given our assumption of a strictly positive density on the support $\left[0, \alpha^{\max }\right] \times\left[0, \beta^{\max }\right] \times\left[0, \gamma^{\max }\right]$. Sellers with $\gamma>0$ will only overcharge if $p^{h}-p^{l}>\gamma$. Thus, for (exogenously given) prices satisfying $p^{h}-p^{l}<\gamma^{\max }$ the overcharging rate is below $100 \%$ and increasing in $p^{h}-p^{l}$ due to our full support assumption. The argument for parts (ii), (iii) and (iv) is similar.

\section{Prediction $B^{N S} 2$ (Acceptance Behavior).}

(i) Consider $\mathbf{B} / \mathbf{N}$, suppose $\alpha^{\max }>4$ and that this is common knowledge. Then, for any $\left\{p^{l}, p^{h}\right\}$ with $p^{l}=p^{h} \leq 8$ there exist expectations such that a consumer with those expectations is willing to trade (in particular, a consumer might be willing to trade even if $p^{h}>3$ ). Furthermore, for any $\left\{p^{l}, p^{h}\right\}$ with $p^{l}<p^{h}, p^{h}-p^{l}<\gamma^{\max }$ and $\left(p^{l}+p^{h}\right) / 2 \leq 8$ there exist expectations such that a consumer with those expectations is willing to trade (in particular, a consumer might be willing to trade even if $p^{h}>8$ ).

(ii) Consider $\mathbf{B} / \mathbf{L}$, suppose that $\gamma^{\max }>0$ and that this is common knowledge. Then for any $\left\{p^{l}, p^{h}\right\}$ with $p^{l}<p^{h}, p^{h}-p^{l}<\gamma^{\max }$ and $\left(p^{l}+p^{h}\right) / 2 \leq 8$ there exist expectations such that a consumer with those expectations is willing to trade (in particular, a consumer might be willing to trade even if $p^{h}>8$ ).

(iii) Consider $\mathbf{B} / \mathbf{V}$, suppose $\alpha^{\max }>0$ and $\beta^{\max }>0$ and that this is common knowledge. Then for any $\left\{p^{l}, p^{h}\right\}$ with $|x| \leq \operatorname{Min}\left\{\alpha^{\max }, \beta^{\max }\right\}$ and $\left(p^{l}+p^{h}\right) / 2 \leq 8$ there exist expectations such that a consumer with those expectations is willing to trade (in particular, a consumer might be willing to accept an undertreatment vector with $p^{l}>3$, and an overtreatment vector with $\left.p^{h}>8\right)$.

(iv) Consider $\mathbf{B} / \mathbf{L V}$, suppose $\beta^{\max }>0$ and that this is common knowledge. Then for any $\left\{p^{l}, p^{h}\right\}$ with $x<\beta^{\max }$ and $\left(p^{l}+p^{h}\right) / 2 \leq 8$ there exist expectations such that a consumer with those expectations is willing to trade (in particular, a consumer might be willing to accept an overtreatment vector with $p^{h}>8$ ). 
Proof: Part (i): Consider a price-vector $\left\{p^{l}, p^{h}\right\}$ with $p^{l}=p^{h}=p$ and suppose a consumer expects that $x \%$ of the sellers who offer such a vector have an $\alpha \geq 4$ (since $\alpha^{\max }>4$ such expectations are feasible for any $x \leq 100)$. Then he is willing to accept iff $x \geq 100[(p+1.6) / 5$ 1]. Setting $x$ equal to 100 and solving for $p$ yields $p \leq 8.4$. Similarly, if $\gamma^{\max }>0$ then prices that fulfil $\left(p^{l}+p^{h}\right) / 2 \leq 8.4$ and $p^{h}-p^{l}<\gamma^{\max }$ are attractive to customers who place sufficient weight on $\alpha$ realizations in $\left[4, \alpha^{\max }\right]$ and $\gamma$ realizations in $\left[p^{h}-p^{l}, \gamma^{\max }\right]$. The proof for parts (ii) to (iv) is similar.

Prediction $\boldsymbol{B}^{N S_{3}}$ (Interaction). Suppose some consumers have optimistic expectations. Then there exists an equilibrium in which the interaction frequency is strictly positive even if neither observability nor liability (nor both) holds (that is, even in $\mathbf{B} / \mathbf{N}$, where prediction $\boldsymbol{B}^{\boldsymbol{S}_{3}}$ predicts complete market break down).

Proof: First notice that sellers with $\alpha \geq 4$ are committed to deliver $t^{h}$ to consumers of type $t^{h}$. Knowing this, they will never offer a price-vector $\left\{p^{l}, p^{h}\right\}$ with $p^{h}<6$. Therefore a pooling PBE involving constant prices must have $p^{l}=p^{h} \geq 6$. Suppose (i) that all sellers offer $\left\{p^{l}, p^{h}\right\}$ $=\{6,6\}$, (ii) that opportunistic experts (sellers with $\alpha<4$ ) always provide the minor treatment under each price-vector while committed experts (sellers with $\alpha \geq 4$ ) always provide the appropriate treatment under each price-vector, and (iii) that consumers' expectations are correct along the equilibrium path. Then consumers with optimistic expectations (expecting that at least $52 \%$ of sellers offering $\{6,6\}$ have a $\alpha \geq 4$ ) are willing to accept since $10[0.52+0.48 / 2]-6 \geq 1.6=o$. The term in the squared brackets is the probability to be served sufficiently - meeting a committed expert $(\alpha \geq 4)$ with probability $52 \%$, and meeting a non-committed seller $(\alpha<4)$ with probability $48 \%$, but needing only $t^{l}$ (with probability $1 / 2$ ).

Predictions $\boldsymbol{R}^{N S} 1$ to $\boldsymbol{R}^{N S} 3$. Suppose that $\alpha^{\max }>4$ and that this is common knowledge. Contrary to the prediction with standard preferences, equilibria exist in $\mathbf{R} / \mathbf{N}$ in which

- the interaction frequency is $100 \%$ in early rounds and remains strictly positive throughout the game and

- all sellers provide the appropriate treatment in early rounds and some sellers provide the appropriate treatment throughout the game.

Proof: We are searching for a Kreps-Wilson-Milgrom-Roberts type of good reputation equilibrium in which opportunistic experts (sellers with $\alpha<4$ ) mimic committed experts 
(sellers with $\alpha>4$ ) in early rounds. For commitment types only price-vectors with $p^{h} \geq 6$ are profitable, we therefore search for a PBE in which all types pool on $\left\{p^{l}, p^{h}\right\}=\{6,6\}$. In equilibrium consumers expect (i) that experts posting $\left\{p^{l}, p^{h}\right\}=\{6,6\}$ will serve them efficiently in early rounds (the meaning of "in early rounds" will be specified below) while experts posting other price-vectors will undertreat them throughout the game, and (ii) that only committed experts posting $\left\{p^{l}, p^{h}\right\}=\{6,6\}$ will serve them efficiently in later rounds while opportunistic experts will undertreat them later on. Consumers revise their expectations if and only if they are undertreated in early rounds. In this case they infer that the respective expert is an opportunistic one who will undertreat them in any future interaction. Consumers interact with a seller posting $\left\{p^{l}, p^{h}\right\}=\{6,6\}$ iff they have not been undertreated in an earlier round by this seller and they interact with a seller posting a different price-vector iff this price-vector has $p^{h} \leq 3$. Committed experts (sellers with $\alpha \geq 4$ ) offering $\left\{p^{l}, p^{h}\right\}=\{6,6\}$ always provide the appropriate treatment while opportunistic experts (sellers with $\alpha<4$ ) offering $\left\{p^{l}, p^{h}\right\}=\{6,6\}$ provide the appropriate treatment until round $T$ and always the minor treatment in periods $T+1, T+2, \ldots, 16 .{ }^{8}$ We search for that period $T$ until which there exists no incentive for an opportunistic seller to undertreat because this would lead to a loss of business in the future ${ }^{9}$. Let $v_{x}=\left[(4-x)^{*} 4+x^{*} 1.6\right] / 4$ denote the (expected) value of a round in which $x(=0,1,2,3,4)$ customers reject treatment because they have been undertreated by this seller before. Also, let $p_{x}=(4+\mathrm{x}) / 8$ denote the probability that at the end of a round the number of customers willing to interact with a seller is the same as at the beginning of the round given that (i) $x$ customers are willing to interact with the seller at the beginning of the round and (ii) the seller provides the minor treatment in the current round. ${ }^{10}$ Finally, let $V_{T}$ denote the expected value of all future interactions, including the current one, given that (i) the seller has provided appropriate treatment to all customers up to period $T$, (ii) the seller provides the minor treatment to a customer with the major problem in period $T$, and (iii) the seller provides the minor treatment in all periods succeeding $T$. Then $V_{16}=v_{0}$ and for $T<16$

\footnotetext{
${ }^{8}$ Given this trigger strategy of consumers it is straightforward to see that if a seller undertreats in period $t$ she will also undertreat in period $t+1$ as the (potential) loss in business decreases in the number of rounds played.

${ }^{9}$ The incentive not to undertreat comes from the fact that the customer may return in the future with a minor problem which then generates a profit that can compensate for the forgone opportunity to undertreat.

${ }^{10}$ This probability is the sum of the probability that a customer wishes not to interact because he was undertreated before - $x / 4$ - plus the probability that the customer interacts but only needs low quality and hence cannot be undertreated - $(4-x) / 4 * 0.5$.
} 


$$
\begin{aligned}
& V_{T}=V_{T+1}+I_{T \leq 15} p_{1}^{15-T} v_{1}+I_{T \leq 14} v_{2}\left(1-p_{1}\right) \sum_{t=0}^{14-T} p_{1}^{t} p_{2}^{14-T-t} \\
& +I_{T \leq 13} v_{3}\left(1-p_{1}\right)\left(1-p_{2}\right) \sum_{t=0}^{13-T 13-T-t} \sum_{s=0}^{s} p_{1}^{s} p_{2}^{t} p_{3}^{13-T-t-s} \\
& +I_{T \leq 12} v_{4}\left(1-p_{1}\right)\left(1-p_{2}\right)\left(1-p_{3}\right) \sum_{t=0}^{12-T 12-T-t} \sum_{s=0}^{12-T-t-s} \sum_{r=0}^{12} p_{1}^{r} p_{2}^{s} p_{3}^{t} p_{4}^{13-T-t-s-r}
\end{aligned}
$$

Next, let $W_{T}$ denote the expected value of all future interactions including the current one given that (i) the seller has provided appropriate treatment to all customers up to period $T$, (ii) the seller provides the major treatment to a customer with the major problem in period $T$, and (iii) the seller provides the minor treatment to her customer in all periods beyond $T$. Then $W_{16}$ $=0$ and for $T<16$

$$
\begin{aligned}
& W_{T}=W_{T+1}+I_{T \leq 15} p_{0}^{15-T} v_{0}+I_{T \leq 14} v_{1}\left(1-p_{0}\right) \sum_{t=0}^{14-T} p_{0}^{t} p_{1}^{14-T-t} \\
& +I_{T \leq 13} v_{2}\left(1-p_{0}\right)\left(1-p_{1}\right) \sum_{t=0}^{13-T 13-T-t} \sum_{s=0}^{s} p_{0}^{s} p_{1}^{t} p_{2}^{13-T-t-s} \\
& +I_{T \leq 12} v_{3}\left(1-p_{0}\right)\left(1-p_{1}\right)\left(1-p_{2}\right) \sum_{t=0}^{12-T 12-T-t} \sum_{s=0}^{12-T-t-s} \sum_{r=0}^{r} p_{0}^{r} p_{1}^{s} p_{2}^{t} p_{3}^{13-T-t-s-r} \\
& +I_{T \leq 11} v_{4}\left(1-p_{0}\right)\left(1-p_{1}\right)\left(1-p_{2}\right)\left(1-p_{3}\right) \sum_{t=0}^{12-T 12-T-t} \sum_{s=0}^{12-T-t-s} \sum_{r=0}^{12-T-t-s-r} \sum_{q=0}^{q} p_{0}^{q} p_{1}^{r} p_{2}^{s} p_{3}^{t} p_{4}^{13-T-t-s-r-q}
\end{aligned}
$$

We are searching for the highest integer $T$ for which $W_{T}>V_{T}$. Solving this problem (with Mathematica) yields $T=2 .{ }^{11}$ Thus, in the first two rounds it is profitable for opportunistic sellers to mimic committed ones, while in later rounds it is not.

Prediction $C^{N S} 1$ (Provision and Charging Policy). Consider set $\mathbf{N}$, suppose that $\alpha^{\max }>4$ and that (some) consumers have naive expectations. Then undertreatment is higher in $\mathbf{C} / \mathbf{N}$ than in $\mathbf{B} / \mathbf{N}$.

Proof: From prediction $\boldsymbol{B}^{N S_{3}}$ we know that if some consumers have optimistic expectations then there exists a pooling PBE in which the interaction frequency is strictly positive even if neither observability nor liability (nor both) holds (that is, even in $\mathbf{B} / \mathbf{N}$ ). In this equilibrium (i) all sellers post $\left\{p^{l}, p^{h}\right\}=\{6,6\}$, (ii) opportunistic experts (sellers with $\alpha<4$ ) always provide the minor treatment and (iii) committed experts (sellers with $\alpha \geq 4$ ) always provide the appropriate treatment. Thus, if at least one committed seller populates the market, then the

\footnotetext{
${ }^{11}$ The Mathematica notebook yielding this result is available from the authors upon request.
} 
undertreatment rate in this market is below $100 \%$ in $\mathbf{B} / \mathbf{N}$. Now consider $\mathbf{C} / \mathbf{N}$. If consumers have not only opportunistic but also naive expectations then they believe that experts' behavior does not depend on the prices they post. Thus, opportunistic experts can undercut their committed rivals because a $p^{h}<6$ yields a lower payoff to commitment types than no interaction at all. Thus, if at least one opportunistic expert populates a market, committed experts are driven out of business in that market leading to an undertreatment rate of $100 \%$ in that market (and to a higher undertreatment rate on average over all markets in $\mathbf{C} / \mathbf{N}$ ). 
Appendix B. Experimental Instructions (for condition CR/LV - instructions for the other conditions are available upon request)

\section{INSTRUCTIONS FOR THE EXPERIMENT}

Thank you for participating in this experiment. Please do not to talk to any other participant until the experiment is over.

\section{Roles and 16 Rounds}

This experiment consists of $\mathbf{1 6}$ rounds, each of which consists of the same sequence of decisions. This sequence of decisions is explained in detail below.

There are 2 kinds of roles in this experiment: player $\mathbf{A}$ and player $\mathbf{B}$. At the beginning of the experiment you will be randomly assigned to one of these two roles. On the first screen of the experiment you will see which role you are assigned to. Your role remains the same throughout the experiment.

In your group there are 4 players A and 4 players B. The players of each role get a number. If you are a player B your potential interaction partners are the players A1, A2, A3 and A4. In case you are a player A your potential interaction partners are the players B1, B2, B3 and B4. Attention: The numbers of all players $\mathbf{A}$ are fixed, i.e. the same number always represents the same person, e.g. "A1".

But: The numbers of all players B are not fixed, i.e. the number representing a given person might change (the probability that a number is represented by the same person as in the previous round is exactly $25 \%$ ).

All participants get the same information on the rules of the game, including the costs and payoffs of both players.

\section{Overview of the Sequence of Decisions in a Round}

Each round consists of a maximum of 4 decisions which are made consecutively. Decisions 1 , 3 and 4 are made by player A, decision 2 is made by player B.

\section{Short Overview of the Sequence of Decisions in a Round}

1. Player A chooses one price for action 1 and one price for action 2. 
2. Player B gets to know the prices chosen by the 4 players A (A1 to A4). Then player B decides whether he/she wants to interact with one of the players A. If not, this round ends for him/her.

3. Each player A gets to know which players B decided to interact with him/her. A maximum of all 4 players B can interact with a particular player A. Then each player $\mathrm{A}$ is informed about the types of all players B who decided to interact with him/her. There are two possible types of player B: he/she is of either type 1 or type 2 . This type is not necessarily identical for all players B. Player A has to choose an action for each player interacting with him: either action 1 or action 2 .

4. Player B has to pay the price specified by his/her player A in decision 1 for the action chosen by his/her player A in decision 3 .

\section{Detailed Illustration of the Decisions and Their Consequences Regarding Payoffs}

\section{Decision 1}

In case of an interaction each player $\mathbf{A}$ has to choose between 2 actions (action 1 and action 2) at decision 3. Each chosen action causes costs which are as follows:

Action 1 costs player A 2 points (= currency of the experiment).

Action 2 costs player A 6 points.

Player A can charge prices for these actions from all those players B who decide to interact with him/her. At decision 1 each Player A has to set the prices for both actions. Only (strictly) positive integer numbers are possible, i.e., only 1, 2, 3, 4, 5, 6, 7, 8, 9, 10 and 11 are valid prices. Note that the price for action 1 must not exceed the price for action 2 . 


\section{Decision 2}

Player B gets to know the prices set by each of the four players A for the two actions at decision 1. Then player B decides whether he/she wants to interact with one of the players $\mathrm{A}$ and (if he/she wants to do so) with which one.

If he/she wants to do so, player A can choose an action at decision 3 and charge a price for that action at decision 4 (see below).

If he/she doesn't want to interact, this round ends for this player B and he/she gets a payoff of 1.6 points for this round.

In case none of the players $\mathbf{B}$ wants to interact with a certain player $\mathbf{A}$, this player A gets a payoff of 1.6 points for this round as well.

Below is an exemplary screen which shows decision 2. In case you wish to interact with a certain player A please click "Ja" (Yes) in the corresponding column and confirm your entry by clicking "OK" (you don't have to click "Nein" (No) for the other players A). If you don't want any interaction at all, you just have to click "OK" (you don't have to click "Nein" for all players A). See explanation on the screen.

In the lower half of the screen you can see all previous rounds (on the exemplary screen round 5 is ongoing). The columns are defined as follows:

- "Runde": The round, in which something happened

- "Interaktion": Shows if you had an interaction with a player A (here: rounds 2-4)

- "Verbindung zu": Shows with which player A you interacted (here: in rounds 2 and 4 with player A4)

- "Preis für Aktion 1": Price which was set by player A for action 1 (in case you didn’t have an interaction this field shows "_.", like here in round 1)

- "Preis für Aktion 2": Price which was set by player A for action 2

- "Rundengewinn": Your earnings in each particular round denoted in points (the calculation is explained below) 


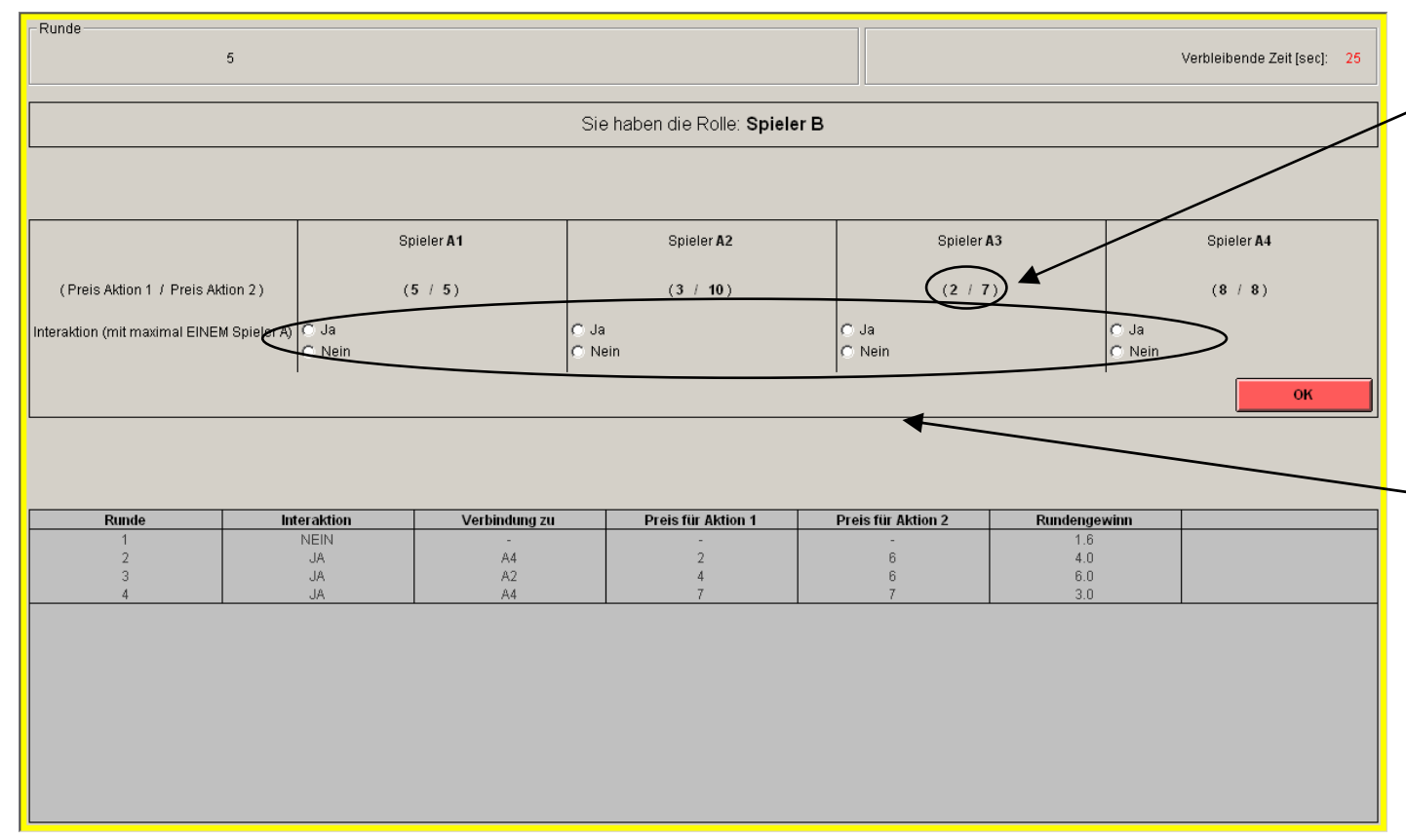

The first number denotes the price for action 1; the second number denotes the price for action 2

"Ja" can be activated for a maximum of one column. If you do not activate anything and confirm by clicking "OK" you will not interact in this round.

\section{Decision 3}

Before decision 3 is made (in case player B chose "Yes" at decision 2) a type is randomly assigned to player B. Player B can be one of the two types: type $\mathbf{1}$ or type 2. This type is determined for each player $B$ in each new round. The determination is random and independent of the other players' types. With a probability of $\mathbf{5 0 \%}$ player B is of type $\mathbf{1}$, and with a probability of $\mathbf{5 0 \%}$ he/she is of type $\mathbf{2}$. Imagine that a coin is tossed for each player B in each round. If the result is e.g. "heads", player B is of type 1, if the result is "tails" he/she is of type 2 .

Every player A gets to know the types of all players B who interact with him/her before he makes his decision 3. Then player A chooses an action for each player B, either action 1 or action 2. In case he interacts with more than one player B these actions are allowed to differ. There are two possibilities a player A can have during choosing his action:

a) In case player B is a type 1 player, player A can chose either action 1 or action 2.

b) In case player B is a type 2 player, player $A$ has to choose action 2.

At no time player B will be informed whether he/she is of type 1 or a type 2 player. Player B will also not be informed about the total number of players B player A interacted with.

Below there is an exemplary screen which shows decision 3. Player A gets to know which of the 4 players B decided to interact with him and which didn't (first row). If a player B 
interacts with the player A under consideration then the type of player B is displayed in the corresponding column. The two prices which player A set at his decision 1 are shown.

The last row has to be filled out for each player who agreed to interact (the row "Interaktion" shows "JA" (Yes)). For each of these interacting players B an action has to be chosen (1 or 2). On the exemplary screen the players B1 and B2 decided to interact with player A, hence player A needs to enter the actions for these players (i.e. replace the “0”).

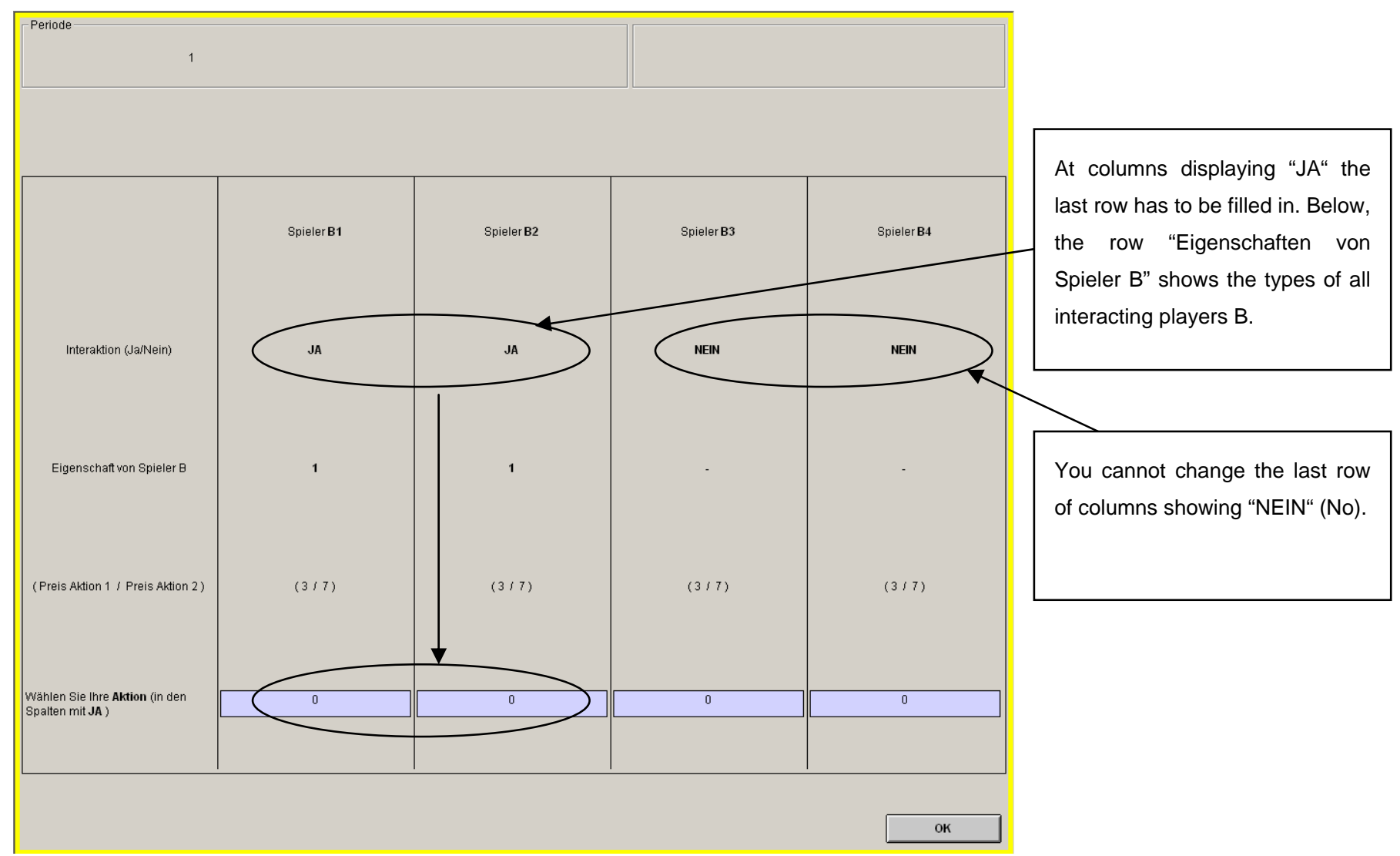

\section{Decision 4}

Player A charges the price (which he determined at decision 1) for the action he chose at his decision 3 from each player B. 


\title{
$\underline{\text { Payoffs }}$
}

\section{No Interaction}

If player B chose not to interact with any of the players A (decision "No" for all 4 players $A$ ) he/she gets 1.6 points for this particular round. If no player B decided to interact with a certain player A this player A gets $\mathbf{1 . 6}$ points for this particular round as well.

Otherwise (decision "Yes" by player B) the payoffs are as follows:

\section{Interaction}

For each player B he/she interacts with, player A receives the according price (denoted in points) he/she charged at his/her decision 4 less the costs for the action chosen at decision 3 , i.e. the payoff of a player A consists of all interactions he/she had within this round.

Player B gets 10 points less the price charged at decision 4 for the action chosen at decision 3.

At the beginning of the experiment you receive an initial endowment of 6 points. In addition you received 2 Euro (equals 8 points) for filling out the questionnaire. With this endowment you are able to cover losses that might occur in some rounds. Losses can also be compensated by gains in other rounds. If your total payoff sums up to a loss at the end of the experiment you will have to pay this amount to the supervisor of the experiment. By participating in this experiment you agree to this term. Please note that there is always a possibility to avoid losses in this experiment.

To calculate the final payoff the initial endowment and the profits of all rounds are added up. This sum is then converted into cash using the following exchange rate:

\author{
1 point $=25$ Euro-cents
}

(i.e. 4 points $=1$ Euro) 


\section{List of NCER Working Papers}

No. 41 (Download full text)

Adam Clements, Mark Doolan, Stan Hurn and Ralf Becker

On the efficacy of techniques for evaluating multivariate volatility forecasts

No. 40 (Download full text)

Lawrence M. Kahn

The Economics of Discrimination: Evidence from Basketball

No. 39 (Download full text)

Don Harding and Adrian Pagan

An Econometric Analysis of Some Models for Constructed Binary Time Series

No. 38 (Download full text)

Richard Dennis

Timeless Perspective Policymaking: When is Discretion Superior?

No. 37 (Download full text)

Paul Frijters, Amy Y.C. Liu and Xin Meng

Are optimistic expectations keeping the Chinese happy?

No. 36 (Download full text)

Benno Torgler, Markus Schaffner, Bruno S. Frey, Sascha L. Schmidt and Uwe Dulleck

Inequality Aversion and Performance in and on the Field

No. 35 (Download full text)

T M Christensen, A. S. Hurn and K A Lindsay

Discrete time-series models when counts are unobservable

No. 34 (Download full text)

Adam Clements, A S Hurn and K A Lindsay

Developing analytical distributions for temperature indices for the purposes of pricing temperature-based weather derivatives

No. 33 (Download full text)

Adam Clements, A S Hurn and K A Lindsay

Estimating the Payoffs of Temperature-based Weather Derivatives

No. 32 (Download full text)

T M Christensen, A S Hurn and K A Lindsay

The Devil is in the Detail: Hints for Practical Optimisation

No. 31 (Download full text)

Uwe Dulleck, Franz Hackl, Bernhard Weiss and Rudolf Winter-Ebmer

Buying Online: Sequential Decision Making by Shopbot Visitors

No. 30 (Download full text)

Richard Dennis

Model Uncertainty and Monetary Policy 
No. 29 (Download full text)

Richard Dennis

The Frequency of Price Adjustment and New Keynesian Business Cycle Dynamics

No. 28 (Download full text)

Paul Frijters and Aydogan Ulker

Robustness in Health Research: Do differences in health measures, techniques, and time frame matter?

No. 27 (Download full text)

Paul Frijters, David W. Johnston, Manisha Shah and Michael A. Shields

Early Child Development and Maternal Labor Force Participation: Using Handedness as an Instrument

No. 26 (Download full text)

Paul Frijters and Tony Beatton

The mystery of the U-shaped relationship between happiness and age.

No. 25 (Download full text)

T M Christensen, A S Hurn and K A Lindsay

It never rains but it pours: Modelling the persistence of spikes in electricity prices

No. 24 (Download full text)

Ralf Becker, Adam Clements and Andrew McClelland

The Jump component of S\&P $\mathbf{5 0 0}$ volatility and the VIX index

No. 23 (Download full text)

A. S. Hurn and V.Pavlov

Momentum in Australian Stock Returns: An Update

No. 22 (Download full text)

Mardi Dungey, George Milunovich and Susan Thorp

Unobservable Shocks as Carriers of Contagion: A Dynamic Analysis Using Identified

Structural GARCH

No. 21 (Download full text) (forthcoming)

Mardi Dungey and Adrian Pagan

Extending an SVAR Model of the Australian Economy

No. 20 (Download full text)

Benno Torgler, Nemanja Antic and Uwe Dulleck

Mirror, Mirror on the Wall, who is the Happiest of Them All?

No. 19 (Download full text)

Justina AV Fischer and Benno Torgler

Social Capital And Relative Income Concerns: Evidence From 26 Countries

No. 18 (Download full text)

Ralf Becker and Adam Clements

Forecasting stock market volatility conditional on macroeconomic conditions. 
No. 17 (Download full text)

Ralf Becker and Adam Clements

Are combination forecasts of S\&P $\mathbf{5 0 0}$ volatility statistically superior?

No. 16 (Download full text)

Uwe Dulleck and Neil Foster

Imported Equipment, Human Capital and Economic Growth in Developing Countries

No. 15 (Download full text)

Ralf Becker, Adam Clements and James Curchin

Does implied volatility reflect a wider information set than econometric forecasts?

No. 14 (Download full text)

Renee Fry and Adrian Pagan

Some Issues in Using Sign Restrictions for Identifying Structural VARs

No. 13 (Download full text)

Adrian Pagan

Weak Instruments: A Guide to the Literature

No. 12 (Download full text)

Ronald G. Cummings, Jorge Martinez-Vazquez, Michael McKee and Benno Torgler

Effects of Tax Morale on Tax Compliance: Experimental and Survey Evidence

No. 11 (Download full text)

Benno Torgler, Sascha L. Schmidt and Bruno S. Frey

The Power of Positional Concerns: A Panel Analysis

No. 10 (Download full text)

Ralf Becker, Stan Hurn and Vlad Pavlov

Modelling Spikes in Electricity Prices

No. 9 (Download full text)

A. Hurn, J. Jeisman and K. Lindsay

Teaching an Old Dog New Tricks: Improved Estimation of the Parameters of Stochastic

Differential Equations by Numerical Solution of the Fokker-Planck Equation

No. 8 (Download full text)

Stan Hurn and Ralf Becker

Testing for nonlinearity in mean in the presence of heteroskedasticity.

No. 7 (Download full text) (published)

Adrian Pagan and Hashem Pesaran

On Econometric Analysis of Structural Systems with Permanent and Transitory Shocks and Exogenous Variables.

No. 6 (Download full text) (published)

Martin Fukac and Adrian Pagan

Limited Information Estimation and Evaluation of DSGE Models. 
No. 5 (Download full text)

Andrew E. Clark, Paul Frijters and Michael A. Shields

Income and Happiness: Evidence, Explanations and Economic Implications.

No. 4 (Download full text)

Louis J. Maccini and Adrian Pagan

Inventories, Fluctuations and Business Cycles.

No. 3 (Download full text)

Adam Clements, Stan Hurn and Scott White

Estimating Stochastic Volatility Models Using a Discrete Non-linear Filter.

No. 2 (Download full text)

Stan Hurn, J.Jeisman and K.A. Lindsay

Seeing the Wood for the Trees: A Critical Evaluation of Methods to Estimate the Parameters of Stochastic Differential Equations.

No. 1 (Download full text)

Adrian Pagan and Don Harding

The Econometric Analysis of Constructed Binary Time Series. 